\title{
Acquisition strategies for spatially resolved magnetic resonance detection of hyperpolarized nuclei
}

\author{
Geoffrey J. Topping ${ }^{1}$. Christian Hundshammer ${ }^{1}$. Luca Nagel ${ }^{1}$. Martin Grashei ${ }^{1} \cdot$ Maximilian Aigner $^{1}$. \\ Jason G. Skinner ${ }^{1} \cdot$ Rolf F. Schulte $^{2} \cdot$ Franz Schilling $^{1}$ (i)
}

Received: 9 April 2019 / Revised: 8 October 2019 / Accepted: 21 November 2019 / Published online: 6 December 2019

(c) The Author(s) 2019

\begin{abstract}
Hyperpolarization is an emerging method in magnetic resonance imaging that allows nuclear spin polarization of gases or liquids to be temporarily enhanced by up to five or six orders of magnitude at clinically relevant field strengths and administered at high concentration to a subject at the time of measurement. This transient gain in signal has enabled the non-invasive detection and imaging of gas ventilation and diffusion in the lungs, perfusion in blood vessels and tissues, and metabolic conversion in cells, animals, and patients. The rapid development of this method is based on advances in polarizer technology, the availability of suitable probe isotopes and molecules, improved MRI hardware and pulse sequence development. Acquisition strategies for hyperpolarized nuclei are not yet standardized and are set up individually at most sites depending on the specific requirements of the probe, the object of interest, and the MRI hardware. This review provides a detailed introduction to spatially resolved detection of hyperpolarized nuclei and summarizes novel and previously established acquisition strategies for different key areas of application.
\end{abstract}

Keywords Magnetic resonance imaging (MRI) $\cdot$ Hyperpolarization · Spectroscopy $\cdot$ Spectroscopic imaging (MRSI) · Metabolic imaging

\section{Introduction}

The main limiting factor in molecular imaging by magnetic resonance imaging (MRI) is its inherently low sensitivity, resulting from low spin polarization at thermal equilibrium and exacerbated by low concentrations in vivo of many compounds of potential interest that contain NMR-active isotopes. These limitations can be overcome temporarily by increasing the polarization by more than five orders of magnitude beyond thermal equilibrium, which is possible through several hyperpolarization techniques [1], and administering the exogenous hyperpolarized substance to the subject during or shortly before acquisition. The most prominent techniques, dissolution dynamic nuclear polarization (dDNP) [2] and spin exchange optical pumping (SEOP) [3],

Franz Schilling

schilling@tum.de

1 Department of Nuclear Medicine, Klinikum rechts der Isar, Technical University of Munich, Munich, Germany

2 General Electric Healthcare, Munich, Germany have led to breakthroughs in molecular imaging by means of MRI. Detection of biologically relevant hyperpolarized ${ }^{13} \mathrm{C}$-labeled substrates in the micromolar concentration range, such as $\left[1-{ }^{13} \mathrm{C}\right]$ pyruvate $[4],{ }^{13} \mathrm{C}$-bicarbonate [5], or $\left[1,4-{ }^{13} \mathrm{C}_{2}\right]$ fumarate [6], as well as their respective metabolic products $\left[1-{ }^{13} \mathrm{C}\right]$ lactate, $\left[{ }^{13} \mathrm{C}\right]$ carbon dioxide, and $\left[1,4-{ }^{13} \mathrm{C}_{2}\right]$ malate, has become possible, and can give new insights into biochemical pathways in vivo [7]. The evaluation of the clinical potential is currently underway, with more than 20 ongoing clinical trials focusing on hyperpolarized $\left[1-{ }^{13} \mathrm{C}\right]$ pyruvate [8]. Imaging of inhaled hyperpolarized noble gases ${ }^{129} \mathrm{Xe}[9]$ and ${ }^{3} \mathrm{He}$ [10] with SEOP and its application for measurement of flow [11] and diffusion [12] is used clinically primarily to assess lung health [13-16], particularly in the acinar airways that cannot be assessed with computed tomography [17].

Several different techniques have been developed to overcome the low net spin polarization imposed by the Boltzmann distribution at thermal equilibrium at clinically relevant field strengths. By various means, these methods induce a transient state of increased nuclear polarization that decays with the spin-lattice relaxation time $T_{1}$. Five different 
approaches are currently used to create a hyperpolarized spin state for various nuclear isotopes, which currently include ${ }^{1} \mathrm{H}$ (protons), and various others (X-nuclei): ${ }^{3} \mathrm{He},{ }^{6} \mathrm{Li},{ }^{13} \mathrm{C}$, ${ }^{15} \mathrm{~N},{ }^{29} \mathrm{Si},{ }^{31} \mathrm{P},{ }^{129} \mathrm{Xe},{ }^{83} \mathrm{Kr}$, and ${ }^{107,109} \mathrm{Ag}$ :

1. Brute-force hyperpolarization methods that exploit low temperatures and high $B_{0}$ field are generally applicable but achieve only moderate polarization levels $[18,19]$.

2. Spin exchange optical pumping (SEOP) is used to polarize the noble gases ${ }^{3} \mathrm{He}[10],{ }^{83} \mathrm{Kr}$ [20], and ${ }^{129} \mathrm{Xe}$ [9] using circularly polarized laser light to excite specific transitions of alkali metal vapors. The polarization is then transferred to the nuclei of the noble gas atoms by spin exchange collisions of the alkali metal and the noble gas atoms [3]. The hyperpolarized gas may be delivered and measured as a gas or after dissolution in a liquid solvent [21].

3. Parahydrogen-induced polarization (PHIP) uses a chemical reaction to transfer the high para-state spin order of hydrogen to bonded atoms through $J$-coupling [22] in the liquid state, e.g. for ${ }^{13} \mathrm{C}$ [23].

4. Signal amplification by reversible exchange (SABRE) transfers polarization from parahydrogen to the molecule of interest in the liquid state using an activated catalyst for, e.g. ${ }^{1} \mathrm{H},{ }^{13} \mathrm{C},{ }^{15} \mathrm{~N},[24,25]$, and ${ }^{31} \mathrm{P}[26,27]$.

5. Dissolution dynamic nuclear polarization (dDNP) can transfer electron polarization to nuclear spins in the solid state at cryogenic temperatures, which are subsequently heated, dissolved in a liquid, and preserved at room temperature, e.g. for ${ }^{13} \mathrm{C}[2],{ }^{6} \mathrm{Li}[28],{ }^{15} \mathrm{~N}[29],{ }^{19} \mathrm{~F}[30],{ }^{29} \mathrm{Si}$ [31], ${ }^{31} \mathrm{P}[32]$, and ${ }^{107,109} \mathrm{Ag}$ [33].

Regardless of hyperpolarization technique and route of administration into the subject or object of interest, efficient acquisition strategies are needed, which are adapted to the properties of hyperpolarized signals. The hyperpolarized magnetization decays with $T_{1}$, which can be on the order of a few tens of seconds in vivo (e.g. for ${ }^{13} \mathrm{C}$ compounds [34, 35 ] or ${ }^{129} \mathrm{Xe}$ in an MR magnet [9]). Each RF excitation further reduces the available signal for subsequent excitations, which is particularly limiting when using dDNP, which typically provides single doses of hyperpolarized compound solution with intervals of more than 30 min between dissolutions. This is also the case for inhaled gas imaging, in which the available magnetization (and thus signal) can be replenished at most once per subject breath. Hyperpolarized compounds and their metabolites, particularly those labeled with ${ }^{13} \mathrm{C}$ or ${ }^{15} \mathrm{~N}$, as well as ${ }^{129} \mathrm{Xe}$ in various solutions or trapped in molecular cages [36-38], can cover a wide range of chemical shifts, which can hinder or help the design of sequences to separate their signal contributions, particularly in combination with the smaller gyromagnetic ratio of non-proton nuclei and the consequent need for higher gradient field strengths. For metabolic imaging, it is often necessary to acquire temporally resolved data, in order to extract metabolite dynamics. For imaging of lung ventilation, temporally resolved data allow gas flow to be visualized [11]. Temporally resolved data can also help ensure that the peak signal is measured after a hyperpolarized compound is administered, as the timing of its arrival in the area of interest may not be known prior to the measurement.

In this article, we review acquisition strategies for the measurement of hyperpolarized nuclei that are used to address these challenges, including strategies for pre-scan adjustments, hardware and field strength considerations, and sequence components including spectral encoding, spatial encoding, and excitation and contrast. We also discuss in more detail several important acquisition strategies and individually notable pulse sequences, including nonimaging spectroscopy, free induction decay (FID) chemical shift imaging (FID-CSI), echo planar spectroscopic imaging (EPSI), spiral multi-echo methods, free precession sequences, spectral-spatial excitation, and relaxometry.

\section{Hardware considerations}

In addition to the pulse sequence, system hardware, including most notably the static magnetic field strength and the radiofrequency (RF) coils used, are important considerations for localized hyperpolarized spectroscopy and imaging experiments.

\section{Static magnetic field strength}

The static magnetic field $\left(B_{0}\right)$ strength has several impacts on hyperpolarized nuclear magnetic resonance imaging and spectroscopy, with some differences to those of thermal proton measurements.

The imaging system field strength does not determine polarization level [39] or strongly affect signal strength for hyperpolarized compounds that are introduced from an external source [40]. Hyperpolarized measurements have thus been performed in vivo at $3 \mathrm{mT}$ with ${ }^{3} \mathrm{He}$ [40, 41], $15 \mathrm{mT}$ with ${ }^{129} \mathrm{Xe}$ and ${ }^{3} \mathrm{He}$ [42], $48.7 \mathrm{mT}$ with ${ }^{13} \mathrm{C}$ [43], and $100 \mathrm{mT}$ with ${ }^{3} \mathrm{He}$ [39], which are much lower field strengths than are typically used for thermal proton measurements.

There are several advantages associated with lower static magnetic field strengths for hyperpolarized measurements. Lower field strengths show reduced susceptibility effects, resulting in threefold increase in $T_{2} *$ at $0.43 \mathrm{~T}$ compared with $1.5 \mathrm{~T}$ for ${ }^{3} \mathrm{He}$ imaging in vivo, providing an effective increase in signal strength for sequences with long echo times [44]. The $T_{1}$ relaxation rates of many hyperpolarized

${ }^{13} \mathrm{C}$ compounds are also strongly dependent on the $B_{0}$ field strength [45]. Lower field strengths can also compensate 
for the greater demands placed on gradient systems with $\mathrm{X}$-nuclei due to their lower gyromagnetic ratio than that of protons. The same $k$-space trajectory, slice profile, or pulsed-gradient diffusion weighting will require proportionally larger gradient strengths for X-nuclei. This can be particularly problematic for sequences that traverse $k$-space rapidly with long readout gradients, such as multi-gradient echo spectroscopic measurements of ${ }^{13} \mathrm{C}$ compounds, which can display a much wider range of chemical shifts [46] than protons in most biologically interesting compounds, and thus benefit from rapid echo spacing and associated wide spectral bandwidth. At lower fields, however, these gradient demands are proportionally reduced. Additionally, heteronuclear decoupling of protons, particularly for molecules containing ${ }^{13} \mathrm{C}$ or ${ }^{15} \mathrm{~N}$ atoms, can require prohibitively large $\mathrm{RF}$ power in humans at high field for decoupling large spectral bandwidths due to specific absorption rate (SAR) restrictions [47, 48]. Last, lower field permanent magnets can be advantageous due to their lower costs compared with cryogenically cooled superconducting magnets [39].

As with thermal proton spectroscopy, a major advantage of higher field strengths for hyperpolarized spectroscopy is improved separation of spectral peaks [47, 49]. This is useful with hyperpolarized nuclei in liquids, such as precise measurement of chemical shifts for ${ }^{13} \mathrm{C}[50]$ or frequency-selective saturation with ${ }^{129} \mathrm{Xe}$ HYPER-CEST [38]. Additionally, peak splitting due to $J$-coupling, affecting molecules containing multiple spin $1 / 2$ atoms, such as protons and ${ }^{13} \mathrm{C}$ or ${ }^{15} \mathrm{~N}$, is not field dependent, and is thus less problematic at higher field strengths, without the need for decoupling.

Hyperpolarized spectroscopy and imaging measurements in vivo are normally conducted in combination with thermal proton imaging for anatomical reference to guide the planning of the hyperpolarized measurement, to provide complementary parametric or functional information, and for pre-scan adjustments. As such, the most suitable field strength for hyperpolarized imaging is often the field of an existing MRI system, to which X-nucleus imaging capability is added. The impacts of field strength on proton imaging are thus also relevant for most hyperpolarized X-nucleus experiments.

\section{Radiofrequency coils}

Radiofrequency (RF) coils and resonators are used to transmit and receive the radiofrequency fields that both manipulate magnetization and convey the signal in NMR and MRI measurements. For both proton and X-nucleus measurements, RF coils are produced in a wide variety of sizes and configurations, designed for particular measurement scenarios and geometries. RF coils may be categorized in by three independent properties: (1) the $B_{0}$ field, nucleus, and frequency for which an RF coil is resonant,
(2) the coil size and shape, including whether coils are volume resonators or surface coils, and (3) whether coils are single channel, multi-channel, or phased arrays. These properties directly impact the types of hyperpolarized measurements for which a coil is suitable.

RF coils are designed to be resonant within a relatively narrow band of frequencies, in order to be optimally sensitive within that band and be minimally sensitive to other signals. For hyperpolarized measurements on standard NMR and MRI systems, which are normally designed and used primarily at proton frequencies, additional RF coils designed for $\mathrm{X}$-nucleus applications are required. For X-nuclei with substantially lower gyromagnetic ratio than that of protons (i.e. those other than ${ }^{19} \mathrm{~F}$ ), the Larmor frequency at which the RF coil operates is similarly reduced, which affects its noise characteristics [10,51]. For example, at $3 \mathrm{~T}, 128 \mathrm{MHz}$ for ${ }^{1} \mathrm{H}$ is sample noise dominated, whereas $32 \mathrm{MHz}$ for ${ }^{13} \mathrm{C}$ has relatively more noise contribution from the coil [52], meaning improved coil design can be more impactful. Dual resonance coils are also available for ${ }^{1} \mathrm{H}$ and ${ }^{13} \mathrm{C},{ }^{23} \mathrm{Na}$, or ${ }^{31} \mathrm{P},[48,53-58]$, which are useful for heteronuclear ${ }^{1} \mathrm{H}-{ }^{13} \mathrm{C}$ decoupling [48, 59] and polarization transfer applications, which involve simultaneous transmission on multiple frequency channels. Triple resonance coils $[60,61]$ can also be helpful for $B_{1}$ calibration of hyperpolarized compounds containing ${ }^{13} \mathrm{C}$ by using signal from natural abundance ${ }^{23} \mathrm{Na}$, because their Larmor frequencies are similar.

Coil geometry substantially impacts the applications for which the coil is suitable. Volume resonators surround the subject and provide relatively uniform $B_{1}$ transmit and receive profiles, and are most suitable for imaging applications where the overall distribution of signal across the field of view is important, such as when the signal magnitude in well-separated regions is directly compared, e.g. for lung gas distribution [16, 62]. Even when a surface receive coil is used, a separate volume coil is often used for transmission, due to the importance in some pulse sequences of uniform and well-calibrated transmit $B_{1}$, which can be particularly challenging to achieve with hyperpolarized measurements. Surface coils, conversely, produce strongly spatially varying transmit and receive $B_{1}$ profiles [63], dependent on the distance from and size of the coil [64], which can reduce noise and amplify signal near the coil. This can be an advantage when a superficial tissue or organ is being studied, such as preclinical studies of subcutaneous tumors [50, 65-67], brain [68, 69], heart [70-75], liver [37, 64], or kidneys [50], and clinical studies of the heart [76]. However, spatially varying intensity from surface receive coils can substantially complicate interpretation of images, even when taking ratios of multiple metabolite signals. Additionally, endorectal coils have been developed for human prostate hyperpolarized ${ }^{13} \mathrm{C}$ imaging [77-80]. 
Quadrature coils $[60,81,82]$ provide a theoretical $\sqrt{ } 2$ increase in $B_{1}$ over similar-geometry linear coils, but provide no independent receive or transmit channel capability. Multiple independent channel coil arrays enable pulse sequence optimizations for hyperpolarized measurements, which are not possible with single-channel linear and quadrature coils. Receiver arrays coils with 4, or 8 channels have been used for hyperpolarized ${ }^{13} \mathrm{C}$ parallel imaging [83-85], including controlled aliasing for chemical shift separation [86]. An array with 32 channels has been used for hyperpolarized ${ }^{129} \mathrm{Xe}$ parallel imaging [87]. Multi-channel arrays are also advantageous for improved spatial coverage with good SNR in hyperpolarized imaging [88].

Cryogenically cooled coils can improve SNR through reduction of coil noise compared to coils operating at room temperature [51]. This can be particularly helpful for $\mathrm{X}$-nuclei imaging, with lower Larmor frequencies than that of protons, as coil noise has a larger impact on SNR [52]. A threefold SNR enhancement has recently been demonstrated for a $30 \times 40 \mathrm{~mm}^{2}{ }^{13} \mathrm{C}$ cryocoil at $3 \mathrm{~T}[89]$.

\section{Pre-scan adjustments}

Before MRI measurements, several pre-scan adjustments may be performed, including shimming the static magnetic field [90], sequence $k$-space trajectory measurement, and transmit $B_{1}$ calibration. Although some gas imaging uses exogenous hyperpolarized gas for pre-scan adjustments, for most liquid-state hyperpolarized magnetization is nonrenewable, so pre-scan adjustments are not usually done with the same hyperpolarized magnetization that is used for subsequent measurement. Instead, because all nuclei are influenced by the same $B_{0}$ field, shimming for X-nuclei is most often performed using signal from protons [60] in the subject, with shim current adjusted iteratively [90] or based on measured $B_{0}$ field maps [91, 92]. $k$-space trajectories can similarly be measured with proton signal $[49,93,94]$, with correction for the different gyromagnetic ratios between nuclei [95], or can be measured with a highly concentrated thermally polarized X-nuclei phantom. Techniques for transmit $B_{1}$ calibration are discussed below.

\section{$B_{1}$ calibration for $X-$ nuclei}

Transmit $B_{1}$ calibration is necessary to determine accurate RF pulse amplitudes, which are necessary in many sequences to produce the desired contrast, optimal signal, and artifact-free images [96]. For lower-frequency coils with stable coil loading, transmit $B_{1}$ calibration may be performed just once, and the same calibration used for all subsequent measurements. In other cases, calibration may be repeated separately for each new subject.
Sequences with higher flip angle pulses are in general more sensitive to flip angle accuracy, including non-adiabatic inversions and refocusing pulses to produce spin echoes [97]. Flip angle accuracy is also important for the quantification of metabolite concentrations [96]. Sequences with low flip angles, especially sequences with a series of variable (and low) flip angle pulses [98], as well as adiabatic RF pulses [99], are less affected by the $B_{1}$ calibration.

For thermal proton MRI, several standard transmit $B_{1}$ calibration procedures are used on preclinical and clinical MRI systems [100-104], using signal from the subject. For $\mathrm{X}$-nuclei, however, transmit $B_{1}$ calibration is more challenging. Due to their low in vivo concentrations and smaller gyromagnetic ratio, natural abundance $\mathrm{X}$-nuclei often produce too little signal to be used for thermally polarized $B_{1}$ calibration [105]. Furthermore, most hyperpolarized signal is non-renewable, and is thus often not suitable for use in $B_{1}$ calibration [73], with the exceptions of ${ }^{3} \mathrm{He}$ and ${ }^{129} \mathrm{Xe}$ lung imaging $[62,87]$. Instead, a separate high concentration gas or liquid thermally polarized phantom is normally used to calibrate $B_{1}$ before most X-nuclei hyperpolarized measurements [106-108]. For coils with subject-dependent loading, such a phantom may be placed adjacent to the subject, near the region or structure of interest to ensure similar coil loading and local $B_{1}$, and may be removed or left in place for the subsequent hyperpolarized measurement. Alternatively, a phantom may be designed to simulate the presence of a subject [105].

Some pulse sequences additionally require receive coil $B_{1}$ profiles for each independent channel of multiple-channel coils, independent of the transmit coil $B_{1}$ profile. These include parallel reconstruction with sensitivity encoding (SENSE) [83, 109, 110]. Receiver coil $B_{1}$ calibration has most of the same limitations for hyperpolarizing imaging applications, relating to lack of signal for calibration measurements.

Several methods have been developed for calibration of the transmit $B_{1}$ field in measurements using hyperpolarized $\mathrm{X}$-nuclei. Some methods produce only a single $B_{1}$ calibration factor for a given experimental configuration, which may only be accurate within a limited spatial region of the subject, particularly for surface transmit RF coils or subjects that extend outside a volume coil. Other methods produce a $B_{1}$ map, which indicates the spatial variation of flip angles.

\section{Pulse power incrementation}

A thermally polarized phantom is placed next to the subject, and the non-selective or slice-selective FID signal is measured after excitation at varying RF power levels (or nominal flip angles). The resulting curve can be fitted with a sinusoid [111], or the flip angle calibration determined from the point where the spectral peak crosses zero (or its phase inverts) 
[107], which corresponds to a $180^{\circ}$ excitation pulse [105, $112]$ at the location of the phantom. To produce an accurate calibration, the phantom must be limited in size and placed in a location with the same local $B_{1}$ as the region of interest in the subject.

\section{Scaling $B_{1}$ for different nuclei}

The $B_{1}$ transmit calibration for X-nuclei can be estimated using the $B_{1}$ calibration of another nucleus with a similar gyromagnetic ratio and Larmor frequency. This proportionality will be different for any unique pair of coils, however, and will not account for local $B_{1}$ variations. The $B_{1}$ calibrations of ${ }^{1} \mathrm{H}$ and ${ }^{3} \mathrm{He}$ have been shown to be proportional between separate single-nucleus volume coils [113]. The $B_{1}$ calibration for ${ }^{13} \mathrm{C}$ can also be estimated with that of ${ }^{23} \mathrm{Na}$ using a dual-tuned ${ }^{23} \mathrm{Na} /{ }^{13} \mathrm{C}$ coil with a scaling factor, which is useful because ${ }^{23} \mathrm{Na}$ is present in most biological tissue at relatively large concentration, which simplifies the design and operation of such coils [96].

\section{Repeated excitation with small flip angle}

A series of RF excitation pulses or spoiled gradient echo images with constant power can be used to measure the $B_{1}$ calibration or generate $B_{1}$ maps from the signal variation with number of excitations $[114,115]$. This is similar to the variable power method, except that it requires approximate initial estimate of the $B_{1}$ calibration and $T_{1}$ relaxation time, but uses only small flip angles. The spacing between excitation pulses may also be varied to simultaneously measure $T_{1}$ and the $B_{1}$ calibration [116].

\section{Magnetization inversion}

Flip angle measurement by magnetization inversion can be applied to hyperpolarized gas. Magnetization is prepared with two RF excitation pulses, separated by a $B_{0}$ field gradient to produce a spatially varying phase. The RF pulses have flip angle above $45^{\circ}$, so that magnetization is inverted (more than $90^{\circ}$ effective flip angle) after both pulses, in a band where the gradient field is weakest. The flip angle of the RF pulses can then be determined from the width of the inverted band of magnetization, and is unaffected by oxygen-related relaxation, imperfect slice profiles, or diffusion [114].

\section{Bloch-Siegert shift}

The Bloch-Siegert method is a relatively fast method for $B_{1}$ calibration and measuring $B_{1}$ maps [117]. Magnetization is excited, and then an off-resonant RF pulse is applied to produce a $B_{1}$-dependent phase shift [118]. An example pulse sequence for mapping $B_{1}$ using this method is shown in Fig. 1. The Bloch-Siegert method has been used for slice-selective $B_{1}$ calibration with thermal ${ }^{13} \mathrm{C}$ phantoms and hyperpolarized ${ }^{3} \mathrm{He}$ in lungs [112], and for $B_{l}$ mapping during dynamic in vivo ${ }^{13} \mathrm{C}$-pyruvate image acquisition [73] and triggered by bolus tracking immediately before dynamic in vivo ${ }^{13} \mathrm{C}$-pyruvate image acquisition (Fig. 2) [119].

\section{Signal reduction}

When two low-flip angle images or spectra are acquired in succession, of non-renewable magnetization that does not flow into or out of the excited volume, the second image's intensity is reduced due to excitation losses and $T_{1}$ relaxation. This has been applied for flip angle mapping in human lungs, with breath holding, of hyperpolarized ${ }^{129} \mathrm{Xe}$ and ${ }^{3} \mathrm{He}$ $[62,87]$. Similar methods are also used for in vitro spectroscopic measurements [120].

\section{Pulse sequence components}

A wide variety of pulse sequences have been developed for measuring hyperpolarized nuclei, from simple NMR acquisitions to sophisticated optimized sequences. These sequences in general use some combination of (1) spectral encoding, (2) spatial encoding, and (3) excitation and contrast scheme. Various possible pulse sequence elements are listed below, within these categories. Not all variations can
Fig. 1 Bloch-Siegert $B_{1}$ mapping sequence diagram, with spectral-spatial RF pulse, offresonance RF pulse, and spiral readout gradients

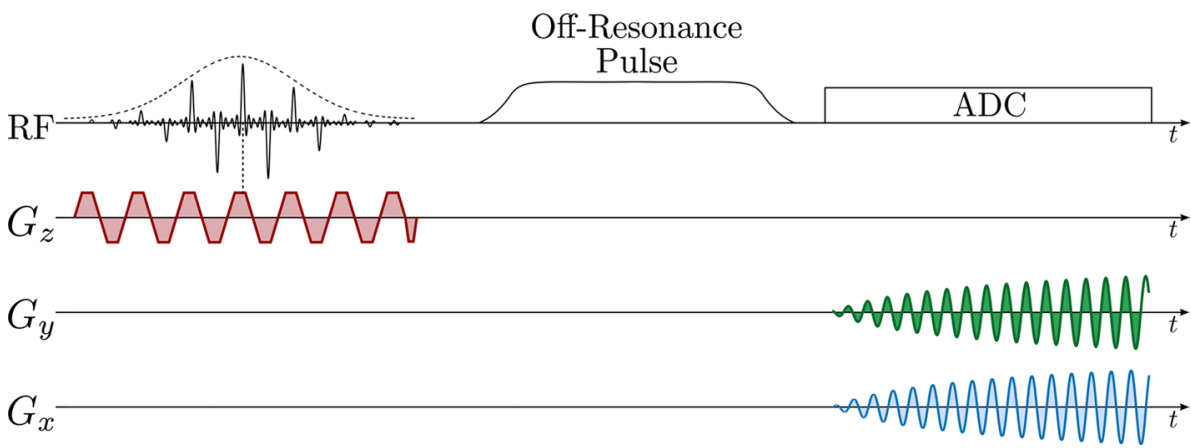



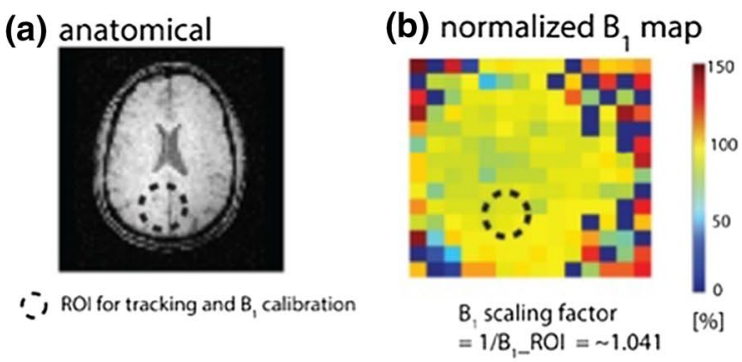

(c) acquired spectrum

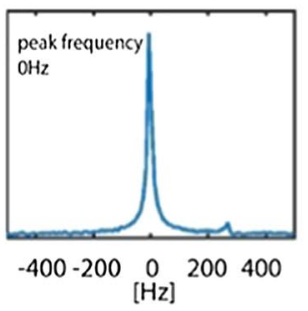

(d) ${ }^{13} \mathrm{C}$ results displayed by time

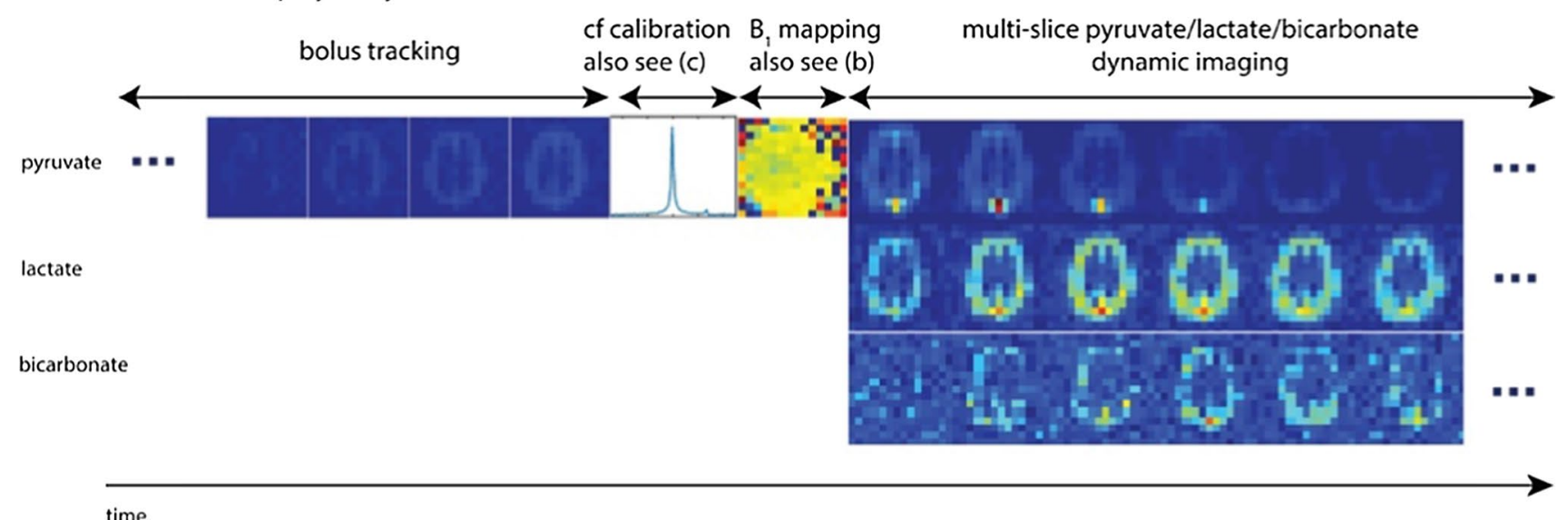

time

Fig. 2 Results of hyperpolarized $\left[1-{ }^{13} \mathrm{C}\right]$ pyruvate studies on a healthy human volunteer using bolus tracking, Bloch-Siegert $B_{1}$ mapping, and multi-slice dynamic imaging of ${ }^{13} \mathrm{C}$ metabolites. a Proton image

or have been combined, but each usable sequence will use one or more of the methods in each category.

\section{Spectral encoding}

Spectral encoding methods separate NMR signal by frequency (chemical shift) of the nucleus being measured. Different chemical shifts of the same nucleus arise from different local magnetic fields at the sites of the nucleus, which are induced by the different chemical environments in different molecular species that incorporate the nucleus, by their different positions within a single molecular species, or the solution, surface [121], or molecular cage [38] in which it resides. In cases with only one measurable chemical shift, no spectral encoding is required. If more than one distinct chemical shift is present, spectral encoding isolates the signals at those frequencies, and thereby measures their distinct amplitudes, distributions, or time-courses. This separation may be accomplished with frequency selective excitation, during signal readout from the phase evolution of a time-series of measurements, or a combination of these two methods.

Most measurements of hyperpolarized agents have relatively sparse spectra. Only one or a small number of distinct molecules are usually present in the administered of slice 5. b Normalized ${ }^{13} \mathrm{C} B_{1}$ maps. c Acquired frequency spectrum for center frequency calibration. $\mathbf{d}^{13} \mathrm{C}$ results of slice 5 displayed in the order of time. Reprinted with permission from Tang et al. [119]

hyperpolarized agent. These molecules may be chemically stable during the time course of measurement, may be rapidly metabolized into a small number of additional compounds, or may be present in a small number of distinguishable chemical environments. Furthermore, the design of a hyperpolarized experiment will usually ensure that the compounds of interest have relatively well-separated chemical shifts. This is in contrast to many in vivo proton NMR spectroscopic measurements, in which many endogenous compounds appear close together in the spectra. For such hyperpolarized signals with relatively easy to separate sparse spectra, a variety of spectral encoding schemes can be used.

\section{Free induction decay (FID)}

Signal is measured without applied gradients $[4,34$, 122-126]. The spectrum is the Fourier transform of the FID signal. This method can provide wide spectral bandwidth without placing high demands on the gradient hardware.

\section{Multi-echo model-free}

Multiple gradient echoes are acquired with evenly spaced echo times $[127,128]$. The echo train at each $k$-space point may be treated similarly to an FID [129], depending whether 
the echoes are acquired with symmetric or flyback gradient shapes. The spacing of echoes should be sufficiently short to give spectral bandwidth that is adequate to separate the frequency offsets of the compounds of interest, without problematic frequency wrapping of the spectrum [130].

\section{Multi-echo sparse}

A relatively small number of gradient echoes are acquired [131]. At least one more echo than distinct spectral components is needed [132], and the number and timing of echoes may be adjusted to optimize sensitivity to and separation of an expected number and distribution of frequency components in the signal [133]. Images for expected frequency components are separately reconstructed from the phases of measured echoes and the known timing of the echoes using matrix inversion $[125,134]$ or iterative least-squares (IDEAL) [132, 135] methods.

\section{Chemical shift offset separation}

Images are acquired with frequency encoding during readout with sufficiently low receive bandwidth that multiple frequency components in the signal are chemically shifted to produce separate images [136], or partially aliased images that can be separated with parallel imaging reconstruction [86].

\section{Frequency selective excitation}

Frequency selective RF pulses excite or invert a single frequency, a narrow range of frequencies [137], or alternate between frequencies [138].

\section{Spectral-spatial (SPSP) excitation}

Specially designed RF pulses, in combination with spatial encoding gradients, are used to excite within a band of frequencies that include only a single hyperpolarized compound and within a spatially limited region $[65,139]$ or which selectively excite multiple frequency bands [140, 141]. Multiple alternating excitations also can be used to acquire images of multiple frequencies [70].

\section{Spatiotemporal encoding}

RF excitation or inversion pulses are swept in frequency (chirped or adiabatic) while an encoding gradient is active, and a decoding gradient is applied during signal readout $[142,143]$. Spatially resolved spectral content of the resulting signals can be separated $[142,144]$.

\section{No spectral encoding}

Images are acquired with a non-spectroscopic MRI sequence. This method is used for hyperpolarized ${ }^{129} \mathrm{Xe}$ imaging [9, 106, 145], ${ }^{3} \mathrm{He}$ imaging [146-148], or other angiography imaging $[34,149,150]$ for which spectroscopic separation of multiple chemical shifts is not needed.

\section{Spatial encoding}

Spatial encoding separates NMR signal by location in space. Most in vivo measurements require some form of spatial encoding in the pulse sequence or receive coil(s) to localize signal to an organ or other region of interest or to produce images that are spatially resolved in two or three dimensions. Conversely, most in vitro measurements use the total signal from the entire sensitive volume of the receiver coil, with no additional spatial localization than that from the limited size of the object and the coil's sensitivity profile.

NMR signal spatial localization may be accomplished with the sensitivity profiles of receiver coils, spatially selective RF pulses, field gradients after excitation and before or during signal acquisition, or with a combination of these methods.

For imaging hyperpolarized agents with non-renewable magnetization, fast spatial encoding is required, as is keeping the number of RF excitations used to acquire the image data minimal. This is particularly true for multi-frame acquisitions, which need relatively short times between frames to follow signal dynamics, and also need to preserve magnetization for later frames. Various trajectories and strategies for traversing $k$-space have been used for hyperpolarized imaging, mainly initially for thermal proton imaging and subsequently adapted. These include several techniques for accelerating the acquisition by under-sampling data in the spatial and spectral dimensions and recovering the missing information using parallel receiver coil arrays or by taking advantage of the sparsity of the spectral dimension.

\section{Hardware-sensitivity localized}

The receiver and transmit radiofrequency (RF) coil hardware sensitivity profiles ( $B_{1}$ field) determine the measurement's spatial sensitivity to the signal. The pulse sequence itself does not localize the origin of the signal [34].

\section{Slice selective excitation}

The excitation radio frequency (RF) pulse is applied while a linear gradient field is active $[151,152]$. The excited volume is a thin 2D slice or thick 3D slab in space [65]. If more than one chemical shift is present in the object $[121,153]$, there 
is a spatial offset between the slices corresponding to different chemical shifts [68]. This offset leads to the so-called chemical shift displacement artifact, which can be reduced by using a high transmit bandwidth relative to the chemical shift offset, or avoided with spectral-spatial excitation pulses.

\section{Voxel-selective excitation}

Three orthogonal slice-selective excitation and refocusing or inversion RF pulses restrict the excited volume to a cuboidal voxel $[154,155]$. The resulting signal may be spin or stimulated echoes, depending on the pulse phase and amplitude. Alternatively, slice-selective outer volume suppression [156, 157] may be applied prior to excitation, to the volumes surrounding a target volume. Outer volume suppression does not require echo generation using multiple slice-selective high-flip-angle excitation, refocusing, or inversion pulses applied to the target volume.

\section{Phase encoding}

Phase-encoding gradient blips are applied after excitation and before readout $[122,124]$ or repeatedly during readout $[158,159]$ to move between $k$-space points or lines.

\section{Frequency-encoded readout}

Frequency encoding gradients are active and constant during signal readout [9]. This is typically combined with an initial dephasing blip, during phase-encoding, so that the phase of the image passes through the center of $k$-space in the frequency encoding direction during the readout, producing a gradient-recalled echo.

\section{Multi-gradient echo}

A train of gradient echoes is acquired to read multiple $k$-space lines [146] (EPI) or multiple echoes of the same line $[128,160,161]$ (EPSI) per excitation or refocusing RF pulse. $B_{0}$ field inhomogeneity can limit the use of long echo trains [12] or require correction algorithms [162].

\section{Symmetric}

Frequency encoding gradients during readout have alternating polarity, moving through $k$-space in opposite directions [134], also referred to as bipolar readout gradients. Chemical shift offsets and inconsistency in gradient response between directions can lead to differences between odd and even numbered echoes [163], for which bipolar gradient corrections have been developed [164].

\section{Flyback}

Frequency encoding gradients are constant during readout, alternating with gradient pulses that use the maximum slew rate to rewind the encoding and prepare for the next readout $[165,166]$. Compared with symmetric or non-frequencyencoded readouts, encoding efficiency is lower, as data are not acquired during rewind pulses.

\section{Cartesian $k$-space trajectory}

$K$-space points are acquired in a standard MRI pattern of orthogonal rows and columns (or also a third dimension). Grid spacing may be uniform or uneven depending on whether constant or ramped gradients are used during acquisition.

\section{Centric encoding}

$K$-space points or lines are acquired in a center-out order [4, 147], rather than sequentially across $k$-space. This improves signal strength with non-renewable hyperpolarized magnetization and is less sensitive to motion, but can increase spatial blurring artifacts [167].

\section{Spiral $k$-space trajectory}

Gradients are continuously adjusted during readout to trace a spiral pattern from the center to the periphery of $k$-space. $K$-space may be covered in a single spiral, giving non-spectroscopic data $[11,70]$, or a series of spirals giving spectroscopic data $[125,131,168]$. Such a pattern will produce a non-Cartesian sampling of $k$-space, and thus will require a suitable reconstruction method $[131,169,170]$.

\section{Radial trajectory}

Frequency encoding is applied radially out from the center of $k$-space [123]. This can give very short effective echo times for gas $T_{2} *$ measurement, or useful oversampling of the center of $k$-space, giving good sensitivity to contrast changes for dynamic imaging [171-174]. Alternating radial gradients to produce multiple echoes have also been used for ${ }^{13} \mathrm{C}$-pyruvate spectroscopic imaging [175].

\section{Concentric rings trajectory}

Frequency encoding is applied in a series of retraced circles $[176,177]$. This trajectory has timing, sampling efficiency, and gradient-demand advantages compared with spiral or Cartesian $k$-space sampling trajectories. 


\section{Under-sampling}

Image data are under-sampled in the spatial and spectral dimensions during acquisition and the reconstruction compensates for the missing information. Pseudo-random undersampling is referred to as compressed sensing $[79,158,159$, 178-181]. Regular under-sampling, with fully sampled training data in the center of $k$-space, can be reconstructed with $k$ - $t$ principal component analysis, using a limited number of temporal basis functions that are derived and used to constrain the image reconstruction for each spatial location [ $[74$, $182,183]$.

\section{Parallel imaging}

A multi-receiver coil array is used during acquisition with a field of view that does not fully cover the subject [86]. Reduced field of view, and thus spatial aliasing of the image, is equivalent to omitting $k$-space lines during acquisition, which is corrected in reconstruction using information from the spatial distribution of the receiver array. Parallel reconstruction methods include sensitivity encoding (SENSE) [83, 109, 110], autocalibrating parallel acquisition (GRAPPA) [12, 87, 184], and calibrationless parallel imaging [185-187]. Omitting $k$-space lines allows fewer excitations [87] and higher flip angles [12] to be used in sequences using multiple excitations, improving temporal resolution without loss of SNR, as would be the case with thermal polarization [188], or reducing overall scan time [12]. Alternatively, multiple slices are excited simultaneously, and signals are separated using coil sensitivity information [189].

\section{Partial Fourier}

Symmetry in $k$-space is exploited to under-sample by omitting acquisition of almost half of the $k$-space $[84,148,190]$.

\section{Spatiotemporal encoding}

RF excitation or inversion pulses are swept in frequency (chirped or adiabatic) while an encoding gradient is active, and a decoding gradient is applied during signal readout $[142,143,191]$. The excited magnetization has a phase that varies quadratically in space, and the decoding gradient moves the vertex of the phase parabola, where magnetization is in phase, during readout [192].

\section{Excitation scheme and contrast}

RF pulses and static magnetic field gradients are used to manipulate magnetization to produce signal and to control its contrast and sensitivity to various physical properties in the subject. Every NMR measurement has an excitation pulse, which tilts magnetization into the transverse plane, where its precession produces the RF signal that is acquired. Further RF and $B_{0}$ field gradient manipulations may be applied prior to excitation, between excitation and readout, or during readout.

For hyperpolarized agents, non-renewable magnetization limits sequence timing and the use of contrast mechanisms that are common for thermally polarized measurements. Flip-back RF pulses and balanced gradients are of increased importance, rather than spoiling residual transverse magnetization after readout. For refocusing and inversion, adiabatic RF pulses are preferred due to their relative insensitivity to transmit power calibration, as are non-spatially selective pulses, to avoid mixing of inverted and non-inverted magnetization and saturation effects adjacent to the targeted slice at high flip angles. Sequence repetition times are kept to a minimum, to avoid loss of hyperpolarized magnetization due to relaxation, compared with thermally polarized acquisition, in which longer repetition times allow relaxation to increase the longitudinal magnetization available for subsequent excitations. For hyperpolarized gases, diffusion imposes further limits on sequence design.

\section{Constant flip angle}

Magnetization is excited at a constant flip angle RF pulse $[9,124]$.

\section{Variable flip angle}

Flip angle is varied between excitations or chemical shift. Angle may be increased with time to compensate for loss of magnetization due to previous excitations and $T_{1}$ decay [25, 130, 193-195]. The flip angle may also be varied between frequency-specific excitations, when one compound has much higher concentration than another, or to avoid depleting the substrate of a reaction being investigated (e.g. pyruvate being converted to lactate) $[65,140,162,178]$. Angle may also be varied in a more complicated pattern over time and chemical shift to optimize estimate precision of a rate constant [196].

\section{Spin echo}

Magnetization is excited and then refocused with a second RF pulse or train of refocusing pulses [149]. Spin echoes are useful for hyperpolarized gases which have short $T_{2}$ * due to diffusion effects [146, 149], unless the sequence also involves intense gradient activity [145]. Spin echo sequences 
can also rapidly deplete hyperpolarized magnetization [145] and are sensitive to flip angle calibration [146]. Inverted magnetization will also mix with non-inverted magnetization through blood perfusion, resulting in opposite-polarity cancellation and loss of signal [128].

\section{Adiabatic refocusing}

Magnetization is excited at a low flip angle and then refocused by a pair or train of adiabatic inversion [197] spatially non-selective RF pulses [140]. Adiabatic pulses are relatively insensitive to flip angle calibration and off-resonance effects [198], and can produce good refocusing and low signal loss from dephasing [199]. By refocusing twice, the magnetization is effectively returned to the state it had after the initial low flip angle excitation, allowing an effective low flip angle to be used, preserving magnetization for subsequent acquisitions. A train of adiabatic refocusing pulses can produce a series of spin echoes, with signal acquired after each refocusing pulse [199]. Blood perfusion magnetization cancellation issues are also avoided by inverting nonselectively [128].

\section{Free precession}

Magnetization is repeatedly and rapidly (relative to the relaxation times $T_{1}$ and $T_{2}$ ) excited [200] and refocused with constant [34, 150] or variable flip angles [195], with alternating phase, and without spoiling gradients. Typically, balanced gradients are used, which have zeroth gradient moment of zero between successive RF pulses [34, 134, 201-204]. Free precession sequences are often referred to as (balanced) steady-state free precession (bSSFP), although for hyperpolarized measurements, no measurable steady state is reached, due to the lack of magnetization recovery from $T_{1}$ relaxation, as occurs in thermal proton measurements.

\section{Stimulated echo}

Magnetization is excited and tilted back into the longitudinal direction after a short dephasing time. The prepared magnetization is then excited by a third RF pulse after a mixing time. This produces a stimulated echo [205] with timing dependent on the timing of the RF pulses [206]. Stimulated echoes can be used to provide diffusion or perfusion weighting $[207,208]$ for hyperpolarized ${ }^{13} \mathrm{C}$ imaging. Stimulated echoes can be preferable to spin echoes for measurements using long echo times [209].

\section{Saturation and inversion}

Using a frequency-selective RF pulse, magnetization is saturated or inverted [138]. This can be useful to observe how metabolite signals exchange after selective saturation of ${ }^{13} \mathrm{C}$-labeled molecules [66], to investigate how selectively saturated magnetization of encapsulated ${ }^{129} \mathrm{Xe}$ chemically exchanges with the hyperpolarized ${ }^{129} \mathrm{Xe}$ pool in solution at a different chemical shift (HYPER-CEST) in [38], or to selectively destroy signal outside a region of interest to ensure that metabolites flowing into a region do not disturb the temporal relationship between metabolites [210]. Saturation is also used in continuous flow (replenished) hyperpolarized ${ }^{129} \mathrm{Xe}$ gas measurements of microstructural exchange properties in materials [211] and lungs [13].

\section{Polarization transfer}

Polarization transfers from one nucleus to another spontaneously due to heteronuclear cross-relaxation [212], or the transfer may be induced by RF pulses [213], such as with (reverse) insensitive nuclei enhanced by polarization transfer (INEPT) [35, 157, 214-216]. Hyperpolarizing ${ }^{13} \mathrm{C}$ or ${ }^{15} \mathrm{~N}$ and then transferring the polarization to ${ }^{1} \mathrm{H}$ before measurement is useful due to their longer $T_{1}$ relaxation times [217, 218 ] and because nuclei with higher gyromagnetic ratios place lower demands on the gradient system for equivalent signal encoding. Furthermore, assuming efficient transfer of polarization and minimal losses due to other pulse sequence differences compared with direct X-nucleus polarization measurement, the higher gyromagnetic ratio $(\gamma)$ of protons theoretically provides higher detection sensitivity [35, 46, 215] and SNR, proportional to $\gamma^{2}$.

\section{Diffusion}

Apparent diffusion coefficient (ADC) may be assessed with paired pulsed gradients [219, 220]. Varying strength and separation of the gradient pulses controls the diffusion weighting $b$-value and thus the amount of motiondependent dephasing and signal intensity reduction [221]. Diffusion over longer distances can also be measured with spatial modulation of the longitudinal magnetization [222]. In vivo hyperpolarized diffusion imaging is used to assess lung microstructure $[12,223]$ with gases and liver fibrosis [224] with ${ }^{13} \mathrm{C}$. Most imaging sequences will also have some inherent diffusion weighting, dependent on the strength of gradients they use [145, 148].

\section{Flow}

Sensitivity to liquid flow or perfusion can be introduced with stimulated echo pulse sequences, which dephase magnetization before the second RF pulse, and rephase it after the third RF pulse unless the magnetization has moved from its initial position [207, 208, 225]. Phase variation in vitro has also been used to image flowing hyperpolarized water [226]. 


\section{Static/single or dynamic/multiple excitations}

A single image is acquired [4, 9], or multiple images are acquired over time, allowing a time-course of signal to be reconstructed $[65,146,227]$.

\section{Spoiling}

After signal readout, substantial magnetization may remain in the transverse plane, although it will usually have been dephased by phase and frequency encoding. The transverse magnetization may be further dephased (spoiled), by again turning on a strong gradient $[131,150]$, so that it will not contribute directly to the signal after subsequent RF pulses or produce stimulated echoes.

\section{Decoupling}

NMR spectral peaks can split due to heteronuclear $J$-couplings. Particularly at lower field strengths, this leads to separation of signal into multiple peaks, which may be independently less distinguishable from background noise. Continuous wave RF irradiation at the Larmor frequency of a nucleus, e.g. proton, that is coupled to an X-nucleus, e.g. ${ }^{13} \mathrm{C}$, suppresses the $J$-coupling evolution during the signal acquisition and removes the peak splitting. This has been used on clinical MRI scanners with hyperpolarized compounds, and produced narrower spectral line widths [228] and substantial sensitivity improvement [64] in vivo, and in non-imaging NMR measurements of hyperpolarized compounds [229]. In addition, off-resonance decoupling has been used to obtain heteronuclear chemical shift correlations from hyperpolarized compounds [230-232].

\section{Pulse sequences}

Many pulse sequence variations have been proposed and demonstrated for hyperpolarized imaging and spectroscopy, which make use of various combinations of the sequence components discussed above. Several important sequences or groups of sequences are discussed below, in rough order from less to more complicated, including non-imaging and imaging methods.

\section{Non-imaging spectroscopic methods}

NMR spectroscopic methods omit spatial encoding gradients during signal acquisition and (in most techniques) during RF excitation. The signal may still be localized with the sensitivity profiles of the RF transmit and/or receiver coils, or with gradients applied during excitation and refocusing RF pulses to provide slice or voxelselectivity. These methods employ a wide variety of contrasts and spectral encoding schemes for hyperpolarized experiments.

\section{Non-localized spectroscopy}

Non-localized spectroscopy originates with first nuclear magnetic resonance (NMR) experiments of Bloch [233] and Purcell [234]. RF pulses are used to invert, saturate, refocus, and excite magnetization across, and signal is received from, the entire sensitive volume of the RF transmit and receive coil. For hyperpolarized nuclei, the most common acquisition scheme is free induction decay (FID) [2, 39]. Single high-angle or multiple low-flip angle iterative excitations are applied, typically spaced several seconds apart [137] to follow physical, physiological, or metabolic processes for up to several minutes [124]. Constant or variable flip angle schemes are used [235]. Material science applications include Xe gas adsorption on solids [121]. In vitro experiments include enzymatic assays [236], cell metabolism experiments [65], or whole resected organs [237], at a wide range of field strengths from $0.0487 \mathrm{~T}$ [43] to $14.1 \mathrm{~T}$ [238]. Because the entire sample is contained within the sensitive volume of the coil, inflow and outflow of hyperpolarized magnetization do not need to be accounted for, facilitating kinetic modeling [239].

MRI systems are also used for non-localized in vivo spectroscopy [34, 124], when the subject fits within the RF coil. In any other case, signal will be localized by the sensitivity profile of the coil, even without any localization from the pulse sequence.

\section{Localization by coil sensitivity}

The $B_{1}$ field profile of a surface coil $[63,65]$ can be exploited to isolate signal near the coil's position. A small solenoid or volume coil [227] can similarly be placed over a region of interest to isolate signal within. Both the RF transmission and reception $B_{1}$ profiles can be used, with transmission to limit the volume of excited magnetization, and with reception to limit the volume from which signal is received. When used to transmit, surface coils produce spatially varying effective excitation angle (less so with adiabatic pulses) which can complicate signal interpretation. Signal localization by coil sensitivity profile can also be combined with selective excitation and spatial encoding with magnetic field gradients. 
In vivo, surface receive coils are used for detection of signal from superficial regions and near-surface organs such as subcutaneously implanted tumors [21], heart, liver, or head [240]. Coil size is adapted to the application, from more than $13 \mathrm{~cm}$ diameter [241], down to $8 \mathrm{~mm}$ [242], and most commonly $20 \mathrm{~mm}$ in preclinical small animal experiments [75, 243, 244].

\section{Slice-selective excitation}

Slice selective or spectral-spatial pulses are used to excite magnetization in a slice, limited in one spatial dimension. Typical slice thicknesses for hyperpolarized experiments range from $5 \mathrm{~mm}$ [65] to $40 \mathrm{~mm}$ [245].

As with non-selective excitation, slice selective excitation can be applied iteratively at low flip angles, preserving hyperpolarized magnetization during dynamic measurements. For in vivo studies, however, in-flowing magnetization can complicate quantitative modeling. Multiple slices may be interleaved with alternating excitations, in order to simultaneously measure separate body regions [153] or objects [246]. Slice excitation can also be combined with surface-coil localization [65]. This approach is well suited for single organs [25, 243] or subcutaneous tumors [65].

\section{Voxel-selective (echo) spectroscopy}

An excitation pulse is followed by orthogonal-slice selective RF pulses to produce a spin or stimulated echo within a cuboidal voxel. Stimulated echo acquisition mode (STEAM) $[247,248]$ produces a stimulated echo with three $90^{\circ}$ pulses. Point resolved spectroscopy (PRESS) [155, 249] produces a spin echo with an excitation pulse followed by two $180^{\circ}$ refocusing pulses. Localization by adiabatic selective refocusing (LASER) [197] produces a spin echo with a nonselective excitation and three pairs of adiabatic refocusing pulses.

Both STEAM and PRESS, using shaped slice-selective pulses or spectral-spatial excitation, require accurate $B_{1}$ transmit calibration to produce effective refocusing pulses. Adiabatic pulses are less sensitive to $B_{1}$ calibration. Adiabatic and spectral-spatial pulses provide improved robustness to the chemical shift displacement artifact, which can complicate data interpretation [250] with simple slice selection. They can also produce low effective flip angles for dynamic acquisition, without saturation effects outside the target voxel, as can occur with high angle simple slice selective pulses [155]. These saturation effects can also be mitigated for single time-point sequential acquisition in multiple voxels by careful orientation and positioning of voxel edges to preserve magnetization in other regions [251]. Such multi-voxel approaches [252] can be an efficient alternative to imaging for isolating signal to a small number of discrete regions of interest [154].

\section{Multi-dimensional and exchange spectroscopy}

Two-dimensional NMR spectroscopy traditionally involves multiple excitations with varying parameters, such as evolution or mixing times between excitations or excitation frequencies [253].

Exchange spectroscopy (EXSY) employs stimulated echoes with varied evolution time between the first and second RF pulses and fixed mixing time between the second and third RF pulses [254]. During the evolution time, the magnetization acquires a phase at a rate dependent on its chemical shift, which is separable from the chemical shift measured during the readout, allowing a 2D spectrum to be extracted that describes the distribution of exchanging magnetizations before and after the mixing time. EXSY can be applied to renewably hyperpolarized magnetization in vitro, such as generated with SABRE [255].

For two-site exchange, MAD-STEAM [256, 257] can be applied with only a single encoding and acquisition, with slab selective excitation, making it more suitable for hyperpolarized measurements in vivo. MAD-STEAM produces a phase shift in magnetization that depends on the frequency difference between the two exchanging sites and the echo time. This technique allows signal of in-flowing metabolite to be separated from that arising from metabolic conversion. Ultra-fast exchange spectroscopy (UFEXSY) [252] extends MAD-STEAM, with multiple echoes and sparse sampling to separate multiple exchanging metabolites and voxel selective excitation.

Ultrafast two-dimensional spectroscopy uses a series of frequency-stepped slice selective excitations [258-260] or swept-frequency excitations [261] or inversions [262] and a multi-echo readout. Although the excitations are localized, they are applied to a uniform object and are used to parallelize the evolution times. This method has been applied to hyperpolarized ${ }^{13} \mathrm{C}$ and ${ }^{15} \mathrm{~N}$ in combination with polarization transfer to ${ }^{1} \mathrm{H}$ before readout [46, 260, 263].

\section{Diffusion spectroscopy}

Diffusion weighting can be introduced with paired pulsed gradients with spin echo [219] or stimulated echo [209, 256] acquisition. For hyperpolarized measurements, because the magnetization decays rapidly and non-renewably, the mixing time [264] and echo time [265] are kept short and constant, with gradient strengths varied to control the diffusion weighting $b$-value, and higher diffusion weightings are acquired first to optimize SNR [221, 266]. 


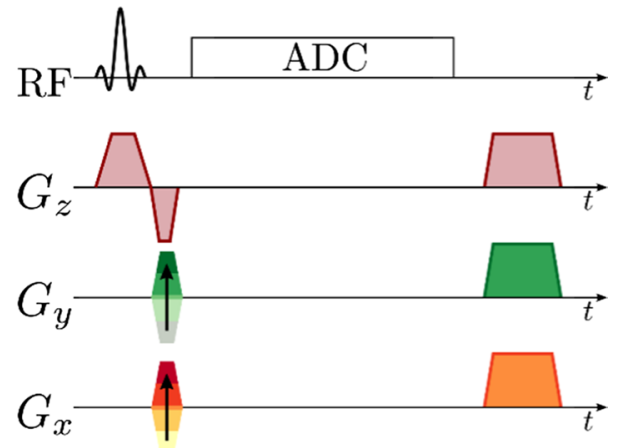

Fig. 3 FID-CSI pulse sequence with slice-selective excitation and 2D phase encoding, acquisition window without any gradients active, and post-acquisition spoiler gradients

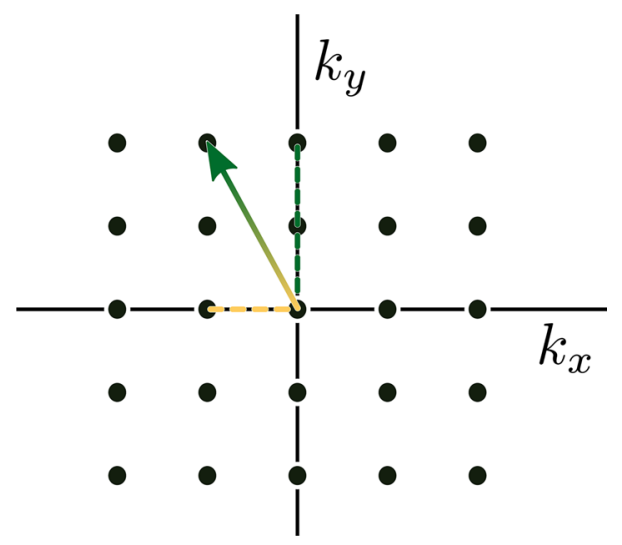

Fig. $4 k$-space acquisition pattern of a 2-spatial-dimensional FID-CSI pulse sequence. Phase encode gradients are applied simultaneously for all spatial dimensions before acquisition starts so that a single point in $k$-space is encoded for the duration of each acquisition. Subsequent acquisitions are used to acquire additional $k$-space points

Saturation recovery sequences can also produce diffusion weighting in continuous flow experiments [267].

Diffusion weighting is used to characterize in vivo microstructures [221, 268], transgene expression [67], and transport processes [269]. Hyperpolarized in vitro diffusion spectroscopy with ${ }^{13} \mathrm{C}$ has been used to separate intraand extra-cellular metabolites [264], in combination with non-diffusion-weighted spectra to separate signal decay from $T_{1}$ or metabolic conversion [266].

\section{Free induction decay chemical shift imaging (FID-CSI)}

Free induction decay (FID) chemical shift imaging (FIDCSI) is the simplest spectroscopic imaging method and was used early for spectroscopic imaging of hyperpolarized ${ }^{13} \mathrm{C}$ compounds [4] and for ${ }^{129} \mathrm{Xe}$ in gas and liquid phases [137]. It consists of 2D single-slice, multi-slice, or 3D slab selective low-flip angle excitation, 2D or 3D phase encoded spatial localization, and FID readout with no gradients active [122]. An example pulse sequence for mapping $B_{1}$ using FID-CSI is shown in Fig. 3, and an example pattern of $k$-space acquisition is shown in Fig. 4.

Because FID-CSI does not use any gradients during readout, it places relatively little demand on the gradient system and is minimally affected by non-ideal gradient response and eddy currents. It is also relatively robust to static field $\left(B_{0}\right)$ inhomogeneity, which is particularly helpful at higher field strengths, and can be used to measure $B_{0}$ variations from spectral frequency shifts from voxel to voxel in the image. Furthermore, FID-CSI is able to acquire with broad spectral bandwidths [270], limited by the digitizer sampling rate, rather than the rate at which gradient echoes can be generated as in many other sequence types.

In the context of hyperpolarized imaging, FID-CSI uses magnetization relatively inefficiently because each $k$-space point is separately read out as an FID after phase-encoding [270]. Maximizing spectral resolution requires a readout long enough for the transverse magnetization to have mostly decayed, which requires a long TR, which can make the time to acquire a full $k$-space prohibitively long [271], during which the longitudinal magnetization is also decaying. Shorter readout can be used, at the cost of limiting spectral resolution and wasting any remaining transverse magnetization, which is then typically spoiled before the next excitation. Even with short readout for each $k$-space point, spatial matrix sizes are limited [134]: typically $16 \times 16$ pixels for static dissolved ${ }^{129} \mathrm{Xe}$ or ${ }^{13} \mathrm{C}$ imaging $[65,124,131,271]$.

FID-CSI is relatively robust; it can be used with compounds with multiple chemical shifts that are not precisely known prior to imaging (Fig. 5), and in cases with $B_{0}$ variation, which leads to broader spectral line widths and variations in peak position across the field of view. Multi-frame FID-CSI is suitable when very limited spatial resolution and moderate spectral resolution are acceptable, and when the temporal resolution may be relatively poor (on the order of $5 \mathrm{~s}$ per time frame). Multi-slice FID-CSI is also possible, with additional compromises on the temporal, spectral, and spatial resolutions. 3D FID-CSI is generally impractical for multi-frame, as even a minimal $8 \times 8 \times 8$ matrix will require too many phase-encodes and excitations per frame to have meaningful time resolution and dynamic time-course information with a hyperpolarized substance.

\section{Echo-planar spectroscopic imaging (EPSI)}

Echo-planar spectroscopic imaging (EPSI) is an accelerated spectroscopic imaging sequence and is the most commonly used sequence for clinical hyperpolarized $\left[{ }^{13} \mathrm{C}\right]$ pyruvate studies [272, 273]. It uses an oscillating readout gradient to sample one line in $k$-space multiple times after each 

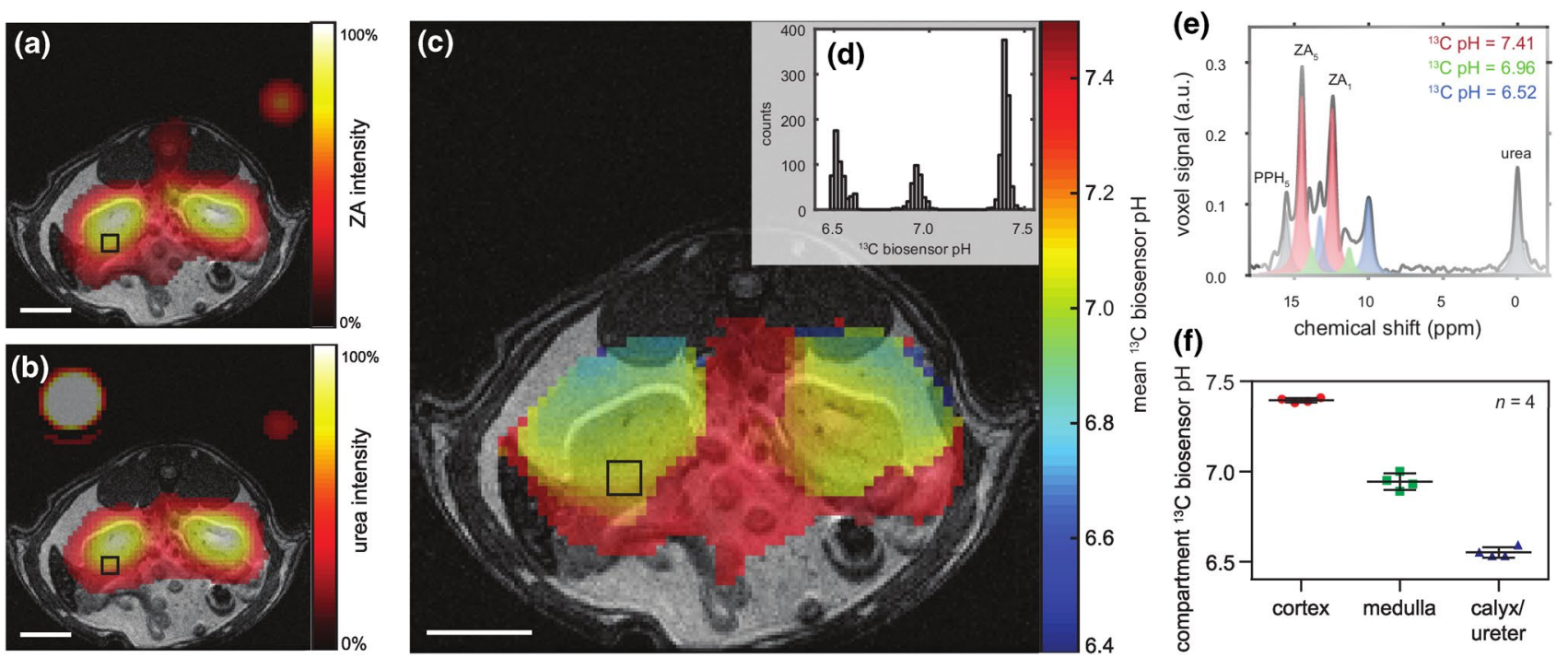

Fig. 5 Hyperpolarized ZA in vivo $\mathrm{pH}$ measurements show three $\mathrm{pH}$ compartments in rat kidneys at $7 \mathrm{~T}$. Representative kidney data from a hyperpolarized ${ }^{13} \mathrm{C}$ measurement (colored) in an axial slice overlayed on anatomical proton images (grayscale). A calibration phantom containing ${ }^{13} \mathrm{C}$ urea and the catheter used for injection are visible. The two simultaneously hyperpolarized and injected substances (a) ZA and (b) urea show high signal intensities in both kidneys of a healthy rat. (c) The mean $\mathrm{pH}$ map shows lower $\mathrm{pH}$ values in the kid- neys compared to the surrounding tissue. (e) A voxel can contain up to three pairs of ZA peaks (red, green, blue) and a noticeable amount of $\mathrm{PPH}$. The $\mathrm{pH}$ values group into three clusters (d, shown for one representative animal), consistently demonstrated in four animals (f, individual datapoints and mean \pm s.d.). For all ${ }^{13} \mathrm{C}$ images, intensity windows are based on sufficiently high signal levels for either (intensity images) or both ( $\mathrm{pH}$ images) $\mathrm{ZA}$ and urea. Scale bars, 1 $\mathrm{cm}$. Reprinted with permission from Düwel et al. [50] excitation [160]. The spectral and one spatial dimension are thus sampled simultaneously. Additional spatial dimensions [158] are phase encoded between excitation and readout (Figs. 5, 6).

EPSI uses hyperpolarized magnetization relatively efficiently for spectroscopic imaging, in contrast with FID-CSI, because it acquires (the equivalent of) a full line of $k$-space after each excitation. Acquisition times can be on the order of a few seconds for fully sampled single images of hyperpolarized compounds. EPSI can thus be used for dynamic sampling of biochemical pathways [270] (Fig. 6) with ${ }^{13} \mathrm{C}$ in tissues, but may be impractical for gas imaging due to long effective echo times and diffusion-related dephasing while gradients are oscillating.

Particularly for non-proton nuclei with lower gyromagnetic ratios, the gradient strength and slew rate determine the minimum echo spacing and thus the maximum spectral bandwidth [273], potentially limiting the metabolites that can be imaged without spectral aliasing with EPSI. Gradient strength also imposes limits on the minimum field of view and the maximum spatial resolution in the readout direction, which can be problematic for smaller subjects at higher static field strengths.

Several $k$-space encoding strategies are used with EPSI. Symmetric readout gradients [273] acquire data while moving in alternating directions through $k$-space, minimizing echo spacing. However, this may lead to odd-even echo inconsistencies and spectral ghosting related to static field inhomogeneity [274] and gradient-induced eddy currents [275]. Ghosting may be reduced by separately reconstructing the odd and even echoes at the cost of a reduced spectral bandwidth [273]. Flyback readout gradients acquire data in only one gradient readout direction $[128,166]$ and eliminate odd-even echo inconsistencies, but at the cost of higher echo spacing, lower spectral bandwidth [273], and lower sampling efficiency [95] because data are not acquired during the flyback portion of the gradient shape. Ramped gradients during readout move through $k$-space at the maximum possible speed, but produce irregular and unpredictable spacing of samples within $k$-space, exacerbating odd-even echo inconsistencies and complicating reconstruction. Irregularly sampled $k$-space data may be regridded [170, 273] based on a reference $k$-space trajectory measurement [95]. EPSI acquisition can also be accelerated using compressed sensing, by sparsely sampling $k$-space and frequency information by applying blipped phase-encode gradients during the EPSI echo train [79, 158, 159, 178, 179, 181], or using parallel imaging [276]. Example EPSI pulse sequences are shown below, with symmetric fully sampled readout (Fig. 7), and with flyback pseudo-randomly under-sampled readout (Fig. 8). A simplified model $k$-space trajectory, illustrating jumps between $k$-space lines, is shown in Fig. 9. 
(a)
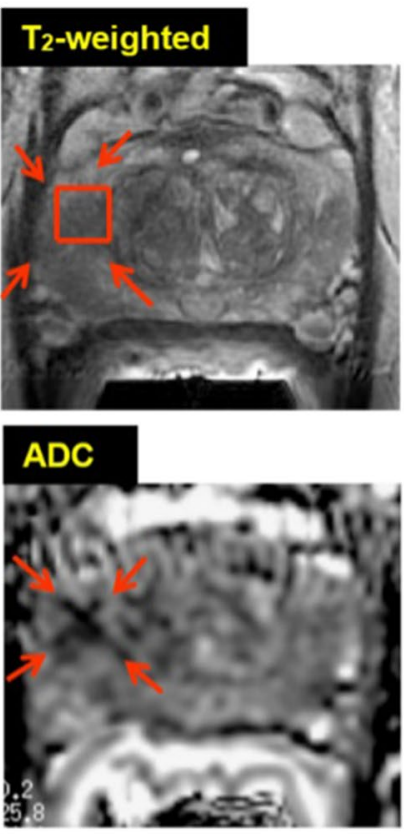

(c)

\section{Cancer}

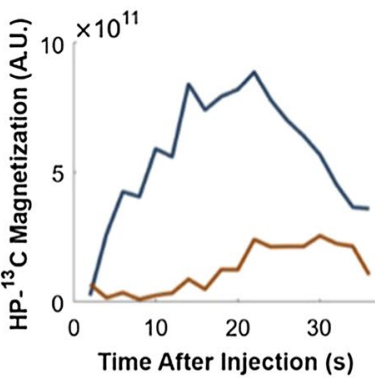

(d)

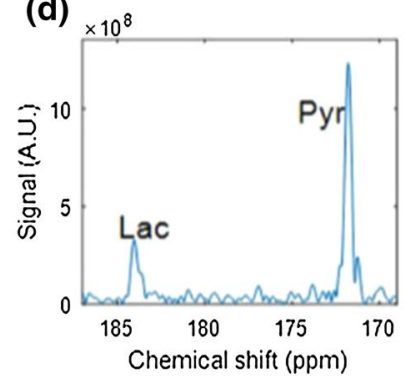

Normal Appearing
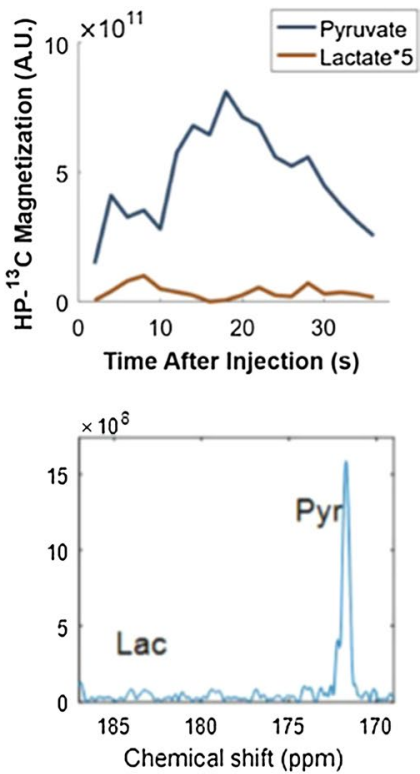

(b)

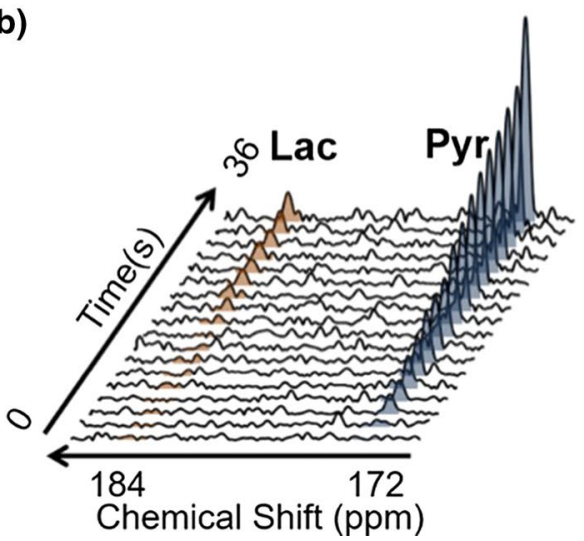

Fig. 6 Dynamic echo-planar spectroscopic images (EPSI) of hyperpolarized ${ }^{13} \mathrm{C}$ pyruvate to lactate conversion in clinical prostate tumor patient. a Anatomical and diffusion images. b Dynamic pyruvate and lactate time course within voxel indicated on anatomical image. c Flip-angle-corrected dynamic pyruvate and lactate time-courses

\section{Spiral readout methods}

Spiral sequences use continuously varying gradients during readout to move in a spiral trajectory from the center to the periphery of 2D $k$-space [277]. A third spatial dimension may be measured by acquiring multiple slices separately [70, 278], or by applying phase encoding before readout or between multiple spiral readouts [168, 199]. Example pulse sequences using spiral readouts are shown in Fig. 1, with a single spiral per excitation, and in Fig. 10, with multiple spiral gradient echoes per excitation. Projections of $k-t$ space illustrating the trajectory of a multi-echo spiral readout are shown in Fig. 11. (e)

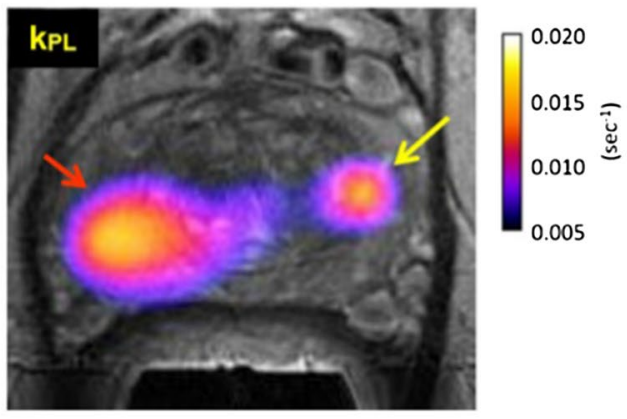

in tumor and normal-appearing tissue. d Representative spectra at $t=36 \mathrm{~s}$. e Pyruvate-to-lactate conversion $k_{\mathrm{PL}}$ parameter map, with localized high values marked with arrows, which were later confirmed as Gleason score $4+3$ prostate cancer by post-surgical histopathology. Reprinted with permission from Chen et al. [79]

Because they sample the center of $k$-space first and after every excitation, spiral trajectories give good signal to noise ratio (SNR), can be used to implement self-navigating sequences [279], and can acquire with very short echo times. Spiral trajectories also sample $k$-space rapidly and efficiently [270], and can acquire one or more full 2D $k$-spaces in a single shot. These properties are beneficial for hyperpolarized imaging with non-renewable magnetization, particularly when acquiring dynamic image series $[66,280]$ (Figs. 12 and 13) or when the magnetization preparation unavoidably consumes all longitudinal magnetization. Spiral gradient trajectories are also relatively insensitive to motion and flow effects [278]. 


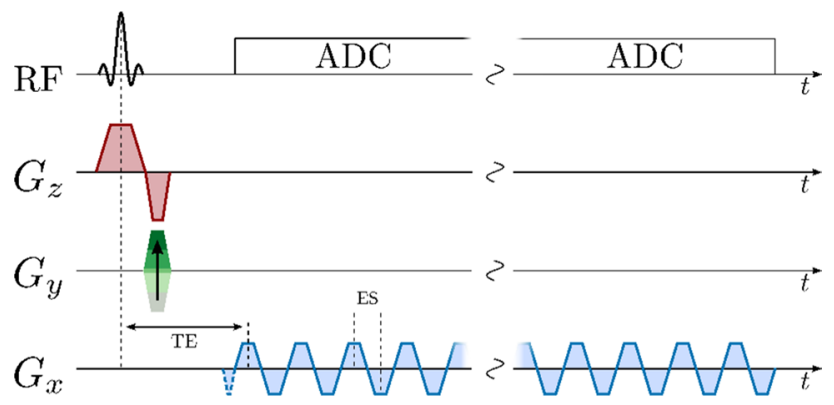

Fig. 7 EPSI pulse sequence with slice-selective excitation pulse, a single phase-encoding gradient blip after excitation, and symmetric bipolar readout gradients moving in alternating directions through $k$-space during a multi-echo acquisition

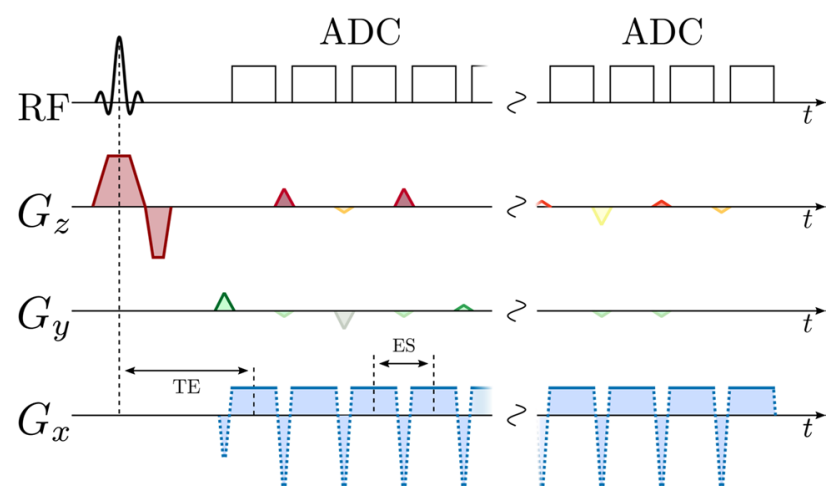

Fig. 8 EPSI pulse sequence with slice-selective excitation pulse, flyback gradient pulses between signal acquisitions that all move in the same direction through $k$-space, and phase-encoding gradient blips in $k_{y}$ and $k_{z}$ between acquisitions, to move between $k$-space lines to accelerate acquisition by pseudo-randomly under-sampling the spectral and $k$-space information

A disadvantage of spiral trajectories is that they are prone to $B_{0}$ non-uniformity related distortions [131, 279], and thus require good shimming, more so at higher field strengths, but less so for X-nuclei with lower gyromagnetic ratios, and less apparently with lower image matrix sizes. More complicated reconstruction is also required due to the non-Cartesian $k$-space sampling [168-170]. Irregular $k$-space sampling is also difficult to combine with parallel imaging [279].

When spectral encoding during readout is not required, due to there being only a single measurable compound, e.g. with hyperpolarized gases (Fig. 12) or after a spectrally selective excitation [70] (Fig. 13), single-shot [277] or interleaved $[11,168,278,280]$ spiral readouts may be used. For imaging with spectroscopic acquisition (Fig. 14), the readout is repeated with multiple echo times, using a multiple-echo flyback trajectory or with shifting delays after excitations $[125,131,168]$. These echoes may be uniformly spaced and interpreted as a model-free multi-echo time series, or their timing may be varied to optimize separation of spectral

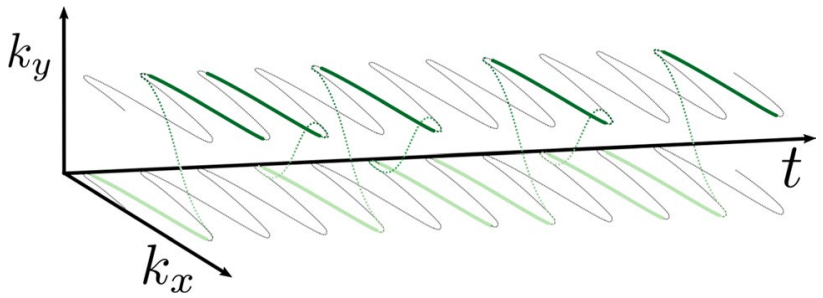

Fig. 9 Model flyback EPSI $k$-space trajectory with just two phaseencodes. Pseudo-random phase-encoding jumps in $k_{y}$ occur simultaneously with rapid flyback to low $k_{x}$ (dotted green lines) between the signal acquisitions (solid green lines), which always move in the same direction through $k$-space, from low to high $k_{x}$

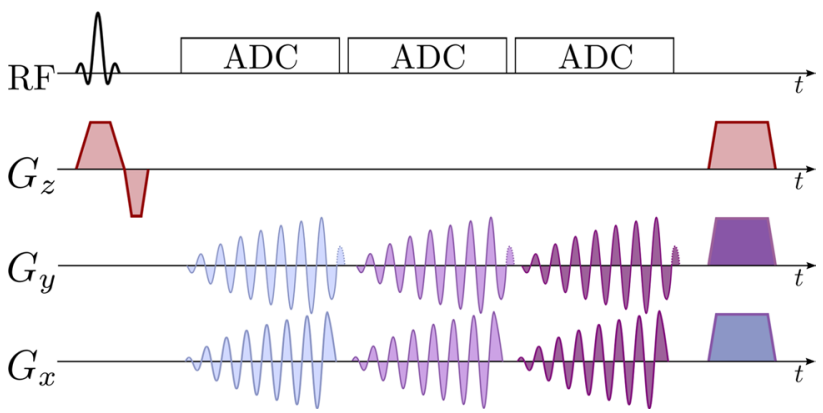

Fig. 10 Pulse sequence using multi-echo spiral $k$-space trajectory, with slice-selective excitation followed by a series of gradient spirals during acquisition, and finally spoiler gradients

peaks at expected chemical shifts using a sparse spectral sampling scheme [131].

Robustness to flow and motion makes cardiac imaging an important application of spiral readout sequences [70, 278, 281]. Acquisition with very short echo times is beneficial for hyperpolarized gas imaging, which can have very short $T_{2}$ * and strong diffusion effects $[11,280]$.

\section{Balanced steady-state free precession}

Balanced steady-state free precession (bSSFP, also known as TrueFISP, balanced FFE, or FIESTA) is fast, magnetization efficient, and can provide a high SNR [282, 283]. The bSSFP sequence uses a spin echo train with repetition time (TR) much less than the transverse $\left(T_{2}\right)$ and longitudinal $\left(T_{1}\right)$ relaxation times, and balanced gradients with zeroth gradient moment equal to zero. For thermally polarized samples, a steady-state transverse magnetization is maintained [200] following an initial transient [282]. For hyperpolarized ${ }^{129} \mathrm{Xe}[62,284]$ or, e.g. ${ }^{13} \mathrm{C}$ in liquid, a pseudo steady-state is reached in which the hyperpolarized magnetization is gradually consumed [150] after inhalation or administration. In either case, an initial half-alpha half-TR preparation RF pulse [285] can help reach the (pseudo) steady-state much faster [150, 283]. 
Fig. 11 Spiral $k$-space trajectory, left: $k_{x}-k_{y}$ projection and right: $k_{x}-t$ projection

Fig. 12 Dynamic spiral readout hyperpolarized ${ }^{3} \mathrm{He}$ lung images of patients demonstrating variations in lung ventilation with a severe asthma, b cystic fibrosis, c emphysema secondary to $\alpha-1$ antitrypsin deficiency. Reproduced with permission from Salerno et al. [11]
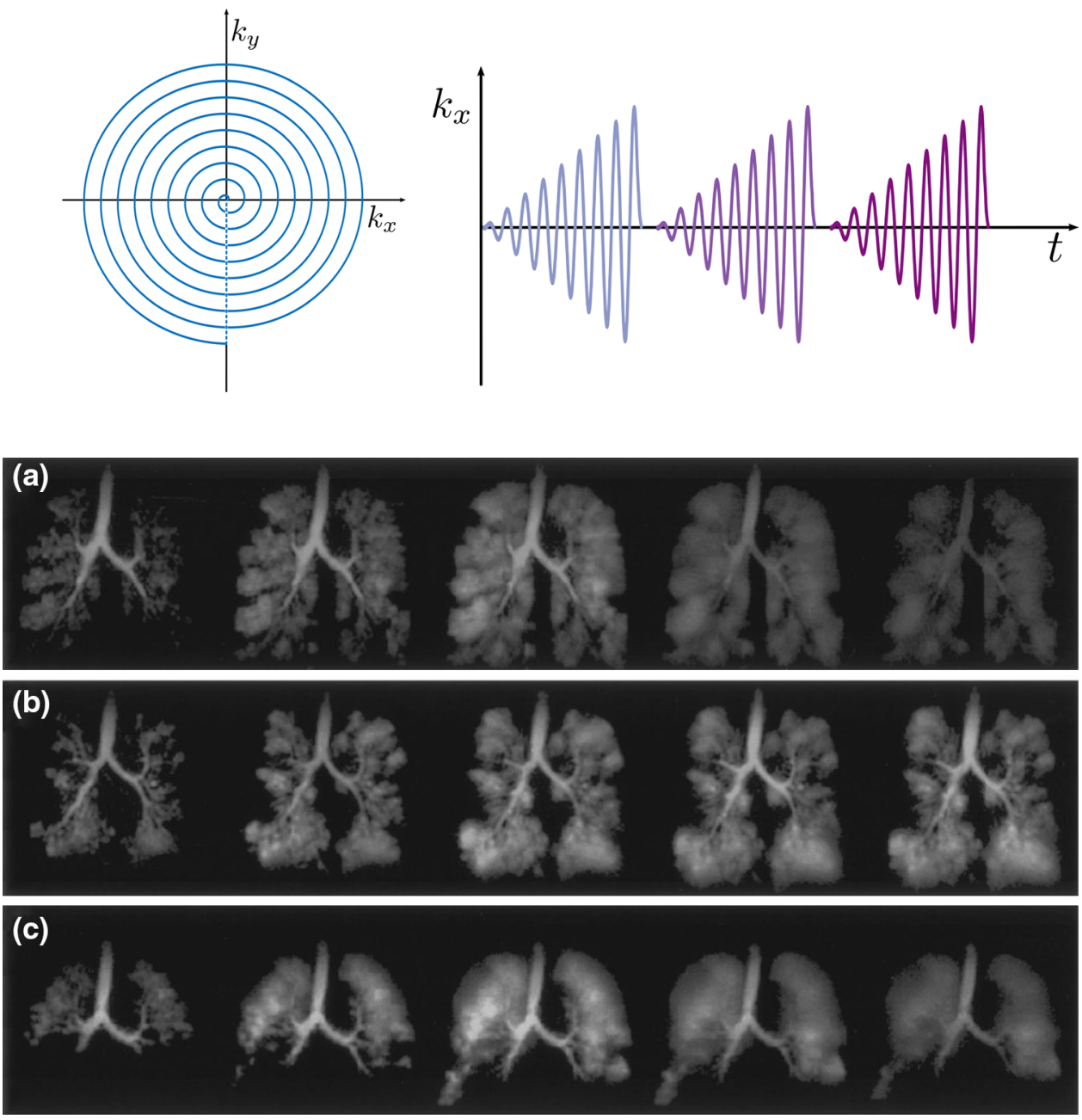

Fig. 13 In vivo short-axis pig heart multi-slice dynamic cardiac-gated images of hyperpolarized ${ }^{13} \mathrm{C}$ pyruvate (top row) and bicarbonate (bottom row) acquired with a spiral $k$-space trajectory after single-metabolite-resonance spectral-spatial RF excitations. Reproduced with permission from Lau et al. [70]

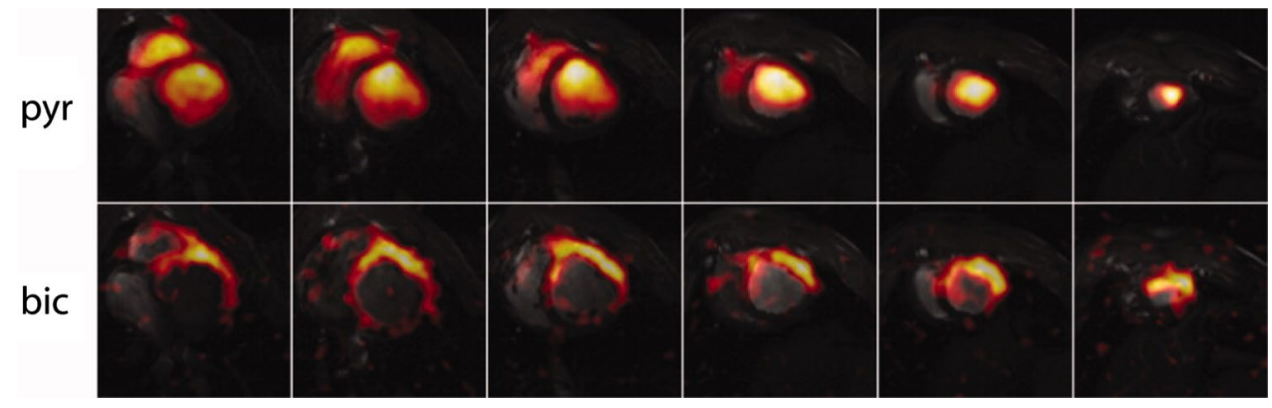

Balanced gradients and refocusing each TR lead to characteristic and well-defined banding artifacts for off resonant spins [286] that can also cause considerable signal and effective slice thickness variations across the imaging slice for spins near the stopbands [287]. For non-spectroscopic imaging, the central passband of this frequency response is centered on the RF transmission $\left(B_{1}\right)$ frequency by alternating the phase of the excitation pulses [283].

For imaging of multiple chemical shifts, careful consideration of sequence timing is required. Bloch simulations
[233] can be employed to determine TRs that place the hyperpolarized resonances of interest in the passbands of the bSSFP frequency response and undesired resonances in the stopbands [134, 282, 283, 288]. Various approaches based on combining acquisitions of different constant RF pulse phase increments [289] or varying the TR have been developed to alleviate or emphasize this frequency response, as desired. Multiple resonances can then be measured individually and sequentially using an interleaved, single readout [288] (Fig. 15), or concurrently using a sparse multi-echo, 
(a)

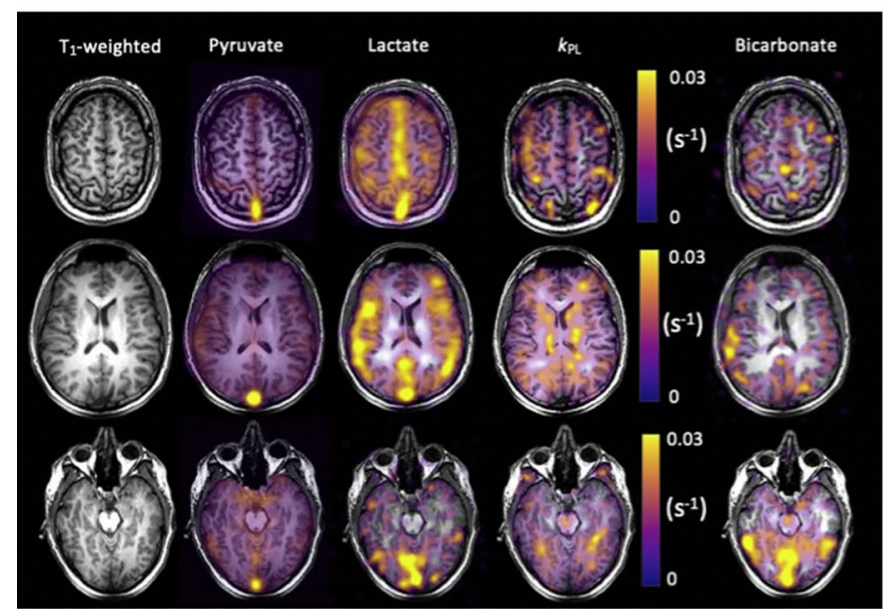

(b)

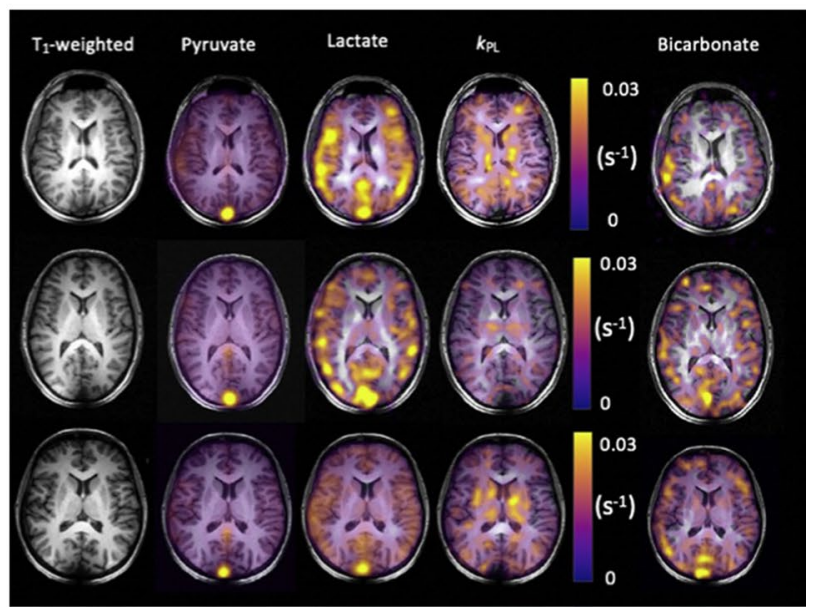

Fig. 14 IDEAL spiral hyperpolarized ${ }^{13} \mathrm{C}$-labeled metabolite imaging in the healthy human brain in two subjects (a) and (b). Reprinted with permission from Grist et al. [111]

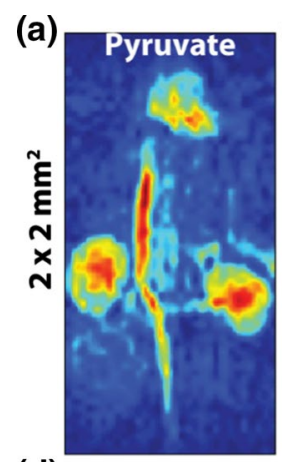

(d)

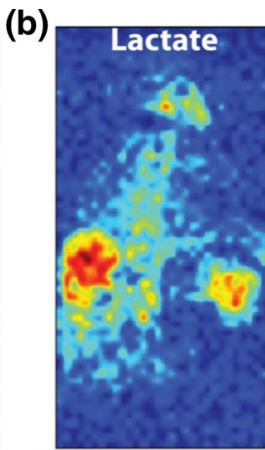

(e)
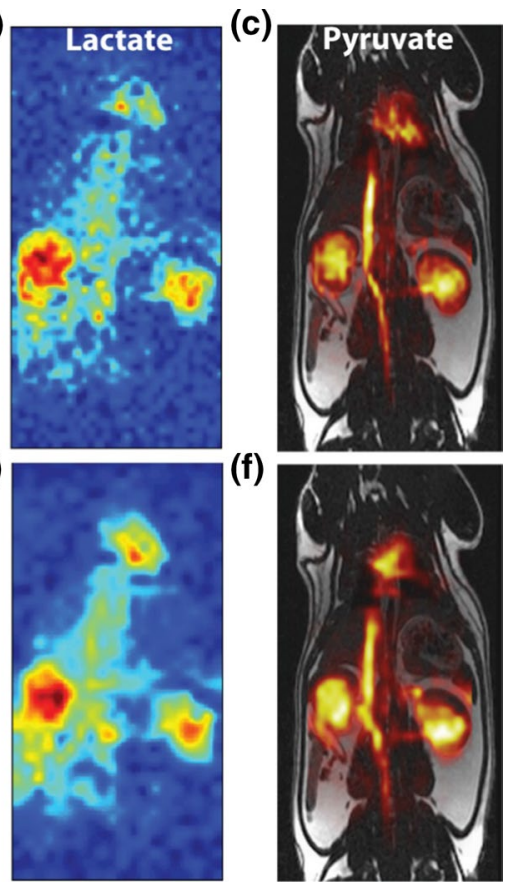

(f)

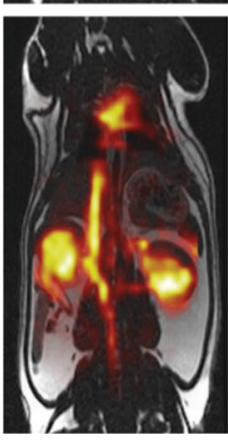

Fig. 15 In vivo ${ }^{13} \mathrm{C}$ rat abdomen bSSFP projection images of pyruvate and lactate acquired $20 \mathrm{~s}$ after start of injection of hyperpolarized pyruvate, with spectral suppression of alanine and pyruvate hydrate resonances before slab-selective excitation and one gradient echo per $\alpha$ RF pulse, alternating between metabolite center frequencies. a Pyruvate and b lactate at $2 \times 2 \mathrm{~mm}^{2}$ acquired in-plane resolution. d Pyruvate and e lactate at $3 \times 3 \mathrm{~mm}^{2}$ acquired in-plane resolution. Pyruvate at c $2 \times 2 \mathrm{~mm}^{2}$ and $\mathbf{f} 3 \times 3 \mathrm{~mm}^{2}$ acquired in-plane resolutions. Reprinted with permission from Milshteyn et al. [290]

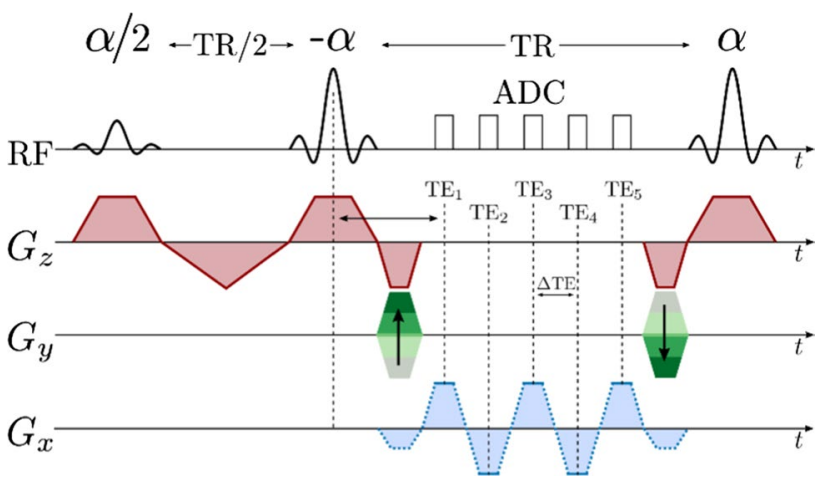

Fig. 16 Balanced steady-state free-precession pulse sequence with multiple symmetric bipolar gradient echoes and signal acquisitions per RF pulse. Spectral information is under-sampled due to the small number of acquired echo times, and is, therefore, reconstructed with an IDEAL approach. The initial $\alpha / 2$ pulse brings the magnetization quickly into a pseudo-steady state. All zeroth-order gradient moments equal zero

multi-readout approach [202]. Spectrally selective RF pulses are generally not used as refocusing pulses within the bSSFP due to their long pulse durations [288], but they have been used as a preparation [290].

High-resolution, temporally interleaved 3D time course metabolic imaging of co-polarized pyruvate and urea has been performed at $14 \mathrm{~T}$ with bSSFP, with metabolite separation enhanced by the use of optimized spectrally selective pulses [288, 291]. The same approach is feasible at $3 \mathrm{~T}$, but saturation pulses prior to each image are required in order to suppress the alanine and pyruvate-hydrate resonances [290]. However, the use of such pulses reduces the rate at which metabolic images can be recorded. 
Fig. 17 Symmetric readout bSSFP sequence $k_{x}$ vs. time trajectory. Signal is read out during constant plateau portions of bipolar readout gradients

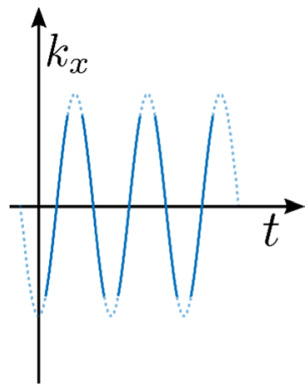

Sparse multi-echo bSSFP may be used to separate multiple chemical shift signals in a single measurement by acquiring a short symmetric train of gradient echoes after each RF pulse, which sample the envelope of the spin echoes [292, 293]. Based on the principle that each distinct resonance frequency will have a distinct phase evolution, iterative leastsquares (IDEAL) reconstruction can be used to reconstruct separate images of multiple chemical shifts [135], such as hyperpolarized ${ }^{13} \mathrm{C}$ pyruvate, alanine, and lactate [202]. This approach has been extended with bipolar gradient correction [164], and has been applied in tumor-bearing rats on a clinical $3 \mathrm{~T}$ scanner [294]. An example multi-echo bSSFP pulse sequence with multiple gradient echoes per RF excitation is shown in Fig. 16, and an illustration of the $k_{x}$ trajectory is shown in Fig. 17.

Further applications of bSSFP in hyperpolarized imaging include non-frequency selective hyperpolarized gas lung imaging in both 2D [284] and 3D [295, 296], single [150] and multi-compound [297] hyperpolarized ${ }^{13} \mathrm{C}$ angiography, rapid imaging of the heart [298], and numerous metabolic imaging approaches $[108,134,202,288]$.

\section{Spectral-spatial excitation}

Spectral-spatial (SPSP) radiofrequency (RF) pulses are simultaneously selective in both frequency and space. They were originally designed for separating fat and water resonances [299], but have since proven particularly useful for imaging hyperpolarized ${ }^{13} \mathrm{C}$-labeled compounds and their metabolites [72]. In this application, SPSP pulses selectively excite individual metabolites, in contrast to multi-echo and free induction decay (FID) sequences that extract spectral information from a time-series of signal measurements. Single resonance SPSP pulses allow much faster encoding of $k$-space, because spectral encoding during readout is not required.

SPSP pulses consist of a series of shaped RF sub-pulses that are transmitted during a periodic oscillating magnetic field gradient. As a rough approximation, the shape of each sub-pulse determines the spatial profile, while the envelope of sub-pulses determines the spectral profile [72]. Important design parameters for SPSP pulses are the duration of sublobes (determining the width of the spectral stop-band), the shape of the envelope (determining the width of the spectral passband), and the total length of the pulse (determining the width of the transition between passband and stopband). Several strategies have been proposed for optimized design of SPSP pulses [139, 140, 300], including a free online software-package that computes RF and gradient pulses for a given specification on spectral and spatial excitation range [301].

SPSP pulses can be designed to excite either a single resonance [139] or multiple resonances (multi-band) [140]. For the case of a single resonance excitation, the SPSP pulse is usually combined with a fast imaging readout in two or

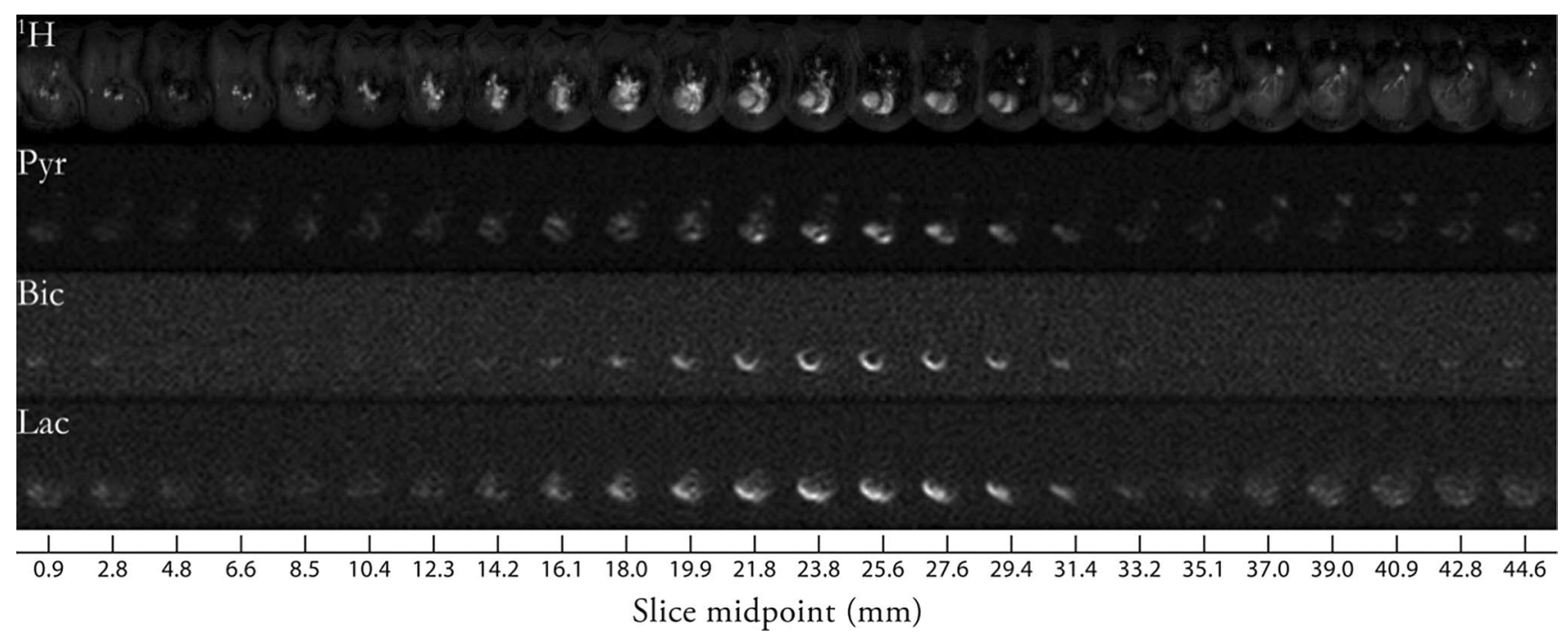

Fig. $18{ }^{1} \mathrm{H}$ anatomical (top) and ${ }^{13} \mathrm{C}$-pyruvate, bicarbonate, and lactate images in in vivo rat heart, acquired with a series of single-metabolitefrequency spectral-spatial slab excitations and 3D EPI readouts. Reproduced from Miller et al. [302] 
three spatial dimensions, such as echo-planar imaging [85, 141, 302] (Fig. 18) or single-shot spirals [66, 199, 303]. By shifting the excitation frequency of the SPSP pulse, different metabolites may be consecutively encoded.

Using multi-band SPSP excitation pulses, multiple selected metabolites can be excited with optimized individual flip angles, to more efficiently use the hyperpolarized magnetization [140, 301, 304]. In this case, chemical shift imaging techniques are required to separate the individual metabolite signals. A hybrid multi-echo spectral-spatial EPI sequence has been shown to achieve improved tolerance to off-resonance effects [85].

Due to their efficient and fast encoding, SPSP excitation acquisition schemes are advantageous when a high spatial resolution is required or when the acquisition needs to be fast because of motion, such as in the heart. Numerous studies have applied SPSP pulses for metabolic imaging in animals, in tumors, as well as in the heart, liver, and kidney (Table 1). Recently, they have also been used to study pyruvate metabolism in human subjects, focusing on healthy brain [305], healthy heart [76], and prostate and brain cancer [80].

\section{Relaxometry}

Relaxometry measurements of hyperpolarized agents can determine their longitudinal $\left(R_{1}\right.$ or $\left.T_{1}\right)$ and transverse $\left(R_{2}\right.$ or $T_{2}$ and $R_{2} *$ or $\left.T_{2}{ }^{*}\right)$ magnetization relaxation rates or times. Several ${ }^{13} \mathrm{C}$ labeled compounds' $T_{1}$ and $T_{2}$ times, and ${ }^{129} \mathrm{Xe}$ gas or in solution $T_{1}$ times, are on the order of tens of seconds in vivo, allowing a series of excitations to sample the $T_{1}$ decay or a series of echoes to sample the $T_{2}$ decay.

The transverse magnetization relaxation from atomic and molecular interactions $\left(R_{2}\right.$ or $\left.T_{2}\right)$ can be measured using a multi-spin echo experiment with a train of refocusing pulses [198, 306, 307] after a single excitation. With hyperpolarized compounds, this is often limited to slice selective [138, 308] or voxel localized [309] experiments. When imaging $T_{2}$, the results are dependent on echo spacing [310, 311], $B_{1}$ calibration [312], and resonance-offsets [313], and are described as an effective $T_{2}$ [107]. Transverse relaxation can be difficult to assess in hyperpolarized gas imaging due to their relatively high diffusion rates, which confound the relaxation signal change [145].

The transverse relaxation including static field $\left(B_{0}\right)$ inhomogeneity effects $\left(R_{2} *\right.$ or $\left.T_{2} *\right)$ can be derived from FID measurements [123, 147, 314]. In cases with minimal variation across the excited slice or volume, a simple nonimaging FID can be fit. Alternatively, a FID-CSI reconstruction can be used to spatially localize spectral peaks, from which a peak width can be fit, with sensitivity only to local $B_{0}$ variations from susceptibility variations. For very short $T_{2}$ * compounds, frequency-encoding with center-out radial [123] (Fig. 19) or spiral trajectories can be used to minimize the shortest echo times. Alternatively, multi-gradient echo images can be fit for $T_{2} *$ [315].

Longitudinal relaxation $\left(R_{1}\right.$ or $\left.T_{1}\right)$ can be determined from the signal magnitude in a series of FID or image acquisitions [34, 147] when no substantial addition, removal, or conversion between hyperpolarized compounds in the volume of interest is expected. Chemical reactions or exchange (e.g. pyruvate to lactate conversion) will alter the affected compounds' signal magnitudes over time, but these processes can also be fit as part of a multicompartment kinetic modeling experiment $[65,120,316]$ that includes one or more $T_{1}$ relaxation parameters. Perfusion or flow into or out of the volume of interest, and metabolic conversion into compounds that are not measured in the experiment, are more challenging; additional free parameters may be added to a kinetic model to account for them, but extra degrees of freedom can lead to noisier fit results or even physically or physiologically implausible results. The magnetization lost to previous excitation RF pulses [34] and the differing signal after varying excitation angle [181] must also be accounted for.

\section{In vivo imaging applications of hyperpolarized substances}

Hyperpolarization allows for functional and metabolic in vivo imaging relying on a great variety of different probes. Noble gases as well as small inorganic and organic molecules bearing half-integer spin nuclei are commonly polarized with SEOP, PHIP and dDNP. This chapter summarizes molecules polarized with these techniques and describes their in vivo applications and the respective acquisition strategies. In Table 1, five of the most prominent in vivo acquisition strategies and in vivo applications of different metabolic probes that are labeled with ${ }^{13} \mathrm{C}$ and polarized with dDNP are listed.

\section{Spin exchange optical pumping (SEOP)}

Noble gases are exclusively polarized by SEOP and are used to characterize gas-filled spaces such as the respiratory tract and the lung [317]. In its early stages, the field of hyperpolarized gas MRI mainly focused on the assessment of lung ventilation and physiological parameters such as partial oxygen pressure [318, 319]. These techniques have been applied to asthma, apnea, cystic fibrosis, emphysema, chronic obstructive lung pulmonary disease, and smoking-related aberrant changes of the lung [320, 321]. Analyzed model systems included small animals (mouse, rat, guinea pig), rabbits, and dogs. Additionally, because 
Table 1 In vivo imaging strategies for ${ }^{13} \mathrm{C}$-labeled dDNP-polarized hyperpolarized probes, sequence details, respective applications and probed species

\begin{tabular}{|c|c|c|c|c|}
\hline Strategy & Additional specifics of acquisition strategy & HP-probe & Application & Species \\
\hline \multirow[t]{21}{*}{ FIDCSI } & \multirow{21}{*}{$\begin{array}{l}\text { 3-Dimensional [373] } \\
\text { Compressed Sensing [374] } \\
\text { ECG-gated and respiratory-gated [241] } \\
\text { Parallel imaging [83] } \\
\text { Variable flip angle [375] }\end{array}$} & \multirow[t]{8}{*}[1-{}^{13}\mathrm{C}]{ pyruvate } & Tumor & M [65], R [343], D [376] \\
\hline & & & Brain & M [377], R [368] \\
\hline & & & Heart & $\mathrm{R}$ [378], P [167] \\
\hline & & & Inflammation & $\mathrm{R}$ [375] \\
\hline & & & Kidney & $\mathrm{R}$ [379], P [380] \\
\hline & & & Lung & $\mathrm{R}[381]$ \\
\hline & & & Obesity & M [382] \\
\hline & & & $T_{2}$-mapping & $\mathrm{R}$ [383] \\
\hline & & {$\left[1-{ }^{13} \mathrm{C}\right]$ acetoacetate } & Redox & $\mathrm{R}[25]$ \\
\hline & & {$\left[1-{ }^{13} \mathrm{C}\right]$ bicarbonate } & $\mathrm{pH}$ & M [5] \\
\hline & & {$\left[1-{ }^{13} \mathrm{C}\right]$ dehydroascorbate } & Redox & M, R [373] \\
\hline & & {$\left[1-{ }^{13} \mathrm{C}, \mathrm{U}_{-}^{2} \mathrm{H}\right]$ ethanol } & Liver & M [370] \\
\hline & & {$\left[1-{ }^{13} \mathrm{C}\right]$ ethyl pyruvate } & Brain & $\mathrm{R}[368]$ \\
\hline & & {$\left[1,3-{ }^{13} \mathrm{C}_{2}\right]$ ethyl acetoacetate } & Tumor & $\mathrm{R}[354]$ \\
\hline & & {$\left[1,4-{ }^{13} \mathrm{C}_{2}\right]$ fumarate } & Necrosis & M [6], R [358] \\
\hline & & {$\left[\mathrm{U}-{ }^{13} \mathrm{C}, \mathrm{U}-{ }^{2} \mathrm{H}\right]$ glucose } & Tumor & M [353] \\
\hline & & {$\left[1-{ }^{13} \mathrm{C}\right] \alpha$-ketobutyrate } & Heart, kidney & $\mathrm{R}$ [363] \\
\hline & & {$\left[1-^{13} \mathrm{C}\right] 2$-ketoisocaproate } & Tumor & M [357] \\
\hline & & {$\left[2-{ }^{13} \mathrm{C}\right]$ pyruvate } & Brain & $\mathrm{R}$ [367] \\
\hline & & {$\left[1,2-{ }^{13} \mathrm{C}\right]$ pyruvate } & Heart, kidney & $\mathrm{R}$ [363] \\
\hline & & {$\left[1,5-{ }^{13} \mathrm{C}_{2}\right]$ zymonic acid } & $\mathrm{pH}$ & $\mathrm{R}[50]$ \\
\hline \multirow[t]{15}{*}{ SPCSI } & \multirow{15}{*}{$\begin{array}{l}\text { 3-Dimensional [361] } \\
\text { Bipolar flow-sensitive gradients [384] } \\
\text { ECG-gated and respiratory-gated [385] } \\
\text { Compressed Sensing [372] } \\
\text { Multi-echo [344] } \\
\text { Multi-echo-SPARSE [125, 131] } \\
\text { Multi-slice [125] } \\
\text { Variable flip angle [344, 386] }\end{array}$} & {$\left[1-{ }^{13} \mathrm{C}\right]$ pyruvate } & Tumor & $\mathrm{R}$ [125] \\
\hline & & & Brain & R [54], P [387], H [111] \\
\hline & & & Heart & $\mathrm{P}[386]$ \\
\hline & & & Kidney & $\mathrm{R}[344]$ \\
\hline & & & Liver & $\mathrm{R}$ [388] \\
\hline & & & Pregnancy & R [389] \\
\hline & & {$\left[1-{ }^{13} \mathrm{C}\right]$ acetate } & Kidney & $\mathrm{R}$ [366] \\
\hline & & {$\left[1-{ }^{13} \mathrm{C}\right]$ acetoacetate } & Heart & $R[372]$ \\
\hline & & {$\left[2-{ }^{13} \mathrm{C}\right]$ dihydroxyacetone } & Liver & $\mathrm{R}$ [372] \\
\hline & & {$\left[1-{ }^{13} \mathrm{C}\right]$ ethyl pyruvate } & Brain & $\mathrm{P}[242]$ \\
\hline & & {$\left[1,4-{ }^{13} \mathrm{C}_{2}\right]$ fumarate } & $\begin{array}{l}\text { Necrosis } \\
\text { Kidney }\end{array}$ & $\begin{array}{l}R \text { [359] } \\
R[360]\end{array}$ \\
\hline & & {$\left[1-{ }^{13} \mathrm{C}\right]$ ketoisocaproate } & Brain & $\mathrm{R}$ [369] \\
\hline & & {$\left[1-{ }^{13} \mathrm{C}\right]$ lactate } & Heart & $\mathrm{R}$ [361] \\
\hline & & {$\left[{ }^{13} \mathrm{C}\right]$ urea } & Perfusion & $\mathrm{R}[350]$ \\
\hline & & {$\left[{ }^{13} \mathrm{C},{ }^{15} \mathrm{~N}_{2}\right]$ urea } & Perfusion & $\mathrm{R}$ [359] \\
\hline \multirow[t]{10}{*}{ EPSI } & \multirow{10}{*}{$\begin{array}{l}\text { 3-Dimensional [390] } \\
\text { Absorptive mode [49] } \\
\text { Bipolar flow-sensitive gradients } \\
\text { Compressed sensing [158, 159] } \\
\text { Double spin echo [128] } \\
\text { Flyback readout [128] } \\
\text { Parallel imaging [84] } \\
\text { Symmetric readout [273, 392] } \\
\text { WALTZ16-decoupling [228] } \\
\text { Variable flip angle [82] }\end{array}$} & {$\left[1-{ }^{13} \mathrm{C}\right]$ pyruvate } & Tumor & M [82], R [393], D [273], H \\
\hline & & & Brain & {$[78,79,272,305]$} \\
\hline & & & Kidney & M [49] \\
\hline & & & Liver & $\mathrm{R}$ [128] \\
\hline & & & & $\mathrm{R}[128]$ \\
\hline & & {$\left[1-{ }^{13} \mathrm{C}\right]$ bicarbonate } & $\mathrm{pH}$ & M [394] \\
\hline & & {$\left[1-{ }^{13} \mathrm{C}\right]$ dehydroascorbate } & Kidney & M [392] \\
\hline & & {$\left[2-{ }^{13} \mathrm{C}\right]$ fructose } & Tumor & M [355] \\
\hline & & {$\left[1-{ }^{13} \mathrm{C}\right]$ lactate } & Kidney, liver & $\mathrm{R}$ [371] \\
\hline & & {$\left[{ }^{13} \mathrm{C}\right]$ urea } & Perfusion & M [346] \\
\hline
\end{tabular}


Table 1 (continued)

\begin{tabular}{|c|c|c|c|c|}
\hline Strategy & Additional specifics of acquisition strategy & HP-probe & Application & Species \\
\hline \multirow[t]{9}{*}{ SSFP } & \multirow{9}{*}{$\begin{array}{l}\text { 3-Dimensional [365] } \\
\text { Bolus tracking [348] } \\
\text { Compressed sensing [307] } \\
\text { Multi-echo-SPARSE [204, } \\
\text { Multi-slice [346] } \\
\text { Spectral suppression [290] } \\
\text { Variable flip angle [290] }\end{array}$} & \multirow[t]{3}{*}[1-^{13}\mathrm{C}]{ pyruvate } & Tumor & M [307] \\
\hline & & & Heart & $\mathrm{P}[298]$ \\
\hline & & & Kidney & P [292] \\
\hline & & {$\left[1-{ }^{13} \mathrm{C}, \mathrm{U}-\mathrm{H}_{2}\right]$ tert-butanol } & Perfusion & M [297], R [345] \\
\hline & & HP001 & Perfusion & M [346], R [348] \\
\hline & & {$\left[1-{ }^{13} \mathrm{C}\right]$ lactate } & $T_{2}$-mapping & M [307] \\
\hline & & {$\left[2-{ }^{13} \mathrm{C}\right]$ pyruvate } & $T_{2}$-mapping & M [307] \\
\hline & & {$\left[{ }^{13} \mathrm{C}\right]$ urea } & $\begin{array}{l}\text { Angiography } \\
\text { Kidney } \\
\text { Perfusion } \\
T_{2} \text {-mapping }\end{array}$ & $\begin{array}{l}\text { R }[34,395] \\
\text { R [396] } \\
\text { M [297] } \\
\text { R [107] }\end{array}$ \\
\hline & & {$\left[{ }^{13} \mathrm{C},{ }^{15} \mathrm{~N}_{2}\right]$ urea } & $\begin{array}{l}\text { Kidney } \\
\text { Perfusion } \\
T_{2} \text {-mapping }\end{array}$ & $\begin{array}{l}\text { R [364], P [365] } \\
\text { P [349] } \\
\text { R [107] }\end{array}$ \\
\hline \multirow[t]{9}{*}{ SPSP } & \multirow{9}{*}{$\begin{array}{l}\text { 3-Dimensional [139] } \\
B_{1} \text {-mapping [73] } \\
\text { Bolus-tracking [397] } \\
\text { Compressed sensing [235] } \\
\text { Double spin echo [140] } \\
\text { ECG-gated [70] } \\
\text { FID-CSI [398] } \\
\text { Unpaired adiabatic pulses [199] } \\
\text { INEPT [216] } \\
k-t \text { Principal component analysis [74] } \\
\text { Multi-band radial frequency encoding [399] } \\
\text { Multi-echo-SPARSE SPCSI [362] } \\
\text { Mult-islice [70] } \\
\text { Parallel imaging [86] } \\
\text { Saturation recovery [66] } \\
\text { Selective non-excitation of pyruvate [400] } \\
\text { Multi-echo SPCSI [72] } \\
\text { Steady state free precession [291] } \\
\text { Flyback echo planar spectroscopic imaging [140] } \\
\text { Symmetric echo planar imaging [95] } \\
\text { Variable flip angle [140] }\end{array}$} & {$\left[1-{ }^{13} \mathrm{C}\right]$ pyruvate } & $\begin{array}{l}\text { Tumor } \\
\text { Brain } \\
\text { Diffusion } \\
\text { Heart } \\
\text { Obesity }\end{array}$ & $\begin{array}{l}\text { M [139, 140], R [66], H [80] } \\
\text { NHP [401], H [119] } \\
\text { M [269] } \\
\text { R [402], P [70, 72], H [76] } \\
\text { R [403] }\end{array}$ \\
\hline & & \multirow{7}{*}{$\begin{array}{l}{\left[1-{ }^{13} \mathrm{C}\right] \text { acetate }} \\
{\left[1-{ }^{13} \mathrm{C}\right] \text { bicarbonate }} \\
{[2-13 \mathrm{C}] \text { dihydroxyacetone }} \\
{\left[1-{ }^{13} \mathrm{C}\right] \text { glycerolcarbonate }} \\
{\left[1-{ }^{13} \mathrm{C}\right] \alpha \text {-ketoglutarate }} \\
\text { HP001 } \\
{\left[2-{ }^{13} \mathrm{C}\right] \text { pyruvate }}\end{array}$} & Heart & $\mathrm{R}[362]$ \\
\hline & & & $\mathrm{pH}$ & R [404] \\
\hline & & & Kidney, liver & $\mathrm{R}$ [301] \\
\hline & & & $\mathrm{pH}$ & M [398] \\
\hline & & & Tumor & $\mathrm{R}[356]$ \\
\hline & & & Perfusion & M [347] \\
\hline & & & $\begin{array}{l}\text { Liver } \\
T_{2} \text {-mapping }\end{array}$ & $\mathrm{R}$ [405] \\
\hline & & $\begin{array}{l}{\left[{ }^{13} \mathrm{C}\right] \text { urea }} \\
{\left[{ }^{13} \mathrm{C},{ }^{15} \mathrm{~N}_{2}\right] \text { urea }}\end{array}$ & Angiography & M [288] \\
\hline
\end{tabular}

$M$ mouse, $R$ rat, $P$ pig, $D$ dog, $N H P$ non-human primate, $H$ human

${ }^{3} \mathrm{He}$ and ${ }^{29} \mathrm{Xe}$ are chemically inert and FDA approved, children and adult patients were also examined [322, 323]. When encapsulated in microbubbles [324], microspheres [147], or as lipid emulsions [106], hyperpolarized noble gases can be delivered to the blood stream at fairly high concentrations and polarization levels, which allows for angiography, as well as brain and heart imaging. Although sparsely applied, hyperpolarized ${ }^{83} \mathrm{Kr}$ has been shown to serve as imaging marker for lung emphysema, based on disease-related surface mediated quadrupolar $T_{1}$ relaxation [325].

The most important in vivo acquisition strategies for hyperpolarized noble gases are based on spoiled gradient echoes [193], gradient recalled echoes (GRASS), echo planar (diffusion-weighted) imaging [146], and bSSFP [195].
FID-CSI has also been used to image blood-dissolved ${ }^{129} \mathrm{Xe}$ in brain [326], heart, kidney, and lung [327].

\section{Parahydrogen induced polarization (PHIP)}

In contrast to noble gases, small inorganic or organic molecules can be polarized by brute force, PHIP, SABRE, and dDNP. However, brute force and SABRE polarized molecules have so far not been used for in vivo MRI. PHIP, based on chemical addition of parahydrogen, relies on unsaturated precursor molecules, which limits the available probes and applications for this hyperpolarization technique. Several molecules such as $\left[1-{ }^{13} \mathrm{C}, \mathrm{D}_{8}\right]$ bis-1,1-(hydroxymethyl)cyclopropane (HP001) [150], $\left[1-{ }^{13} \mathrm{C}\right]$ maleic acid dimethyl ester [149], and $\left[1-{ }^{13} \mathrm{C}, 2,3,3 \mathrm{D}_{3}\right] 2$-hydroxyethylpropionate [328-330] were developed for ${ }^{13} \mathrm{C}$-angiography in rats, 
(a)

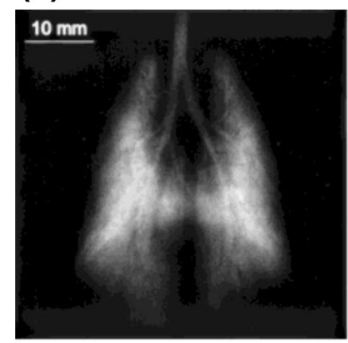

(b)

(c)

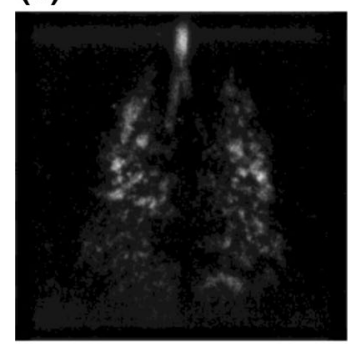

(d)
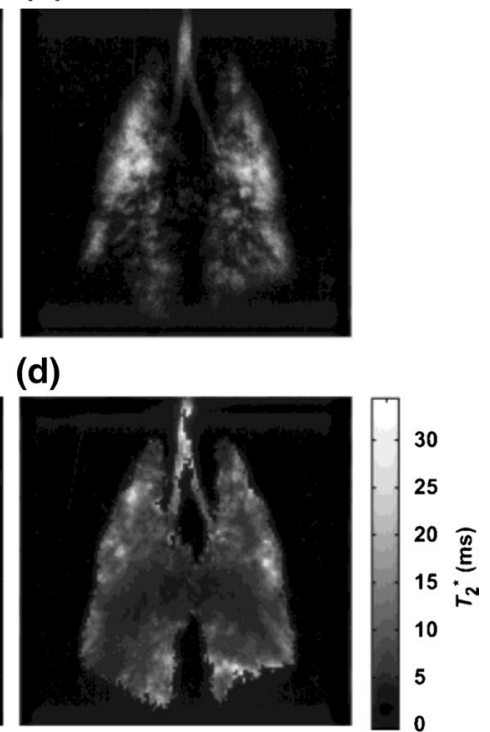

Fig. $19 T_{2}$-weighted non-slice-selective images of ${ }^{3} \mathrm{He}$ in guinea pig lung at $\mathbf{a} \mathrm{TE}=0.26 \mathrm{~ms}, \mathbf{b} \mathrm{TE}=7 \mathrm{~ms}$, and $\mathbf{c} \mathrm{TE}=16 \mathrm{~ms}$. The calculated $T_{2} *$ map is shown in (d). Reprinted with permission from Chen et al. [123]

rabbits, and pigs and measured with bSSFP-based acquisition strategies. Probes like $\left[1-{ }^{13} \mathrm{C}\right]$ succinate and its ethyl ester have, respectively, been applied in malignant brain [331] and kidneys [332] of rodents, but as yet without imaging of their metabolic products. Recently, hyperpolarized $\left[1-{ }^{13} \mathrm{C}\right]$ pyruvate was produced with PHIP-SAH (side arm hydrogenation) for the first time enabling PHIP-based in vivo metabolic chemical shift imaging [333].

\section{Dissolution dynamic nuclear polarization (dDNP)}

dDNP is the most applied hyperpolarization technique for in vivo MRI, mainly using ${ }^{13} \mathrm{C}$-labeled molecules, but is also applied to other spin- $1 / 2$ nuclei including ${ }^{1} \mathrm{H},{ }^{6} \mathrm{Li},{ }^{15} \mathrm{~N}$, and ${ }^{29} \mathrm{Si}$. Hyperpolarized ${ }^{29} \mathrm{Si}$-nanoparticles were developed for tumor perfusion imaging in mice using fast spin echo imaging [334], while spatially localized hyperpolarized ${ }^{6}$-Li distribution was shown in rat brain using gradient recalled echo methods [28]. Hyperpolarized water served as an angiographic probe or as a heart and kidney perfusion marker in preclinical models of rats [335] and pigs [336, 337], measured with gradient echo or bSSFP methods, respectively. With regard to in vivo ${ }^{15} \mathrm{~N}$-applications, so far only $\alpha$-trideuteromethyl $\left[{ }^{15} \mathrm{~N}\right]$ glutamine, exhibiting a long $T_{1}$ for perfusion mapping with spiral sequences in rodents, has been demonstrated [338].

${ }^{13} \mathrm{C}$ is the NMR active surrogate of NMR inactive ${ }^{12} \mathrm{C}$, which is one of the most important atomic components of metabolites in living species. The spin-1/2 nucleus has a

fairly high gyromagnetic ratio, yields high polarization levels, and has $T_{1}$ values of several tens of seconds. In addition, the availability of commercial preclinical [2] and clinical DNP polarizers [339] boosted the development of a variety of hyperpolarizable ${ }^{13} \mathrm{C}$-labeled probes during the last two decades, allowing for real-time metabolic imaging in vivo. An overview of the most important in vivo imaging strategies including sequence details, the hyperpolarized ${ }^{13} \mathrm{C}$-labeled molecules, and respective in vivo applications is given in Table 1.

The most extensively DNP-polarized molecule is $\left[1-{ }^{13} \mathrm{C}\right]$-pyruvate. Its ${ }^{12} \mathrm{C}$-equivalent is the end product of glycolysis, which is the key metabolic pathway to generate energy and $\mathrm{CO}_{2}$ via oxidative phosphorylation. Two alternative metabolic pathways of pyruvate are mediated by alanine-aminotransferase and pyruvate dehydrogenase, which produce alanine and $\mathrm{CO}_{2}$, respectively. In several disease states, the pyruvate metabolism has shown to be aberrant. As prominent example, many tumors show increased consumption of glucose, while switching from oxidative phosphorylation to aerobic glycolysis producing lactate, even under normoxic conditions. This is known as the Warburg effect [340, 341]. Besides this biological importance, $\left[1-{ }^{13} \mathrm{C}\right]$-pyruvate reaches polarization levels up to $70 \%$ [342], and has one of the longest $T_{1}$ values for ${ }^{13} \mathrm{C}$-labeled molecules, which is one main reason why almost every ${ }^{13} \mathrm{C}$ imaging strategy was developed with it. A summary of applications, with representative references using ${ }^{13} \mathrm{C}$-pyruvate for in vivo imaging of healthy and diseased states, is given in Table 1.

Five of the most important ${ }^{13} \mathrm{C}$-acquisition strategies are based on FID-CSI [65, 343], spiral CSI (SPCSI), [125, 344], bSSFP [292, 297], EPSI [128], and SPSP [140]. Applications of hyperpolarized pyruvate are very broad, including solid tumor imaging, metabolic imaging of healthy or diseased states of the brain, heart, lung, or kidneys, and of obesity and pregnancy. Based on extensive work and optimization of the imaging protocols in preclinical models including mice $(\mathrm{M})$, rats $(\mathrm{R})$, dogs $(\mathrm{D})$, pigs $(\mathrm{P})$, and nonhuman primates (NHP), ${ }^{13} \mathrm{C}$-imaging is now being translated to patients. Examples of human $(\mathrm{H})$ applications include imaging of the healthy heart [76], healthy brain [111, 119], prostate tumors [78, 79], as well as untreated [80, 272] and treated [305] brain tumors.

Hyperpolarized pyruvate can also be used as angiographic agent or perfusion marker. However, because it is metabolically active, metabolically inert compounds exhibiting fairly long $T_{1}$ have been polarized with dDNP and suggested as alternative perfusion markers. Prominent examples include $\left[1-{ }^{13} \mathrm{C}\right.$ ]butanol [297, 345], HP001 [346-348], $\left[{ }^{13} \mathrm{C}\right]$ urea [34], and $\left[{ }^{15} \mathrm{~N}-{ }^{13} \mathrm{C}\right.$ ] urea [349], measured mainly with bSSFP and, when co-polarized with other markers, FID-CSI [50], SPCSI [350], or EPSI [346]. 
Another metabolic property of tumors resulting from the Warburg effect is the export of excess lactate to the extracellular space, which leads to an acidification of the tumor microenvironment. Extracellular $\mathrm{pH}$ can be probed by hyperpolarized $\mathrm{pH}$ sensors, whose NMR signals either exhibit a ratiometric $\left(\left[{ }^{13} \mathrm{C}\right]\right.$ bicarbonate $/\left[{ }^{13} \mathrm{C}\right] \mathrm{CO}_{2}$ pair [5]) $\mathrm{pH}$-sensitivity or $\mathrm{pH}$-dependent chemical shifts $\left(\left[1,5-{ }^{13} \mathrm{C}\right]\right.$ zymonic acid [50,351]). Because chemical shift based $\mathrm{pH}-$ sensors require high spectral resolution and exhibit chemical shifts that are not known prior to measurement, FID-CSI is often used as the imaging strategy [352].

Tumors do not necessarily exhibit the Warburg effect, but may instead show other metabolic abnormalities. Therefore, tumor markers other than $\left[1-{ }^{13} \mathrm{C}\right]$ pyruvate, such as uniformly ${ }^{13} \mathrm{C}$-labeled and deuterated glucose [353], [1,3${ }^{13} \mathrm{C}_{2}$ ] ethyl acetoacetate [354], $\left[2-{ }^{13} \mathrm{C}\right]$ fructose [355], $\left[1{ }^{-13} \mathrm{C}\right]$ $\alpha$-ketoglutarate [356], and $\left[1-{ }^{13} \mathrm{C}\right] 2$-ketoisocaproate [357], could also be helpful for precise and non-invasive characterization of tissues.

$\left[1,4-{ }^{13} \mathrm{C}_{2}\right]$ fumarate is a metabolic probe indicating cell death. In vivo, the molecule is converted to $\left[1,4-{ }^{13} \mathrm{C}_{2}\right]$ malate by malate dehydrogenase when released from cells undergoing necrosis, such as after tumor therapy or acute kidney injury $[6,358-360]$.

Like tumors, other non-communicable diseases such as cardiovascular diseases and diabetes are imminent problems for humanity. $\left[1-{ }^{13} \mathrm{C}\right]$ lactate $[361],\left[1-{ }^{13} \mathrm{C}\right]$ acetate [362] , and $\left[{ }^{13} \mathrm{C}\right] \alpha$-ketobutyrate [363] have been applied to probe abnormal changes in the heart, while diabetic changes in the kidney have been assessed with $\left[{ }^{13} \mathrm{C},{ }^{15} \mathrm{~N}_{2}\right]$ urea $[364,365]$. In contrast, renal clearance as a physiological parameter was quantified with $\left[{ }^{13} \mathrm{C}\right]$ acetate [366] and gluconeogenesis, as an example of organ-specific metabolic processes, has been imaged with hyperpolarized $\left[2-{ }^{13} \mathrm{C}\right]$ dihydroxyacetone [301].

Finally, few probes other than $\left[1-{ }^{13} \mathrm{C}\right]$ pyruvate have been mentioned for imaging of brain and liver metabolism. For the brain, these are $\left[2-{ }^{13} \mathrm{C}\right]$ pyruvate $[367],\left[1-{ }^{13} \mathrm{C}\right]$ ethyl pyruvate $[242,368]$, and $\left[1-{ }^{13} \mathrm{C}\right] 2$-ketoisocaproate [369]. For the liver, uniformly deuterated $\left[1-{ }^{13} \mathrm{C}\right]$ ethanol [370] probing aldehyde dehydrogenase activity, and $\left[1-{ }^{13} \mathrm{C}\right]$ lactate [371] and $\left[2-{ }^{13} \mathrm{C}\right]$ dihydroxyacetone [372] to image liver metabolism have been demonstrated.

\section{Conclusion}

Over the past 25 years, the field of hyperpolarized MRI has made tremendous progress, evolving from basic science to preclinical and clinical studies based on multiple interdependent advances in polarization technologies, probe chemistry, imaging hardware, and acquisition methods. The need to use the dramatically enhanced hyperpolarized magnetization most efficiently-within a few tens of seconds-and, at the same time, to separate more than one resonance during the image acquisition, has led to the development of novel imaging methods. Hyperpolarized gas applications for measurements of lung perfusion could be translated to humans early on, building upon standard proton imaging protocols. For hyperpolarized liquids, multiple acquisition strategies to achieve fast, robust, and efficient dynamic spectroscopic imaging in up to three spatial dimensions have been presented, including chemical shift imaging techniques, spectral-spatial excitation, balanced steady-state free precession, and spiral imaging.

While realizing that there are innumerable possibilities in pulse sequence design, we have attempted to summarize the most commonly used pulse sequence components and their combinations for spectral encoding, spatial encoding, and excitation and contrast generation that have so far been presented in the context of hyperpolarized MRI. For the scientist who tries to tailor a pulse sequence for his or her needs to image an individual hyperpolarized probe molecule for a certain application, this could provide helpful information.

However, besides optimizing a pulse sequence for sensitivity, robustness and reproducibility of quantification are equally important for preclinical and clinical applications. The effect of individual pulse sequence components and parameters on the quantification of results as imaging biomarkers, e.g. pyruvate-to-lactate conversion rates $k_{\mathrm{pl}}$, has been discussed recently [391]: A profound effect of sequence parameters on $k_{\mathrm{pl}}$ was found for the cases of magnetization spoiling by RF pulses, flow suppression by crusher gradients, and intrinsic image weightings due to relaxation. Given the large variety of pulse sequence components used in hyperpolarized MRI, a major challenge for this field will be the standardization of acquisition protocols and data analysis procedures for comparison of results across different sites which, is especially important for the validation of biomarkers in clinical studies. A consensus has to be found within the hyperpolarized MR community on which acquisition and analysis strategies should be used for which application. A standardized vendor-independent platform to share acquisition protocols as well as data analysis procedures for quantification of imaging measures such as $k_{\mathrm{pl}}$-maps would help to address this challenge.

Acknowledgements We thank Prof. Dr. Markus Schwaiger, PD Dr. Marion Menzel and Prof. Dr. Axel Haase for helpful discussions and contributions during the preparation of the manuscript.

Funding We acknowledge support from the Deutsche Forschungsgemeinschaft (DFG, German Research Foundation-391523415, SFB 824), the BMBF (FKZ 13EZ1114) and the Young Academy of the Bavarian Academy of Sciences and Humanities. This project has received funding from the European Union's Horizon 2020 research and innovation programme under grant agreement No 820374 . 


\section{Compliance with ethical standards}

Conflict of interest The authors declare that they do not have a conflict of interest.

Open Access This article is distributed under the terms of the Creative Commons Attribution 4.0 International License (http://creativeco mmons.org/licenses/by/4.0/), which permits unrestricted use, distribution, and reproduction in any medium, provided you give appropriate credit to the original author(s) and the source, provide a link to the Creative Commons license, and indicate if changes were made.

\section{References}

1. Witte C, Schroder L (2013) NMR of hyperpolarised probes. NMR Biomed 26(7):788-802

2. Ardenkjaer-Larsen JH, Fridlund B, Gram A, Hansson G, Hansson L, Lerche MH, Servin R, Thaning M, Golman K (2003) Increase in signal-to-noise ratio of $>10,000$ times in liquid-state NMR. Proc Natl Acad Sci USA 100:10158-10163

3. Goodson BM (2002) Nuclear magnetic resonance of laser-polarized noble gases in molecules, materials, and organisms. J Magn Reson 155(2):157-216

4. Golman K, in 't Zandt R, Thaning M (2006) Real-time metabolic imaging. Proc Natl Acad Sci USA 103(30):11270-11275

5. Gallagher FA, Kettunen MI, Day SE, Hu DE, ArdenkjaerLarsen JH, Zandt R, Jensen PR, Karlsson M, Golman K, Lerche MH, Brindle KM (2008) Magnetic resonance imaging of $\mathrm{pH}$ in vivo using hyperpolarized ${ }^{13} \mathrm{C}$-labelled bicarbonate. Nature 453(7197):940-943

6. Gallagher FA, Kettunen MI, Hu DE, Jensen PR, Zandt RI, Karlsson M, Gisselsson A, Nelson SK, Witney TH, Bohndiek SE, Hansson G, Peitersen T, Lerche MH, Brindle KM (2009) Production of hyperpolarized $\left[1,4-{ }^{13} \mathrm{C}_{2}\right]$ malate from $\left[1,4-{ }^{13} \mathrm{C}_{2}\right]$ fumarate is a marker of cell necrosis and treatment response in tumors. Proc Natl Acad Sci USA 106(47):19801-19806

7. Keshari KR, Wilson DM (2014) Chemistry and biochemistry of ${ }^{13} \mathrm{C}$ hyperpolarized magnetic resonance using dynamic nuclear polarization. Chem Soc Rev 43(5):1627-1659

8. Kurhanewicz J, Vigneron DB, Ardenkjaer-Larsen JH, Bankson JA, Brindle K, Cunningham CH, Gallagher FA, Keshari KR, Kjaer A, Laustsen C, Mankoff DA, Merritt ME, Nelson SJ, Pauly JM, Lee P, Ronen S, Tyler DJ, Rajan SS, Spielman DM, Wald L, Zhang X, Malloy CR, Rizi R (2019) Hyperpolarized (13)C MRI: path to clinical translation in oncology. Neoplasia 21(1):1-16

9. Albert MS, Cates GD, Driehuys B, Happer W, Saam B, Springer CS, Wishnia A (1994) Biological magnetic resonance imaging using laser-polarized ${ }^{129} \mathrm{Xe}$. Nature 370(6486):199-201

10. Middleton H, Black RD, Saam B, Cates GD, Cofer GP, Guenther R, Happer W, Hedlund LW, Johnson GA, Juvan K, Swartz J (1995) MR imaging with hyperpolarized ${ }^{3} \mathrm{He}$ gas. Magn Reson Med 33(2):271-275

11. Salerno M, Altes TA, Brookeman JR, de Lange EE, Mugler JP III (2001) Dynamic spiral MRI of pulmonary gas flow using hyperpolarized ${ }^{3} \mathrm{He}$ : preliminary studies in healthy and diseased lungs. Magn Reson Med 46:667-677

12. Chang YV, Quirk JD, Yablonskiy DA (2015) In vivo lung morphometry with accelerated hyperpolarized ${ }^{3} \mathrm{He}$ diffusion MRI: a preliminary study. Magn Reson Med 73(4):1609-1614

13. Stewart NJ, Horn FC, Norquay G, Collier GJ, Yates DP, Lawson R, Marshall H, Wild JM (2017) Reproducibility of quantitative indices of lung function and microstructure from ${ }^{129} \mathrm{Xe}$ chemical shift saturation recovery (CSSR) MR spectroscopy. Magn Reson Med 77(6):2107-2113

14. Chan HF, Stewart NJ, Norquay G, Collier GJ, Wild JM (2018) 3D diffusion-weighted ${ }^{129} \mathrm{Xe}$ MRI for whole lung morphometry. Magn Reson Med 79(6):2986-2995

15. Ruppert K, Qing K, Patrie JT, Altes TA, Mugler JP 3rd (2018) Using hyperpolarized xenon-129 MRI to quantify early-stage lung disease in smokers. Acad Radiol 26(3):355-366

16. Couch MJ, Thomen R, Kanhere N, Hu R, Ratjen F, Woods J, Santyr G (2019) A two-center analysis of hyperpolarized ${ }^{129}$ Xe lung MRI in stable pediatric cystic fibrosis: potential as a biomarker for multi-site trials. J Cyst Fibros 18(5):728-733

17. Quirk JD, Sukstanskii AL, Woods JC, Lutey BA, Conradi MS, Gierada DS, Yusen RD, Castro M, Yablonskiy DA (2016) Experimental evidence of age-related adaptive changes in human acinar airways. J Appl Physiol 120(2):159-165

18. Hirsch ML, Kalechofsky N, Belzer A, Rosay M, Kempf JG (2015) Brute-force hyperpolarization for NMR and MRI. J Am Chem Soc 137(26):8428-8434

19. Hirsch ML, Smith BA, Mattingly M, Goloshevsky AG, Rosay M, Kempf JG (2015) Transport and imaging of brute-force C-13 hyperpolarization. J Magn Reson 261:87-94

20. Cleveland ZI, Pavlovskaya GE, Elkins ND, Stupic KF, Repine JE, Meersmann T (2008) Hyperpolarized ${ }^{83} \mathrm{Kr}$ MRI of lungs. J Magn Reson 195(2):232-237

21. Wolber J, McIntyre DJO, Rodrigues LM, Carnochan P, Griffiths JR, Leach MO, Bifone A (2001) In vivo hyperpolarized Xe129 NMR spectroscopy in tumors. Magn Reson Med 46:586-591

22. Bowers CR, Weitekamp DP (1998) Nuclear magnetic resonance by measuring reaction yield of spin symmetry species. Solid State Nucl Magn Reson 11(1-2):123-128

23. Schmidt AB, Berner S, Schimpf W, Muller C, Lickert T, Schwaderlapp N, Knecht S, Skinner JG, Dost A, Rovedo P, Hennig J, von Elverfeldt D, Hovener JB (2017) Liquid-state carbon-13 hyperpolarization generated in an MRI system for fast imaging. Nat Commun 8:14535

24. Adams RW, Aguilar JA, Atkinson KD, Cowley MJ, Elliott PI, Duckett SB, Green GG, Khazal IG, Lopez-Serrano J, Williamson DC (2009) Reversible interactions with para-hydrogen enhance NMR sensitivity by polarization transfer. Science 323(5922):1708-1711

25. von Morze C, Ohliger MA, Marco-Rius I, Wilson DM, Flavell RR, Pearce D, Vigneron DB, Kurhanewicz J, Wang ZJ (2018) Direct assessment of renal mitochondrial redox state using hyperpolarized ${ }^{13} \mathrm{C}$-acetoacetate. Magn Reson Med 79(4):1862-1869

26. Burns MJ, Rayner PJ, Green GG, Highton LA, Mewis RE, Duckett SB (2015) Improving the hyperpolarization of ${ }^{31} \mathrm{P}$ nuclei by synthetic design. J Phys Chem B 119(15):5020-5027

27. Zhivonitko VV, Skovpin IV, Koptyug IV (2015) Strong ${ }^{31} \mathrm{P}$ nuclear spin hyperpolarization produced via reversible chemical interaction with parahydrogen. Chem Commun (Camb) 51(13):2506-2509

28. van Heeswijk RB, Uffmann K, Comment A, Kurdzesau F, Perazzolo C, Cudalbu C, Jannin S, Konter JA, Hautle P, van den Brandt B, Navon G, van der Klink JJ, Gruetter R (2009) Hyperpolarized lithium- 6 as a sensor of nanomolar contrast agents. Magn Reson Med 61(6):1489-1493

29. Gabellieri C, Reynolds S, Lavie A, Payne GS, Leach MO, Eykyn TR (2008) Therapeutic target metabolism observed using hyperpolarized ${ }^{15} \mathrm{~N}$ choline. J Am Chem Soc 130:4598-4599

30. Lee Y, Zeng H, Ruedisser S, Gossert AD, Hilty C (2012) Nuclear magnetic resonance of hyperpolarized fluorine for characterization of protein-ligand interactions. J Am Chem Soc 134(42):17448-17451 
31. Seo H, Choi I, Whiting N, Hu J, Luu QS, Pudakalakatti S, McCowan C, Kim Y, Zacharias N, Lee S, Bhattacharya P, Lee Y (2018) Hyperpolarized porous silicon nanoparticles: potential theragnostic material for ${ }^{29} \mathrm{Si}$ magnetic resonance imaging. ChemPhysChem 19(17):2143-2147

32. Nardi-Schreiber A, Gamliel A, Harris T, Sapir G, Sosna J, Gomori JM, Katz-Brull R (2017) Biochemical phosphates observed using hyperpolarized ${ }^{31} \mathrm{P}$ in physiological aqueous solutions. Nat Commun 8(1):341

33. Lumata L, Merritt ME, Hashami Z, Ratnakar SJ, Kovacs Z (2012) Production and NMR characterization of hyperpolarized ${ }^{107,109} \mathrm{Ag}$ complexes. Angew Chem Int Ed Engl 51(2):525-527

34. Golman K, Ardenkjær-Larsen J, Petersson JS, Månsson S, Leunbach I (2003) Molecular imaging with endogenous substances. PNAS 100(18):10435-10439

35. Sarkar R, Comment A, Vasos PR, Jannin S, Gruetter R, Bodenhausen G, Hall H, Kirik D, Denisov VP (2009) Proton NMR of ${ }^{15} \mathrm{~N}$-choline metabolites enhanced by dynamic nuclear polarization. J Am Chem Soc 131(44):16014-16015

36. Bifone A, Song Y-Q, Seydoux R, Taylor RE, Goodson BM, Pietrass T, Budinger TF, Navon G, Pines A (1996) NMR of laser-polarized xenon in human blood. Proc Natl Acad Sci USA 93(23):12932-12936

37. Goodson BM, Song Y-Q, Taylor RE, Schepkin VD, Brennan KM, Chingas GC, Budinger TF, Navon G, Pines A (1997) In vivo NMR and MRI using injection delivery of laser-polarized xenon. Proc Natl Acad Sci USA 94(26):14725-14729

38. Schröder L, Lowery TJ, Hilty C, Wemmer DE, Pines A (2006) Molecular imaging using a targeted magnetic resonance hyperpolarized biosensor. Science 314:446-449

39. Darrasse L, Guillota G, Nacher P-J, Tastevin G (1997) Low-field ${ }^{3} \mathrm{He}$ nuclear magnetic resonance in human lungs. Phys appliquee/ Appl Phys 324(11):691-700

40. Bidinosti CP, Choukeife J, Nacher P-J, Tastevin G (2003) In vivo NMR of hyperpolarized ${ }^{3} \mathrm{He}$ in the human lung at very low magnetic fields. J Magn Reson 162(1):122-132

41. Bidinosti CP, Choukeife J, Tastevin G, Vignaud A, Nacher PJ (2004) MRI of the lung using hyperpolarized $3 \mathrm{He}$ at very low magnetic field (3 mT). MAGMA 16(6):255-258

42. Venkatesh AK, Zhang AX, Mansour J, Kubatina L, Oh C-H, Blasche G, Selim Ünlü M, Balamore D, Jolesz FA, Goldberg BB, Albert MS (2003) MRI of the lung gas-space at very lowfield using hyperpolarized noble gases. Magn Reson Imaging 21(7):773-776

43. Coffey AM, Feldman MA, Shchepin RV, Barskiy DA, Truong ML, Pham W, Chekmenev EY (2017) High-resolution hyperpolarized in vivo metabolic ${ }^{13} \mathrm{C}$ spectroscopy at low magnetic field (48.7 mT) following murine tail-vein injection. J Magn Reson 281:246-252

44. Komlosi P, Altes TA, Qing K, Mooney KE, Miller GW, Mata JF, de Lange EE, Tobias WA, Cates GD Jr, Mugler JP 3rd (2017) Signal-to-noise ratio, $T_{2}$, and $T_{2}{ }^{*}$ for hyperpolarized helium-3 MRI of the human lung at three magnetic field strengths. Magn Reson Med 78(4):1458-1463

45. Chattergoon N, Martinez-Santiesteban F, Handler WB, Ardenkjaer-Larsen JH, Scholl TJ (2013) Field dependence of $T_{1}$ for hyperpolarized $\left[1-{ }^{13} \mathrm{C}\right]$ pyruvate. Contrast Media Mol Imaging 8(1):57-62

46. Giraudeau P, Shrot Y, Frydman L (2009) Multiple ultrafast, broadband 2D NMR spectra of hyperpolarized natural products. J Am Chem Soc 131(39):13902-13903

47. Ladd ME, Bachert P, Meyerspeer M, Moser E, Nagel AM, Norris DG, Schmitter S, Speck O, Straub S, Zaiss M (2018) Pros and cons of ultra-high-field MRI/MRS for human application. Prog Nucl Magn Reson Spectrosc 109:1-50
48. Goluch S, Frass-Kriegl R, Meyerspeer M, Pichler M, Sieg J, Gajdosik M, Krssak M, Laistler E (2018) Proton-decoupled carbon magnetic resonance spectroscopy in human calf muscles at $7 \mathrm{~T}$ using a multi-channel radiofrequency coil. Sci Rep 8(1):6211

49. Miloushev VZ, Di Gialleonardo V, Salamanca-Cardona L, Correa F, Granlund KL, Keshari KR (2017) Hyperpolarized ${ }^{13} \mathrm{C}$ pyruvate mouse brain metabolism with absorptive-mode EPSI at $1 \mathrm{~T}$. J Magn Reson 275:120-126

50. Düwel S, Hundshammer C, Gersch M, Feuerecker B, Steiger K, Buck A, Walch A, Haase A, Glaser SJ, Schwaiger M, Schilling F (2017) Imaging of $\mathrm{pH}$ in vivo using hyperpolarized ${ }^{13} \mathrm{C}$-labelled zymonic acid. Nat Commun 8:15126

51. Black RD, Early TA, Roemer PB, Mueller OM, Mogro-Campero A, Turner LG, Johnson GA (1993) A high-temperature superconducting receiver for nuclear magnetic resonance microscopy. Science 5096(259):793-795

52. Sanchez-Heredia JD, Szocska Hansen ES, Laustsen C, Zhurbenko V, Ardenkjaer-Larsen JH (2017) Low-noise active decoupling circuit and its application to ${ }^{13} \mathrm{C}$ cryogenic RF coils at $3 \mathrm{~T}$. Tomography 3(1):60-66

53. Derby K, Tropp J, Hawryszko C (1990) Design and evaluation of a novel dual-tuned resonator for spectroscopic imaging. J Magn Reson 86:645-651

54. Hurd RE, Yen YF, Tropp J, Pfefferbaum A, Spielman DM, Mayer D (2010) Cerebral dynamics and metabolism of hyperpolarized $\left[1-{ }^{13} \mathrm{C}\right]$ pyruvate using time-resolved MR spectroscopic imaging. J Cereb Blood Flow Metab 30(10):1734-1741

55. Meyerspeer M, Seres Roig E, Gruetter R, Magill AW (2014) An improved trap design for decoupling multinuclear RF coils. Magn Reson Med 72(2):584-590

56. Cao P, Zhang X, Park I, Najac C, Nelson SJ, Ronen S, Larson $\mathrm{PE}(2016){ }^{1} \mathrm{H}-{ }^{13} \mathrm{C}$ independently tuned radiofrequency surface coil applied for in vivo hyperpolarized MRI. Magn Reson Med 76(5):1612-1620

57. Rutledge O, Kwak T, Cao P, Zhang X (2016) Design and test of a double-nuclear RF coil for $1 \mathrm{H}$ MRI and ${ }^{13} \mathrm{C}$ MRSI at $7 \mathrm{~T}$. J Magn Reson 267:15-21

58. Han S-D, Heo P, Kim H-J, Song H, Kim D, Seo J-H, Ryu Y, Noh Y, Kim K-N (2017) Double-layered dual-tuned RF coil using frequency-selectable PIN-diode control at 7 T MRI. Concepts Magn Reson Part B: Magn Reson Eng 47(4):e21363

59. Seres Roig E, Magill AW, Donati G, Meyerspeer M, Xin L, Ipek O, Gruetter R (2015) A double-quadrature radiofrequency coil design for proton-decoupled carbon-13 magnetic resonance spectroscopy in humans at 7 T. Magn Reson Med 73(2):894-900

60. Girault FM, Sonnay S, Gruetter R, Duarte JMN (2019) Alterations of brain energy metabolism in type 2 diabetic Goto-Kakizaki rats measured in vivo by ${ }^{13} \mathrm{C}$ magnetic resonance spectroscopy. Neurotox Res 36:268-278

61. Wang C, Li Y, Wu B, Xu D, Nelson SJ, Vigneron DB, Zhang $X$ (2012) A practical multinuclear transceiver volume coil for in vivo MRI/MRS at 7 T. Magn Reson Imaging 30(1):78-84

62. Horn FC, Rao M, Stewart NJ, Wild JM (2017) Multiple breath washout of hyperpolarized 129Xe and $3 \mathrm{He}$ in human lungs with three-dimensional balanced steady-state free-precession imaging. Magn Reson Med 77(6):2288-2295

63. Hansen RB, Gutte H, Larsen MME, Kristensen AT, Kjær A, Ardenkjær-Larsen JH, Hansen AE (2017) Characterization and flip angle calibration of ${ }^{13} \mathrm{C}$ surface coils for hyperpolarization studies. Proc Intl Soc Mag Reson Med

64. von Morze C, Tropp J, Chen AP, Marco-Rius I, Van Criekinge M, Skloss TW, Mammoli D, Kurhanewicz J, Vigneron DB, Ohliger MA, Merritt ME (2017) Sensitivity enhancement for detection of hyperpolarized ${ }^{13} \mathrm{C}$ MRI probes with ${ }^{1} \mathrm{H}$ spin coupling introduced by enzymatic transformation in vivo. Magn Reson Med 80(1):36-41 
65. Day SE, Kettunen MI, Gallagher FA, Hu DE, Lerche M, Wolber J, Golman K, Ardenkjaer-Larsen JH, Brindle KM (2007) Detecting tumor response to treatment using hyperpolarized ${ }^{13} \mathrm{C}$ magnetic resonance imaging and spectroscopy. Nat Med 13(11):1382-1387

66. Schulte RF, Sperl JI, Weidl E, Menzel MI, Janich MA, Khegai O, Durst M, Ardenkjaer-Larsen JH, Glaser SJ, Haase A, Schwaiger M, Wiesinger F (2013) Saturation-recovery metabolic-exchange rate imaging with hyperpolarized $\left[1-{ }^{13} \mathrm{C}\right]$ pyruvate using spectral-spatial excitation. Magn Reson Med 69(5):1209-1216

67. Patrick PS, Kettunen MI, Tee SS, Rodrigues TB, Serrao E, Timm KN, McGuire S, Brindle KM (2015) Detection of transgene expression using hyperpolarized ${ }^{13} \mathrm{C}$ urea and diffusionweighted magnetic resonance spectroscopy. Magn Reson Med 73(4):1401-1406

68. Park JM, Josan S, Jang T, Merchant M, Watkins R, Hurd RE, Recht LD, Mayer D, Spielman DM (2016) Volumetric spiral chemical shift imaging of hyperpolarized $\left[2-{ }^{13} \mathrm{C}\right]$ pyruvate in a rat c6 glioma model. Magn Reson Med 75(3):973-984

69. Girault FM, Sonnay S, Gruetter R, Duarte JMN (2017) Alterations of brain energy metabolism in type 2 diabetic Goto-Kakizaki rats measured in vivo by ${ }^{13} \mathrm{C}$ magnetic resonance spectroscopy. Neurotox Res. https://doi.org/10.1007/s12640-017-9821-y

70. Lau AZ, Chen AP, Ghugre NR, Ramanan V, Lam WW, Connelly KA, Wright GA, Cunningham CH (2010) Rapid multislice imaging of hyperpolarized ${ }^{13} \mathrm{C}$ pyruvate and bicarbonate in the heart. Magn Reson Med 64(5):1323-1331

71. Schroeder MA, Clarke K, Neubauer S, Tyler DJ (2011) Hyperpolarized magnetic resonance: a novel technique for the in vivo assessment of cardiovascular disease. Circulation 124(14):1580-1594

72. Lau AZ, Chen AP, Hurd RE, Cunningham CH (2011) Spectralspatial excitation for rapid imaging of DNP compounds. NMR Biomed 24(8):988-996

73. Lau AZ, Chen AP, Cunningham CH (2012) Integrated BlochSiegert B1 mapping and multislice imaging of hyperpolarized ${ }^{13} \mathrm{C}$ pyruvate and bicarbonate in the heart. Magn Reson Med 67(1):62-71

74. Weiss K, Sigfridsson A, Wissmann L, Busch J, Batel M, Krajewski M, Ernst M, Kozerke S (2013) Accelerating hyperpolarized metabolic imaging of the heart by exploiting spatiotemporal correlations. NMR Biomed 26(11):1380-1386

75. Lau AZ, Miller JJ, Tyler DJ (2017) Mapping of intracellular $\mathrm{pH}$ in the in vivo rodent heart using hyperpolarized $\left[1-{ }^{13} \mathrm{C}\right]$ pyruvate. Magn Reson Med 77(5):1810-1817

76. Cunningham CH, Lau JY, Chen AP, Geraghty BJ, Perks WJ, Roifman I, Wright GA, Connelly KA (2016) Hyperpolarized ${ }^{13} \mathrm{C}$ metabolic MRI of the human heart: initial experience. Circ Res 119(11):1177-1182

77. Tropp J, Calderon P, Carvajal L, Karpodinis K, Chen A, Vigneron D, Hurd R, Ardenkjaer-Larsen J-H (2006) An endorectal dual frequency $13 \mathrm{C}-1 \mathrm{H}$ receive only probe for operation at 3.0 tesla. In: ISMRM 14th Scientific Meeting and Exhibition, Seattle, Washington, USA, 2006. The International Society for Magnetic Resonance in Medicine, p 2594

78. Nelson SJ, Kurhanewicz J, Vigneron DB, Larson PE, Harzstark AL, Ferrone M, van Criekinge M, Chang JW, Bok R, Park I, Reed G, Carvajal L, Small EJ, Munster P, Weinberg VK, Ardenkjaer-Larsen JH, Chen AP, Hurd RE, Odegardstuen LI, Robb FJ, Tropp J, Murray JA (2013) Metabolic imaging of patients with prostate cancer using hyperpolarized [1-(1)(3)C]pyruvate. Sci Transl Med 5(198): 198

79. Chen HY, Larson PEZ, Gordon JW, Bok RA, Ferrone M, van Criekinge M, Carvajal L, Cao P, Pauly JM, Kerr AB, Park I, Slater JB, Nelson SJ, Munster PN, Aggarwal R, Kurhanewicz
J, Vigneron DB (2018) Technique development of 3D dynamic CS-EPSI for hyperpolarized ${ }^{13} \mathrm{C}$ pyruvate MR molecular imaging of human prostate cancer. Magn Reson Med 80(5):2062-2072

80. Gordon JW, Chen HY, Autry A, Park I, Van Criekinge M, Mammoli D, Milshteyn E, Bok R, Xu D, Li Y, Aggarwal R, Chang S, Slater JB, Ferrone M, Nelson S, Kurhanewicz J, Larson PEZ, Vigneron DB (2019) Translation of carbon-13 EPI for hyperpolarized MR molecular imaging of prostate and brain cancer patients. Magn Reson Med 81(4):2702-2709

81. Derby K, Tropp J, Hawryszko C (1990) Design and evaluation of a novel dual-tuned resonator for spectroscopic imaging. J Magn Reson 86(3):645-651

82. Chen AP, Albers MJ, Cunningham CH, Kohler SJ, Yen YF, Hurd RE, Tropp J, Bok R, Pauly JM, Nelson SJ, Kurhanewicz J, Vigneron DB (2007) Hyperpolarized C-13 spectroscopic imaging of the TRAMP mouse at $3 \mathrm{~T}$-initial experience. Magn Reson Med 58(6):1099-1106

83. Arunachalam A, Whitt D, Fish K, Giaquinto R, Piel J, Watkins R, Hancu I (2009) Accelerated spectroscopic imaging of hyperpolarized C-13 pyruvate using SENSE parallel imaging. NMR Biomed 22(8):867-873

84. Ohliger MA, Larson PE, Bok RA, Shin P, Hu S, Tropp J, Robb F, Carvajal L, Nelson SJ, Kurhanewicz J, Vigneron DB (2013) Combined parallel and partial fourier MR reconstruction for accelerated 8-channel hyperpolarized carbon-13 in vivo magnetic resonance spectroscopic imaging (MRSI). J Magn Reson Imaging 38(3):701-713

85. Lau JYC, Geraghty BJ, Chen AP, Cunningham CH (2018) Improved tolerance to off-resonance in spectral-spatial EPI of hyperpolarized $\left[1-{ }^{13} \mathrm{C}\right]$ pyruvate and metabolites. Magn Reson Med 80(3):925-934

86. Shin PJ, Larson PE, Uecker M, Reed GD, Kerr AB, Tropp J, Ohliger MA, Nelson SJ, Pauly JM, Lustig M, Vigneron DB (2015) Chemical shift separation with controlled aliasing for hyperpolarized ${ }^{13} \mathrm{C}$ metabolic imaging. Magn Reson Med 74(4):978-989

87. Dregely I, Ruset IC, Wiggins G, Mareyam A, Mugler JP 3rd, Altes TA, Meyer C, Ruppert K, Wald LL, Hersman FW (2013) 32-channel phased-array receive with asymmetric birdcage transmit coil for hyperpolarized xenon-129 lung imaging. Magn Reson Med 70(2):576-583

88. Dominguez-Viqueira W, Lau AZ, Chen AP, Cunningham CH (2013) Multichannel receiver coils for improved coverage in cardiac metabolic imaging using prepolarized ${ }^{13} \mathrm{C}$ substrates. Magn Reson Med 70(1):295-300

89. Sanchez JD, Johansen DH, Baron RA, Schneider M, Spörl G, Wosik J, Zhurbenko V, Ardenkjær-Larsen JH (2018) Threefold SNR enhancement of small animal ${ }^{13} \mathrm{C}$ MRI using a cryogenically cooled (88 K) RF coil. In: Joint Annual Meeting ISMRMESMRMB 2018, Paris, France, p 1744

90. Prammer MG, Haselgrove JC, Shinnar M, Leigh JS (1988) A new approach to automatic shimming. J Magn Reson 77(1):40-52

91. Webb P, Macovski A (1991) Rapid, fully automatic, arbitraryvolume in vivo shimming. Magn Reson Med 20:113-122

92. Maudsley AA, Simon HF, Hila SK (1984) Magnetic field measurement by NMR imaging. J Phys E: Sci Instrum 17:216-220

93. Duyn JH, Yang Y, Frank JA, van der Veen JW (1998) Simple correction method for $k$-space trajectory deviations in MRI. J Magn Reson 132:150-153

94. Zhang Y, Hetherington HP, Stokely EM, Mason GF, Twieg DB (1998) A novel $k$-space trajectory measurement technique. Magn Reson Med 39:999-1004

95. Gordon JW, Vigneron DB, Larson PE (2017) Development of a symmetric echo planar imaging framework for clinical translation 
of rapid dynamic hyperpolarized (13) C imaging. Magn Reson Med 77(2):826-832

96. Hancu I, Watkins R, Kohler SJ, Mallozzi RP (2007) Accurate flip-angle calibration for ${ }^{13} \mathrm{C}$ MRI. Magn Reson Med 58(1):128-133

97. Wang J, Qiu M, Kim H, Constable RT (2006) $T_{1}$ measurements incorporating flip angle calibration and correction in vivo. $\mathrm{J}$ Magn Reson 182(2):283-292

98. Ouriadov AV, Lam WW, Santyr GE (2009) Rapid 3-D mapping of hyperpolarized ${ }^{3} \mathrm{He}$ spin-lattice relaxation times using variable flip angle gradient echo imaging with application to alveolar oxygen partial pressure measurement in rat lungs. MAGMA 22(5):309-318

99. Silver MS, Joseph RI, Hoult DI (1984) Highly selective Pi/2 and Pi pulse generation. J Magn Reson 59:347-351

100. Insko EK, Bolinger L (1993) Mapping of the radiofrequency field. J Magn Reson Ser A 103(1):82-85

101. Jiru F, Klose U (2006) Fast 3D radiofrequency field mapping using echo-planar imaging. Magn Reson Med 56(6):1375-1379

102. Dowell NG, Tofts PS (2007) Fast, accurate, and precise mapping of the RF field in vivo using the $180^{\circ}$ signal null. Magn Reson Med 58(3):622-630

103. Yarnykh VL (2007) Actual flip-angle imaging in the pulsed steady state: a method for rapid three-dimensional mapping of the transmitted radiofrequency field. Magn Reson Med 57(1):192-200

104. Morrell GR (2008) A phase-sensitive method of flip angle mapping. Magn Reson Med 60(4):889-894

105. Giovannetti G, Frijia F, Flori A, De Marchi D, Aquaro GD, Menichetti L, Ardenkjaer-Larsen JH (2015) A fast and simple method for calibrating the flip angle in hyperpolarized ${ }^{13} \mathrm{C}$ MRS experiments. Concepts Magn Reson Part B: Magn Reson Eng 45(2):78-84

106. Möller H, Chawla M, Chen XJ, Driehuys B, Hedlund LW, Wheeler CT, Johnson GA (1999) Magnetic resonance angiography with hyperpolarized ${ }^{129} \mathrm{Xe}$ dissolved in a lipid emulsion. Magn Reson Med 41:1058-1064

107. Reed GD, von Morze C, Bok R, Koelsch BL, Van Criekinge M, Smith KJ, Hong S, Larson PE, Kurhanewicz J, Vigneron DB (2014) High resolution ${ }^{13} \mathrm{C}$ MRI with hyperpolarized urea: in vivo $T_{2}$ mapping and ${ }^{15} \mathrm{~N}$ labeling effects. IEEE Trans Med Imaging 33(2):362-371

108. Milshteyn E, von Morze C, Reed GD, Shang H, Shin PJ, Larson PEZ, Vigneron DB (2018) Using a local low rank plus sparse reconstruction to accelerate dynamic hyperpolarized ${ }^{13} \mathrm{C}$ imaging using the bSSFP sequence. J Magn Reson 290:46-59

109. Pruessmann KP, Weiger M, Scheidegger MB, Boesiger P (1999) SENSE: sensitivity encoding for fast MRI. Magn Reson Med 42:952-962

110. Tropp J, Lupo JM, Chen A, Calderon P, McCune D, Grafendorfer T, Ozturk-Isik E, Larson PE, Hu S, Yen YF, Robb F, Bok R, Schulte R, Xu D, Hurd R, Vigneron D, Nelson S (2011) Multi-channel metabolic imaging, with SENSE reconstruction, of hyperpolarized [1-(13)C] pyruvate in a live rat at 30 tesla on a clinical MR scanner. J Magn Reson 208(1):171-177

111. Grist JT, McLean MA, Riemer F, Schulte RF, Deen SS, Zaccagna F, Woitek R, Daniels CJ, Kaggie JD, Matys T, Patterson I, Slough R, Gill AB, Chhabra A, Eichenberger R, Laurent MC, Comment A, Gillard JH, Coles AJ, Tyler DJ, Wilkinson I, Basu B, Lomas DJ, Graves MJ, Brindle KM, Gallagher FA (2019) Quantifying normal human brain metabolism using hyperpolarized $\left[1-{ }^{13} \mathrm{C}\right]$ pyruvate and magnetic resonance imaging. NeuroImage 189:171-179

112. Schulte RF, Sacolick L, Deppe MH, Janich MA, Schwaiger M, Wild JM, Wiesinger F (2011) Transmit gain calibration for nonproton MR using the Bloch-Siegert shift. NMR Biomed 24(9):1068-1072

113. Bashir A, Conradi MS, Woods JC, Quirk JD, Yablonskiy DA (2009) Calibration of RF transmitter voltages for hyperpolarized gas MRI. Magn Reson Med 61(1):239-243

114. Rivoire J, Terekhov M, Meise FM, Gast K, Salhi Z, Schreiber LM (2011) Flip-angle measurement by magnetization inversion: calibration of magnetization nutation angle in hyperpolarized (3) He magnetic resonance imaging lung experiments. Magn Reson Med 65(2):399-408

115. Marshall H, Ajraoui S, Deppe MH, Parra-Robles J, Wild JM (2012) K-space filter deconvolution and flip angle self-calibration in $2 \mathrm{D}$ radial hyperpolarised ${ }^{3} \mathrm{He}$ lung MRI. NMR Biomed 25(2):389-399

116. Puckeridge M, Pages G, Kuchel PW (2012) Simultaneous estimation of T1 and the flip angle in hyperpolarized NMR experiments using acquisition at non-regular time intervals. J Magn Reson 222:68-73

117. Sacolick LI, Wiesinger F, Hancu I, Vogel MW (2010) $B_{1}$ mapping by Bloch-Siegert shift. Magn Reson Med 63(5):1315-1322

118. Bloch F, Siegert A (1940) Magnetic resonance for nonrotating fields. Phys Rev 57(6):522-527

119. Tang S, Milshteyn E, Reed G, Gordon J, Bok R, Zhu X, Zhu Z, Vigneron DB, Larson PEZ (2019) A regional bolus tracking and real-time $B_{1}$ calibration method for hyperpolarized (13)C MRI. Magn Reson Med 81(2):839-851

120. Norquay G, Leung G, Stewart NJ, Tozer GM, Wolber J, Wild JM (2015) Relaxation and exchange dynamics of hyperpolarized ${ }^{129}$ Xe in human blood. Magn Reson Med 74(2):303-311

121. Raftery D, Long H, Meersmann T, Grandinetti PJ, Reven L, Pines A (1991) High-field NMR of adsorbed xenon polarized by laser pumping. Phys Rev Lett 66(5):584-587

122. Brown TR, Kincaid BM, Ugurbil K (1982) NMR chemical shift imaging in three dimensions. Proc Natl Acad Sci USA 79(11):3523-3526

123. Chen X, Möller H, Chawla MS, Cofer GP, Driehuys B, Hedlund LW, MacFall JR, Johnson GA (1999) Spatially resolved measurements of hyperpolarized gas properties in the lung in vivo. Part II: $T_{2} *$. Magn Reson Med 42:729-737

124. Swanson SD, Rosen MS, Coulter KP, Welsh RC, Chupp TE (1999) Distribution and dynamics of laser-polarized ${ }^{129} \mathrm{Xe} \mathrm{mag-}$ netization in vivo. Magn Reson Med 42:1137-1145

125. Wiesinger F, Weidl E, Menzel MI, Janich MA, Khegai O, Glaser SJ, Haase A, Schwaiger M, Schulte RF (2012) IDEAL spiral CSI for dynamic metabolic MR imaging of hyperpolarized $\left[1-{ }^{13} \mathrm{C}\right]$ pyruvate. Magn Reson Med 68(1):8-16

126. Scroggins BT, Matsuo M, White AO, Saito K, Munasinghe JP, Sourbier C, Yamamoto K, Diaz V, Takakusagi Y, Ichikawa K, Mitchell JB, Krishna MC, Citrin DE (2018) Hyperpolarized $\left[1-{ }^{13} \mathrm{C}\right]$-pyruvate magnetic resonance spectroscopic imaging of prostate cancer in vivo predicts efficacy of targeting the warburg effect. Clin Cancer Res 24(13):3137-3148

127. Wehrli FW, Perkins TG, Shimakawa A, Roberts F (1987) Chemical shift-induced amplitude modulations in images obtained with gradient refocusing. Magn Reson Imaging 5(2):157-158

128. Cunningham CH, Chen AP, Albers MJ, Kurhanewicz J, Hurd RE, Yen YF, Pauly JM, Nelson SJ, Vigneron DB (2007) Double spinecho sequence for rapid spectroscopic imaging of hyperpolarized ${ }^{13}$ C. J Magn Reson 187(2):357-362

129. Mulkern RV, Paynch LP (2001) Echo planar spectroscopic imaging. Concepts Magn Reson 13(4):213-237

130. Yen YF, Kohler SJ, Chen AP, Tropp J, Bok R, Wolber J, Albers MJ, Gram KA, Zierhut ML, Park I, Zhang V, Hu S, Nelson SJ, Vigneron DB, Kurhanewicz J, Dirven HA, Hurd RE (2009) 
Imaging considerations for in vivo ${ }^{13} \mathrm{C}$ metabolic mapping using hyperpolarized ${ }^{13} \mathrm{C}$-pyruvate. Magn Reson Med 62(1):1-10

131. Mayer D, Levin YS, Hurd RE, Glover GH, Spielman DM (2006) Fast metabolic imaging of systems with sparse spectra: application for hyperpolarized ${ }^{13} \mathrm{C}$ imaging. Magn Reson Med 56(4):932-937

132. Reeder SB, Brittain JH, Grist TM, Yen Y-F (2007) Least-squares chemical shift separation for ${ }^{13} \mathrm{C}$ metabolic imaging

133. Levin YS, Mayer D, Yen YF, Hurd RE, Spielman DM (2007) Optimization of fast spiral chemical shift imaging using least squares reconstruction: application for hyperpolarized ${ }^{13} \mathrm{C}$ metabolic imaging. Magn Reson Med 58:245-252

134. Leupold J, Wieben O, Mansson S, Speck O, Scheffler K, Petersson JS, Hennig J (2006) Fast chemical shift mapping with multiecho balanced SSFP. MAGMA 19(5):267-273

135. Reeder SB, Wen Z, Yu H, Pineda AR, Gold GE, Markl M, Pelc NJ (2004) Multicoil dixon chemical species separation with an iterative least-squares estimation method. Magn Reson Med 51(1):35-45

136. Reed GD, Larson PE, Morze C, Bok R, Lustig M, Kerr AB, Pauly JM, Kurhanewicz J, Vigneron DB (2012) A method for simultaneous echo planar imaging of hyperpolarized ${ }^{13} \mathrm{C}$ pyruvate and ${ }^{13} \mathrm{C}$ lactate. J Magn Reson 217:41-47

137. Wagshul ME, Button TM, Li HF, Liang Z, Springer CS, Zhong K, Wishnia A (1996) In Vivo MR imaging and spectroscopy using hyperpolarized ${ }^{129}$ Xe. Magn Reson Med 36:183-191

138. Kettunen MI, Hu DE, Witney TH, McLaughlin R, Gallagher FA, Bohndiek SE, Day SE, Brindle KM (2010) Magnetization transfer measurements of exchange between hyperpolarized $\left[1{ }^{13} \mathrm{C}\right]$ pyruvate and $\left[1-{ }^{13} \mathrm{C}\right]$ lactate in a murine lymphoma. Magn Reson Med 63(4):872-880

139. Cunningham $\mathrm{CH}$, Chen AP, Lustig M, Hargreaves BA, Lupo J, Xu D, Kurhanewicz J, Hurd RE, Pauly JM, Nelson SJ, Vigneron DB (2008) Pulse sequence for dynamic volumetric imaging of hyperpolarized metabolic products. J Magn Reson 193(1):139-146

140. Larson PEZ, Kerr AB, Chen AP, Lustig MS, Zierhut ML, Hu S, Cunningham CH, Pauly JM, Kurhanewicz J, Vigneron DB (2008) Multiband excitation pulses for hyperpolarized ${ }^{13} \mathrm{C}$ dynamic chemical-shift imaging. J Magn Reson 194(1):121-127

141. Sigfridsson A, Weiss K, Wissmann L, Busch J, Krajewski M, Batel M, Batsios G, Ernst M, Kozerke S (2015) Hybrid multiband excitation multiecho acquisition for hyperpolarized ${ }^{13} \mathrm{C}$ spectroscopic imaging. Magn Reson Med 73(5):1713-1717

142. Schmidt R, Frydman L (2013) In vivo 3D spatial/1D spectral imaging by spatiotemporal encoding: a new single-shot experimental and processing approach. Magn Reson Med 70(2):382-391

143. Schmidt R, Laustsen C, Dumez JN, Kettunen MI, Serrao EM, Marco-Rius I, Brindle KM, Ardenkjaer-Larsen JH, Frydman L (2014) In vivo single-shot ${ }^{13} \mathrm{C}$ spectroscopic imaging of hyperpolarized metabolites by spatiotemporal encoding. J Magn Reson 240:8-15

144. Tal A, Frydman L (2010) Single-scan multidimensional magnetic resonance. Prog Nucl Magn Reson Spectrosc 57(3):241-292

145. Mugler JP 3rd, Altes TA (2013) Hyperpolarized ${ }^{129}$ Xe MRI of the human lung. J Magn Reson Imaging 37(2):313-331

146. Saam B, Yablonskiy DA, Gierada DS, Conradi MS (1999) Rapid imaging of hyperpolarized gas using EPI. Magn Reson Med 42:507-514

147. Chawla MS, Chen XJ, Cofer GP, Hedlund LW, Kerby MB, Ottoboni TB, Johnson GA (2000) Hyperpolarized ${ }^{3} \mathrm{He}$ microspheres as a novel vascular signal source for MRI. Magn Reson Med 43:440-445
148. Wild JM, Paley MNJ, Viallon M, Schreiber WG, van Beek EJR, Griffiths PD (2002) $K$-Space filtering in 2D gradient-echo breathhold hyperpolarized ${ }^{3} \mathrm{He}$ MRI: spatial resolution and signal-tonoise ratio considerations. Magn Reson Med 47(4):687-695

149. Golman K, Axelsson O, Jóhannesson H, Månsson S, Olofsson C, Petersson JS (2001) Parahydrogen-induced polarization in imaging: subsecond ${ }^{13} \mathrm{C}$ angiography. Magn Reson Med 46:1-5

150. Svensson J, Mansson S, Johansson E, Petersson JS, Olsson LE (2003) Hyperpolarized ${ }^{13} \mathrm{C}$ MR angiography using true FISP. Magn Reson Med 50(2):256-262

151. Garroway AN, Grannellx PK, Mansfield P (1974) Image formation in NMR by a selective irradiative process. J Phys C: Solid State Phys 7:L457

152. Mansfield P, Maudsley AA (1977) Medical imaging by NMR. Br J Radiol 50:188-194

153. Spielman DM, Mayer D, Yen YF, Tropp J, Hurd RE, Pfefferbaum A (2009) In vivo measurement of ethanol metabolism in the rat liver using magnetic resonance spectroscopy of hyperpolarized $\left[1-{ }^{13}\right.$ C]pyruvate. Magn Reson Med 62(2):307-313

154. Granot J (1986) Selected volume spectroscopy (SVS) and chemical-shift imaging: a comparison. J Magn Reson 66:197-200

155. Chen AP, Cunningham $\mathrm{CH}$ (2015) Single voxel localization for dynamic hyperpolarized ${ }^{13} \mathrm{C}$ MR spectroscopy. J Magn Reson 258:81-85

156. Choi I-Y, Tkác I, Gruetter R (2000) Single-shot, three-dimensional "non-echo" localization method for in vivo NMR spectroscopy. Magn Reson Med 44:387-394

157. Mishkovsky M, Cheng T, Comment A, Gruetter R (2012) Localized in vivo hyperpolarization transfer sequences. Magn Reson Med 68(2):349-352

158. Hu S, Lustig M, Chen AP, Crane J, Kerr A, Kelley DA, Hurd R, Kurhanewicz J, Nelson SJ, Pauly JM, Vigneron DB (2008) Compressed sensing for resolution enhancement of hyperpolarized ${ }^{13} \mathrm{C}$ flyback 3D-MRSI. J Magn Reson 192(2):258-264

159. Hu S, Lustig M, Balakrishnan A, Larson PE, Bok R, Kurhanewicz J, Nelson SJ, Goga A, Pauly JM, Vigneron DB (2010) 3D compressed sensing for highly accelerated hyperpolarized ${ }^{13} \mathrm{C}$ MRSI with in vivo applications to transgenic mouse models of cancer. Magn Reson Med 63(2):312-321

160. Mansfield P (1984) Spatial mapping of the chemical shift in NMR. Magn Reson Med 1:370-386

161. Matsui S, Sekihara K, Kohno H (1985) High-Speed spatially resolved high-resolution NMR spectroscopy. J Am Chem Soc 107(9):2817-2818

162. Miller JJ, Lau AZ, Tyler DJ (2018) Susceptibility-induced distortion correction in hyperpolarized echo planar imaging. Magn Reson Med 79(4):2135-2141

163. Gordon JW, Larson PEZ (2016) Pulse sequences for hyperpolarized MRS. eMagRes. https://doi.org/10.1002/9780470034590. emrstm1451

164. Peterson P, Månsson S (2014) Fat quantification using multiecho sequences with bipolar gradients: investigation of accuracy and noise performance. Magn Reson Med 71(1):219-229

165. Feinberg DA, Turner R, Jakab PD, Mv Kienlin (1990) Echoplanar imaging with asymmetric gradient modulation and innervolume excitation. Magn Reson Med 13:162-169

166. Cunningham $\mathrm{CH}$, Vigneron $\mathrm{DB}$, Chen $\mathrm{AP}, \mathrm{Xu} \mathrm{D}$, Nelson SJ, Hurd RE, Kelley DA, Pauly JM (2005) Design of flyback echoplanar readout gradients for magnetic resonance spectroscopic imaging. Magn Reson Med 54(5):1286-1289

167. Golman K, Petersson JS, Magnusson P, Johansson E, Akeson P, Chai CM, Hansson G, Mansson S (2008) Cardiac metabolism measured noninvasively by hyperpolarized ${ }^{13} \mathrm{C}$ MRI. Magn Reson Med 59(5):1005-1013 
168. Adalsteinsson E, Irarrazabal P, Topp S, Meyer C, Macovski A, Spielman D (1998) Volumetric spectroscopic imaging with spiral-based $k$-space trajectories. Magn Reson Med 39(6):889-898

169. Hoge RD, Kwan RKS, Pike GB (1997) Density compensation functions for spiral MRI. MRM 38:117-120

170. Fessler JA (2007) On NUFFT-based gridding for non-Cartesian MRI. J Magn Reson 188(2):191-195

171. Wild JM, Paley MN, Kasuboski L, Swift A, Fichele S, Woodhouse N, Griffiths PD, van Beek EJ (2003) Dynamic radial projection MRI of inhaled hyperpolarized ${ }^{3} \mathrm{He}$ gas. Magn Reson Med 49(6):991-997

172. Dupuich D, Berthezene Y, Clouet PL, Stupar V, Canet E, Cremillieux Y (2003) Dynamic ${ }^{3} \mathrm{He}$ imaging for quantification of regional lung ventilation parameters. Magn Reson Med 50(4):777-783

173. Koumellis P, van Beek EJ, Woodhouse N, Fichele S, Swift AJ, Paley MN, Hill C, Taylor CJ, Wild JM (2005) Quantitative analysis of regional airways obstruction using dynamic hyperpolarized ${ }^{3} \mathrm{He}$ MRI-preliminary results in children with cystic fibrosis. J Magn Reson Imaging 22(3):420-426

174. Mosbah K, Cremillieux Y, Adeleine P, Dupuich D, Stupar V, Nemoz C, Canet E, Berthezene Y (2006) Quantitative measurements of regional lung ventilation using helium-3 MRI in a methacholine-induced bronchoconstriction model. J Magn Reson Imaging 24(3):611-616

175. Ramirez MS, Lee J, Walker CM, Sandulache VC, Hennel F, Lai SY, Bankson JA (2014) Radial spectroscopic MRI of hyperpolarized $\left[1-{ }^{13} \mathrm{C}\right]$ pyruvate at 7 tesla. Magn Reson Med 72(4):986-995

176. Wu HH, Lee JH, Nishimura DG (2008) MRI using a concentric rings trajectory. Magn Reson Med 59(1):102-112

177. Jiang W, Lustig M, Larson PE (2016) Concentric rings $k$-space trajectory for hyperpolarized (13)C MR spectroscopic imaging. Magn Reson Med 75(1):19-31

178. Larson PEZ, Hu S, Lustig M, Kerr AB, Nelson SJ, Kurhanewicz J, Pauly JM, Vigneron DB (2011) Fast dynamic 3D MR spectroscopic imaging with compressed sensing and multiband excitation pulses for hyperpolarized ${ }^{13} \mathrm{C}$ studies. Magn Reson Med 65(3):610-619

179. Cao P, Shin PJ, Park I, Najac C, Marco-Rius I, Vigneron DB, Nelson SJ, Ronen SM, Larson PE (2016) Accelerated highbandwidth MR spectroscopic imaging using compressed sensing. Magn Reson Med 76(2):369-379

180. Wang J-X, Merritt ME, Sherry AD, Malloy CR (2016) Accelerated chemical shift imaging of hyperpolarized ${ }^{13} \mathrm{C}$ metabolites. Magn Reson Med 76:1033-1038

181. Larson PEZ, Chen HY, Gordon JW, Korn N, Maidens J, Arcak M, Tang S, Criekinge M, Carvajal L, Mammoli D, Bok R, Aggarwal R, Ferrone M, Slater JB, Nelson SJ, Kurhanewicz J, Vigneron DB (2018) Investigation of analysis methods for hyperpolarized ${ }^{13} \mathrm{C}$-pyruvate metabolic MRI in prostate cancer patients. NMR Biomed 31(11):e3997

182. Pedersen H, Kozerke S, Ringgaard S, Nehrke K, Kim WY (2009) $k-t$ PCA: temporally constrained $k-t$ BLAST reconstruction using principal component analysis. Magn Reson Med 62(3):706-716

183. Wespi P, Steinhauser J, Kwiatkowski G, Kozerke S (2018) High-resolution hyperpolarized metabolic imaging of the rat heart using $k-t$ PCA and $k-t$ SPARSE. NMR Biomed 31(2): 3876

184. Griswold MA, Jakob PM, Heidemann RM, Nittka M, Jellus V, Wang J, Kiefer B, Haase A (2002) Generalized autocalibrating partially parallel acquisitions (GRAPPA). Magn Reson Med 47(6):1202-1210

185. Shin PJ, Larson PE, Ohliger MA, Elad M, Pauly JM, Vigneron DB, Lustig M (2014) Calibrationless parallel imaging reconstruction based on structured low-rank matrix completion. Magn Reson Med 72(4):959-970

186. Feng Y, Gordon JW, Shin PJ, von Morze C, Lustig M, Larson PEZ, Ohliger MA, Carvajal L, Tropp J, Pauly JM, Vigneron DB (2016) Development and testing of hyperpolarized ${ }^{13} \mathrm{C}$ MR calibrationless parallel imaging. J Magn Reson 262:1-7

187. Gordon JW, Hansen RB, Shin PJ, Feng Y, Vigneron DB, Larson PEZ (2018) 3D hyperpolarized C-13 EPI with calibrationless parallel imaging. J Magn Reson 289:92-99

188. Lee RF, Johnson G, Grossman RI, Stoeckel B, Trampel R, McGuinness G (2006) Advantages of parallel imaging in conjunction with hyperpolarized helium-a new approach to MRI of the lung. Magn Reson Med 55(5):1132-1141

189. Lau AZ, Lau JYC, Chen AP, Cunningham CH (2018) Simultaneous multislice acquisition without trajectory modification for hyperpolarized ${ }^{13} \mathrm{C}$ experiments. Magn Reson Med 80(4):1588-1594

190. Feinberg DA, Hale JD, Watts JC, Kaufman L, Mark A (1986) Halving MR imaging time by conjugation: demonstration at 3.5 kG. Radiology 161:527-531

191. Schmidt R, Baishya B, Ben-Eliezer N, Seginer A, Frydman L (2014) Super-resolved parallel MRI by spatiotemporal encoding. Magn Reson Imaging 32(1):60-70

192. Pipe JG (1995) Spatial encoding and with quadratic phase. Magn Reson Med 33:24-33

193. Zhao L, Mulkern R, Tseng C-H, Williamson D, Patz S, Kraft R, Walsworth RL, Jolesz FA, Albert MS (1996) Gradient-echo imaging considerations for hyperpolarized ${ }^{129}$ Xe MR. J Magn Reson Series B 113:179-183

194. Nagashima K (2008) Optimum pulse flip angles for multi-scan acquisition of hyperpolarized NMR and MRI. J Magn Reson 190(2):183-188

195. Deppe MH, Wild JM (2012) Variable flip angle schedules in bSSFP imaging of hyperpolarized noble gases. Magn Reson Med 67(6):1656-1664

196. Maidens J, Gordon JW, Arcak M, Larson PE (2016) Optimizing flip angles for metabolic rate estimation in hyperpolarized carbon-13 MRI. IEEE Trans Med Imaging 35(11):2403-2412

197. Garwood M, DelaBarre L (2001) The return of the frequency sweep: designing adiabatic pulses for contemporary NMR. J Magn Reson 153(2):155-177

198. Zweckstetter M, Hola TA (1998) An adiabatic multiple spin-echo pulse sequence: removal of systematic errors due to pulse imperfections and off-resonance effects. J Magn Reson 133:134-147

199. Wang J, Hesketh RL, Wright AJ, Brindle KM (2018) Hyperpolarized ${ }^{13} \mathrm{C}$ spectroscopic imaging using single-shot $3 \mathrm{D}$ sequences with unpaired adiabatic refocusing pulses. NMR Biomed 31(11):e4004

200. Carr HY (1958) Steady-state free precession in nuclear magnetic resonance. Phys Rev 112(5):1693-1701

201. Oppelt A, Graumann R, Barfuß H, Fischer H, Hartl W, Schajor W (1986) FISP — a new fast MRI sequence. Electromedica 54(1):15-18

202. Leupold J, Mansson S, Petersson JS, Hennig J, Wieben O (2009) Fast multiecho balanced SSFP metabolite mapping of (1) H and hyperpolarized (13)C compounds. MAGMA 22(4):251-256

203. Perman WH, Bhattacharya P, Leupold J, Lin AP, Harris KC, Norton VA, Hovener JB, Ross BD (2010) Fast volumetric spatial-spectral MR imaging of hyperpolarized ${ }^{13} \mathrm{C}$-labeled compounds using multiple echo 3D bSSFP. Magn Reson Imaging 28(4):459-465

204. Varma G, Wang X, Vinogradov E, Bhatt RS, Sukhatme VP, Seth P, Lenkinski RE, Alsop DC, Grant AK (2016) Selective spectroscopic imaging of hyperpolarized pyruvate and its metabolites 
using a single-echo variable phase advance method in balanced SSFP. Magn Reson Med 76(4):1102-1115

205. Hahn EL (1950) Spin echoes. Phys Rev 80(4):580-594

206. Burstein D (1996) Stimulated echoes: description, applications, practical hints. Concepts Magn Reson 8:269-278

207. Larson PEZ, Kerr AB, Reed GD, Hurd RE, Kurhanewicz J, Pauly JM, Vigneron DB (2012) Generating super stimulated-echoes in MRI and their application to hyperpolarized C-13 diffusion metabolic imaging. IEEE Trans Med Imaging 31(2):265-275

208. Larson PEZ, Hurd RE, Kerr AB, Pauly JM, Bok RA, Kurhanewicz J, Vigneron DB (2013) Perfusion and diffusion sensitive ${ }^{13} \mathrm{C}$ stimulated-echo MRSI for metabolic imaging of cancer. Magn Reson Imaging 31(5):635-642

209. Tanner JE (1970) Use of the stimulated echo in NMR diffusion studies. J Chem Phys 52(5):2523-2526

210. Wespi P, Steinhauser J, Kwiatkowski G, Kozerke S (2018) Overestimation of cardiac lactate production caused by liver metabolism of hyperpolarized $\left[1-{ }^{13} \mathrm{C}\right]$ pyruvate. Magn Reson Med 80(5):1882-1890

211. Butler JP, Mair RW, Hoffmann D, Hrovat MI, Rogers RA, Topulos GP, Walsworth RL, Patz S (2002) Measuring surface-to-areavolume ratios in soft porous materials using laser-polarized xenon interphase exchange nuclear magnetic resonance. J Phys: Condens Matter 13:297-304

212. Dzien P, Fages A, Jona G, Brindle KM, Schwaiger M, Frydman L (2016) Following metabolism in living microorganisms by hyperpolarized ${ }^{1}$ H NMR. J Am Chem Soc 138(37):12278-12286

213. Maudsley AA, Ernst RR (1977) Indirect detection of magnetic resonance by heteronuclear two-dimensional spectroscopy. Chem Phys Lett 50(3):368-372

214. Morris GA, Freeman R (1979) Enhancement of nuclear magnetic resonance signals by polarization transfer. J Am Chem Soc 101(3):760-762

215. von Morze C, Reed GD, Larson PE, Mammoli D, Chen AP, Tropp J, Van Criekinge M, Ohliger MA, Kurhanewicz J, Vigneron DB, Merritt ME (2018) In vivo hyperpolarization transfer in a clinical MRI scanner. Magn Reson Med 80(2):480-487

216. Wang J, Kreis F, Wright AJ, Hesketh RL, Levitt MH, Brindle KM (2018) Dynamic ${ }^{1} \mathrm{H}$ imaging of hyperpolarized $\left[1-{ }^{13} \mathrm{C}\right]$ lactate in vivo using a reverse INEPT experiment. Magn Reson Med 79(2):741-747

217. Harris T, Giraudeau P, Frydman L (2011) Kinetics from indirectly detected hyperpolarized NMR spectroscopy by using spatially selective coherence transfers. Chemistry 17(2):697-703

218. Donovan KJ, Lupulescu A, Frydman L (2014) Heteronuclear cross-relaxation effects in the NMR spectroscopy of hyperpolarized targets. ChemPhysChem 15(3):436-443

219. Stejskal EO, Tanner JE (1965) Spin diffusion measurements: spin echoes in the presence of a time-dependent field gradient. J Chem Phys 42(1):288-292

220. Yablonskiy DA, Sukstanskii AL, Leawoods JC, Gierada DS, Bretthorst GL, Lefrak SS, Cooper JD, Conradi MS (2002) Quantitative in vivo assessment of lung microstructure at the alveolar level with hyperpolarized 3He diffusion MRI. Proc Natl Acad Sci USA 99(5):3111-3116

221. Shanbhag DD, Altes TA, Miller GW, Mata JF, Knight-Scott J (2006) q-Space analysis of lung morphometry in vivo with hyperpolarized ${ }^{3} \mathrm{He}$ spectroscopy. J Magn Reson Imaging 24(1):84-94

222. Woods JC, Yablonskiy DA, Chino K, Tanoli TSK, Cooper JD, Conradi MS (2004) Magnetization tagging decay to measure long-range ${ }^{3} \mathrm{He}$ diffusion in healthy and emphysematous canine lungs. Magn Reson Med 51(5):1002-1008

223. Chen XJ, Hedlund LW, Möller HE, Chawla MS, Maronpot RR, Johnson GA (2000) Detection of emphysema in rat lungs by using magnetic resonance measurements of ${ }^{3} \mathrm{He}$ diffusion. PNAS 97(21):1478-11481

224. Marco-Rius I, Gordon JW, Mattis AN, Bok R, Delos Santos R, Sukumar S, Larson PEZ, Vigneron DB, Ohliger MA (2018) Diffusion-weighted imaging of hyperpolarized $\left[{ }^{13} \mathrm{C}\right]$ urea in mouse liver. J Magn Reson Imaging 47(1):141-151

225. Chen AP, Hurd RE, Cunningham CH (2012) Spin tagging for hyperpolarized ${ }^{13} \mathrm{C}$ metabolic studies. J Magn Reson 214(1):319-323

226. McCarney ER, Armstrong BD, Lingwood MD, Han S (2007) Hyperpolarized water as an authentic magnetic resonance imaging contrast agent. PNAS 104(6):1754-1759

227. Kohler SJ, Yen Y, Wolber J, Chen AP, Albers MJ, Bok R, Zhang V, Tropp J, Nelson S, Vigneron DB, Kurhanewicz J, Hurd RE (2007) In vivo 13 carbon metabolic imaging at $3 \mathrm{~T}$ with hyperpolarized ${ }^{13} \mathrm{C}-1$-pyruvate. Magn Reson Med 58(1):65-69

228. Chen AP, Tropp J, Hurd RE, Van Criekinge M, Carvajal LG, Xu D, Kurhanewicz J, Vigneron DB (2009) In vivo hyperpolarized ${ }^{13} \mathrm{C}$ MR spectroscopic imaging with ${ }^{1} \mathrm{H}$ decoupling. J Magn Reson 197(1):100-106

229. Richardson PM, Parrott AJ, Semenova O, Nordon A, Duckett SB, Halse ME (2018) SABRE hyperpolarization enables highsensitivity ${ }^{1} \mathrm{H}$ and ${ }^{13} \mathrm{C}$ benchtop NMR spectroscopy. Analyst 143(14):3442-3450

230. Bowen S, Zeng H, Hilty C (2008) Chemical shift correlations from hyperpolarized NMR by off-resonance decoupling. Anal Chem 80:5794-5798

231. Zhang G, Schilling F, Glaser SJ, Hilty C (2013) Chemical shift correlations from hyperpolarized NMR using a single SHOT. Anal Chem 85(5):2875-2881

232. Zhang G, Schilling F, Glaser SJ, Hilty C (2016) Reaction monitoring using hyperpolarized NMR with scaling of heteronuclear couplings by optimal tracking. J Magn Reson 272:123-128

233. Bloch F (1946) Nuclear induction. Phys Rev 70(7-8):460-474

234. Purcell EM, Torrey HC, Pound RV (1946) Resonance absorption by nuclear magnetic moments in a solid. Phys Rev 69(1-2):37-38

235. Xing Y, Reed GD, Pauly JM, Kerr AB, Larson PE (2013) Optimal variable flip angle schemes for dynamic acquisition of exchanging hyperpolarized substrates. J Magn Reson 234:75-81

236. Barb AW, Hekmatyar SK, Glushka JN, Prestegard JH (2013) Probing alanine transaminase catalysis with hyperpolarized ${ }^{13}$ CD3-pyruvate. J Magn Reson 228:59-65

237. Merritt M, Harrison C, Storey C, Jeffrey FM, Sherry AD, Malloy CR (2007) Hyperpolarized ${ }^{13} \mathrm{C}$ allows a direct measure of flux through a single enzyme-catalyzed step by NMR. PNAS 107(50): 19773-19777

238. Dafni H, Larson PEZ, Hu S, Yoshihara HA, Ward CS, Venkatesh HS, Wang C, Zhang X, Vigneron DB, Ronen SM (2010) Hyperpolarized ${ }^{13} \mathrm{C}$ spectroscopic imaging informs on hypoxia-inducible factor-1 and myc activity downstream of platelet-derived growth factor receptor. Cancer Res 70(19):7400-7410

239. Kazan SM, Reynolds S, Kennerley A, Wholey E, Bluff JE, Berwick J, Cunningham VJ, Paley MN, Tozer GM (2013) Kinetic modeling of hyperpolarized ${ }^{13} \mathrm{C}$ pyruvate metabolism in tumors using a measured arterial input function. Magn Reson Med 70(4):943-953

240. Rao M, Stewart NJ, Norquay G, Griffiths PD, Wild JM (2016) High resolution spectroscopy and chemical shift imaging of hyperpolarized ${ }^{129} \mathrm{Xe}$ dissolved in the human brain in vivo at 1.5 tesla. Magn Reson Med 75(6):2227-2234

241. Schroeder MA, Lau AZ, Chen AP, Gu Y, Nagendran J, Barry J, Hu X, Dyck JR, Tyler DJ, Clarke K, Connelly KA, Wright GA, Cunningham $\mathrm{CH}$ (2013) Hyperpolarized ${ }^{13} \mathrm{C}$ magnetic resonance reveals early- and late-onset changes to in vivo pyruvate metabolism in the failing heart. Eur J Heart Fail 15(2):130-140 
242. Takado Y, Cheng T, Bastiaansen JAM, Yoshihara HAI, Lanz B, Mishkovsky M, Lengacher S, Comment A (2018) Hyperpolarized ${ }^{13} \mathrm{C}$ magnetic resonance spectroscopy reveals the ratelimiting role of the blood-brain barrier in the cerebral uptake and metabolism of 1-lactate in vivo. ACS Chem Neurosci 9(11):2554-2562

243. Le Page LM, Ball DR, Ball V, Dodd MS, Miller JJ, Heather LC, Tyler DJ (2016) Simultaneous in vivo assessment of cardiac and hepatic metabolism in the diabetic rat using hyperpolarized MRS. NMR Biomed 29(12):1759-1767

244. Yoshihara HA, Bastiaansen JA, Berthonneche C, Comment A, Schwitter J (2015) An intact small animal model of myocardial ischemia-reperfusion: characterization of metabolic changes by hyperpolarized ${ }^{13} \mathrm{C}$ MR spectroscopy. Am J Physiol Heart Circ Physiol 309(12):H2058-H2066

245. Hansen AE, Gutte H, Holst P, Johannesen HH, Rahbek S, Clemmensen AE, Larsen MME, Schoier C, Ardenkjaer-Larsen J, Klausen TL, Kristensen AT, Kjaer A (2018) Combined hyperpolarized ${ }^{13} \mathrm{C}$-pyruvate MRS and ${ }^{18} \mathrm{~F}$-FDG PET (hyperPET) estimates of glycolysis in canine cancer patients. Eur J Radiol 103:6-12

246. Ramirez MS, Lee J, Walker CM, Chen Y, Kingsley CV, De La Cerda J, Maldonado KL, Lai SY, Bankson JA (2015) Feasibility of multianimal hyperpolarized ${ }^{13} \mathrm{C}$ MRS. Magn Reson Med 73(5):1726-1732

247. Granot J (1986) Selected volume excitation using stimulated echoes (VEST). Applications to spatially localized spectroscopy and imaging. J Magn Reson 70:488-492

248. Frahm J, Merboldt K-D, Hänicke W (1987) Localized proton spectroscopy using stimulated echoes. J Magn Reson 72:502-508

249. Bottomley PA (1982) Selective volume method for performing localized NMR spectroscopy. United States Patent 4480228

250. Nelson SJ, Ozhinsky E, Li Y, Park I, Crane J (2013) Strategies for rapid in vivo $1 \mathrm{H}$ and hyperpolarized ${ }^{13} \mathrm{C}$ MR spectroscopic imaging. J Magn Reson 229:187-197

251. Marjanska M, Iltis I, Shestov AA, Deelchand DK, Nelson C, Ugurbil K, Henry PG (2010) In vivo ${ }^{13} \mathrm{C}$ spectroscopy in the rat brain using hyperpolarized $\left[1-{ }^{13} \mathrm{C}\right]$ pyruvate and $\left[2-{ }^{13} \mathrm{C}\right]$ pyruvate. J Magn Reson 206(2):210-218

252. Swisher CL, Koelsch B, Sukumar S, Sriram R, Santos RD, Wang ZJ, Kurhanewicz J, Vigneron D, Larson P (2015) Dynamic ultrafast 2D exchange spectroscopy (UF-EXSY) of hyperpolarized substrates. J Magn Reson 257:102-109

253. Aue WP, Bartholdi E, Ernst RR (1976) Two-dimensional spectroscopy: application to nuclear magnetic resonance. J Chem Phys 64(5):2229-2246

254. Jeener J, Meier BH, Bachmann P, Ernst RR (1979) Investigation of exchange processes by two-dimensional NMR spectroscopy. J Chem Phys 71(11):4546-4553

255. Hermkens NKJ, Feiters MC, Rutjes F, Wijmenga SS, Tessari M (2017) High field hyperpolarization-EXSY experiment for fast determination of dissociation rates in SABRE complexes. J Magn Reson 276:122-127

256. Larson PEZ, Kerr AB, Swisher CL, Pauly JM, Vigneron DB (2012) A rapid method for direct detection of metabolic conversion and magnetization exchange with application to hyperpolarized substrates. J Magn Reson 225:71-80

257. Swisher CL, Larson PE, Kruttwig K, Kerr AB, Hu S, Bok RA, Goga A, Pauly JM, Nelson SJ, Kurhanewicz J, Vigneron DB (2014) Quantitative measurement of cancer metabolism using stimulated echo hyperpolarized carbon-13 MRS. Magn Reson Med 71(1):1-11

258. Frydman L, Scherf T, Lupulescu A (2002) The acquisition of multidimensional NMR spectra within a single scan. PNAS 99(25):15858-15862
259. Frydman L, Lupulescu A, Scherf T (2003) Principles and features of single-scan two-dimensional NMR spectroscopy. J Am Chem Soc 125:9204-9217

260. Frydman L, Blazina D (2007) Ultrafast two-dimensional nuclear magnetic resonance spectroscopy of hyperpolarized solutions. Nat Phys 3(6):415-419

261. Mishkovsky M, Frydman L (2008) Progress in hyperpolarized ultrafast 2D NMR spectroscopy. ChemPhysChem 9(16):2340-2348

262. Ahola S, Zhivonitko VV, Mankinen O, Zhang G, Kantola AM, Chen HY, Hilty C, Koptyug IV, Telkki VV (2015) Ultrafast multidimensional Laplace NMR for a rapid and sensitive chemical analysis. Nat Commun 6:8363

263. Szekely O, Olsen GL, Felli IC, Frydman L (2018) High-resolution 2D NMR of disordered proteins enhanced by hyperpolarized water. Anal Chem 90(10):6169-6177

264. Koelsch BL, Sriram R, Keshari KR, Leon Swisher C, Van Criekinge M, Sukumar S, Vigneron DB, Wang ZJ, Larson PEZ, Kurhanewicz J (2016) Separation of extra- and intracellular metabolites using hyperpolarized (13)C diffusion weighted MR. J Magn Reson 270:115-123

265. Koelsch BL, Keshari KR, Peeters TH, Larson PE, Wilson DM, Kurhanewicz J (2013) Diffusion MR of hyperpolarized ${ }^{13} \mathrm{C}$ molecules in solution. Analyst 138(4):1011-1014

266. Schilling F, Duwel S, Kollisch U, Durst M, Schulte RF, Glaser SJ, Haase A, Otto AM, Menzel MI (2013) Diffusion of hyperpolarized ${ }^{13} \mathrm{C}$-metabolites in tumor cell spheroids using real-time NMR spectroscopy. NMR Biomed 26(5):557-568

267. Cheng CY, Bowers CR (2007) Observation of single-file diffusion in dipeptide nanotubes by continuous-flow hyperpolarized xenon-129 NMR spectroscopy. ChemPhysChem 8(14):2077-2081

268. Søgaard LV, Schilling F, Janich MA, Menzel MI, ArdenkjærLarsen JH (2014) In vivo measurement of apparent diffusion coefficients of hyperpolarized ${ }^{13} \mathrm{C}$-labeled metabolites. NMR Biomed 27(5):561-569

269. Zhu X, Gordon JW, Bok RA, Kurhanewicz J, Larson PEZ (2019) Dynamic diffusion-weighted hyperpolarized ${ }^{13} \mathrm{C}$ imaging based on a slice-selective double spin echo sequence for measurements of cellular transport. Magn Reson Med 81:2001-2010

270. Durst M, Koellisch U, Frank A, Rancan G, Gringeri CV, Karas V, Wiesinger F, Menzel MI, Schwaiger M, Haase A, Schulte RF (2015) Comparison of acquisition schemes for hyperpolarised ${ }^{13} \mathrm{C}$ imaging. NMR Biomed 28(6):715-725

271. Hurd RE, Yen YF, Chen A, Ardenkjaer-Larsen JH (2012) Hyperpolarized ${ }^{13} \mathrm{C}$ metabolic imaging using dissolution dynamic nuclear polarization. J Magn Reson Imaging 36(6):1314-1328

272. Miloushev VZ, Granlund KL, Boltyanskiy R, Lyashchenko SK, DeAngelis LM, Mellinghoff IK, Brennan CW, Tabar V, Yang TJ, Holodny AI, Sosa RE, Guo YW, Chen AP, Tropp J, Robb F, Keshari KR (2018) Metabolic imaging of the human brain with hyperpolarized ${ }^{13} \mathrm{C}$ pyruvate demonstrates ${ }^{13} \mathrm{C}$ lactate production in brain tumor patients. Cancer Res 78(14):3755-3760

273. Eldirdiri A, Posse S, Hanson LG, Hansen RB, Holst P, Schoier C, Kristensen AT, Johannesen HH, Kjaer A, Hansen AE, Ardenkjaer-Larsen JH (2018) Development of a Symmetric echo-planar spectroscopy imaging framework for hyperpolarized ${ }^{13} \mathrm{C}$ imaging in a clinical PET/MR scanner. Tomography 4(3):110-122

274. Posse S, Tedeschi G, Risinger R, Ogg R, Le Bihan D (1995) High speed 'H spectroscopic imaging in human brain by echo planar spatial-spectral encoding. Magn Reson Med 33:34-40

275. Du YP, Joe Zhou X, Bernstein MA (2002) Correction of concomitant magnetic field-induced image artifacts in nonaxial echo-planar imaging. Magn Reson Med 48(3):509-515 
276. Zhu X, Ebel A, Ji JX, Schuff N (2007) Spectral phase-corrected GRAPPA reconstruction of three-dimensional echo-planar spectroscopic imaging (3D-EPSI). Magn Reson Med 57(5):815-820

277. Ahn CB, Kim JH, Cho ZH (1986) High-speed spiral-scan echo planar NMR imaging-I. IEEE Trans Med Imaging 5(1):2-7

278. Meyer CH, Hu BS, Nishimura DG, Macovski A (1992) Fast spiral coronary artery imaging. Magn Reson Med 28(2):202-213

279. Delattre BM, Heidemann RM, Crowe LA, Vallee JP, Hyacinthe JN (2010) Spiral demystified. Magn Reson Imaging 28(6):862-881

280. Viallon M, Berthezène Y, Callot V, Bourgeois M, Humblot H, Briguet A, Crémillieux Y (2000) Dynamic imaging of hyperpolarized ${ }^{3} \mathrm{He}$ distribution in rat lungs using interleaved-spiral scans. NMR Biomed 13:207-213

281. Nayak KS, Cunningham CH, Santos JM, Pauly JM (2004) Realtime cardiac MRI at 3 tesla. Magn Reson Med 51(4):655-660

282. Scheffler K, Lehnhardt S (2003) Principles and applications of balanced SSFP techniques. Eur Radiol 13(11):2409-2418

283. Bieri O, Scheffler K (2013) Fundamentals of balanced steady state free precession MRI. J Magn Reson Imaging 38(1):2-11

284. Imai F, Kashiwagi R, Imai H, Iguchi S, Kimura A, Fujiwara H (2011) Hyperpolarized ${ }^{129}$ Xe MR imaging with balanced steadystate free precession in spontaneously breathing mouse lungs. Magn Reson Med Sci 10(1):33-40

285. Deiming M, Heid O (1994) Magnetization Prepared True FISP Imaging. In: Paper presented at the International Society of Magnetic Resonance in Medicine, San Francisco, CA

286. Hargreaves BA, Vasanawala SS, Nayak KS, Hu BS, Nishimura DG (2003) Fat-suppressed steady-state free precession imaging using phase detection. Magn Reson Med 50(1):210-213

287. Staehle F, Leupold J, Hennig J, Mark1 M (2008) Off-resonancedependent slice profile effects in balanced steady-state free precession imaging. Magn Reson Med 59(5):1197-1202

288. Shang H, Sukumar S, von Morze C, Bok RA, Marco-Rius I, Kerr A, Reed GD, Milshteyn E, Ohliger MA, Kurhanewicz J, Larson PEZ, Pauly JM, Vigneron DB (2017) Spectrally selective threedimensional dynamic balanced steady-state free precession for hyperpolarized C-13 metabolic imaging with spectrally selective radiofrequency pulses. Magn Reson Med 78(3):963-975

289. Bangerter NK, Hargreaves BA, Vasanawala SS, Pauly JM, Gold GE, Nishimura DG (2004) Analysis of multiple-acquisition SSFP. Magn Reson Med 51(5):1038-1047

290. Milshteyn E, von Morze C, Gordon JW, Zhu Z, Larson PE, Vigneron DB (2018) High spatiotemporal resolution bSSFP imaging of hyperpolarized $\left[1-{ }^{13} \mathrm{C}\right]$ pyruvate and $\left[1-{ }^{13} \mathrm{C}\right]$ lactate with spectral suppression of alanine and pyruvate-hydrate. Magn Reson Med 80(3):1048-1060

291. von Morze C, Sukumar S, Reed GD, Larson PE, Bok RA, Kurhanewicz J, Vigneron DB (2013) Frequency-specific SSFP for hyperpolarized ${ }^{13} \mathrm{C}$ metabolic imaging at 14.1 T. Magn Reson Imaging 31(2): 163-170

292. Leupold J, Månsson S, Petersson JS, Hennig J, Wieben O (2009) Fast multiecho balanced SSFP metabolite mapping of ${ }^{1} \mathrm{H}$ and hyperpolarized ${ }^{13} \mathrm{C}$ compounds. Magn Reson Mater Phy 22(4):251-256

293. Leupold J, Wieben O, Månsson S, Speck O, Scheffler K, Petersson JS, Hennig J (2006) Fast chemical shift mapping with multiecho balanced SSFP. Magn Reson Mater Phy 19(5):267-273

294. Müller CA, Hundshammer C, Braeuer M, Skinner JG, Hansen AE, Mansson S, Schilling F, Leupold J, von Elverfeldt D, Ardenkjaer-Larsen JH, Schwaiger M, Hennig J, Hövener J-B (2018) In vitro and in vivo $13 \mathrm{C}$ metabolic imaging of pyruvate to lactate conversion with high spatial and temporal resolution using a mebSSFP sequence. In: Paper presented at the Joint Annual Meeting ISMRM-ESMRMB, Paris, France
295. Mugler JPI, Altes TA, Ruset IC, Ketel S, Distelbrink JH, Chang Y, Mata JF, Hersman FW, Ruppert K, Dregely IM (2009) Hyperpolarized Xe129 ventilation imaging using an optimized 3D steady-state free-precession pulse sequence. In: The Proceedings of the international society of magnetic resonance in medicine, Honolulu, Hawai' i, USA, p 2210

296. Stewart NJ, Norquay G, Griffiths PD, Wild JM (2015) Feasibility of human lung ventilation imaging using highly polarized naturally abundant xenon and optimized three-dimensional steadystate free precession. Magn Reson Med 74(2):346-352

297. von Morze C, Bok RA, Reed GD, Ardenkjaer-Larsen JH, Kurhanewicz J, Vigneron DB (2014) Simultaneous multiagent hyperpolarized ${ }^{13} \mathrm{C}$ perfusion imaging. Magn Reson Med 72(6):1599-1609

298. Månsson S, Petersson JS, Scheffler K (2012) Fast metabolite mapping in the pig heart after injection of hyperpolarized ${ }^{13} \mathrm{C}$-pyruvate with low-flip angle balanced steady-state free precession imaging. Magn Reson Med 68(6):1894-1899

299. Meyer CH, Pauly JM, Macovski A, Nishimura DG (1990) Simultaneous spatial and spectral selective excitation. Magn Reson Med 15:287-304

300. Schulte RF, Wiesinger F (2013) Direct design of 2D RF pulses using matrix inversion. J Magn Reson 235:115-120

301. Marco-Rius I, Cao P, von Morze C, Merritt M, Moreno KX, Chang GY, Ohliger MA, Pearce D, Kurhanewicz J, Larson PE, Vigneron DB (2017) Multiband spectral-spatial RF excitation for hyperpolarized $\left[2-{ }^{13} \mathrm{C}\right]$ dihydroxyacetone ${ }^{13} \mathrm{C}-\mathrm{MR}$ metabolism studies. Magn Reson Med 77(4):1419-1428

302. Miller JJ, Lau AZ, Teh I, Schneider JE, Kinchesh P, Smart S, Ball V, Sibson NR, Tyler DJ (2016) Robust and high resolution hyperpolarized metabolic imaging of the rat heart at $7 \mathrm{~T}$ with 3D spectral-spatial EPI. Magn Reson Med 75(4):1515-1524

303. Wang J, Wright AJ, Hu DE, Hesketh R, Brindle KM (2017) Single shot three-dimensional pulse sequence for hyperpolarized ${ }^{13} \mathrm{C}$ MRI. Magn Reson Med 77(2):740-752

304. Harris T, Degani H, Frydman L (2013) Hyperpolarized ${ }^{13}$ C NMR studies of glucose metabolism in living breast cancer cell cultures. NMR Biomed 26(12):1831-1843

305. Park I, Larson PEZ, Gordon JW, Carvajal L, Chen H-Y, Bok R, van Criekinge M, Ferrone M, Slater JB, Xu D, Kurhanewicz J, Vigneron DB, Chang S, Nelson SJ (2018) Development of methods and feasibility of using hyperpolarized carbon-13 imaging data for evaluating brain metabolism in patient studies. Magn Reson Med 80(3):864-873

306. Meiboom S, Gill D (1958) Modified spin-echo method for measuring nuclear relaxation times. Rev Sci Instrum 29(8):688-691

307. Milshteyn E, von Morze C, Reed GD, Shang H, Shin PJ, Zhu Z, Chen HY, Bok R, Goga A, Kurhanewicz J, Larson PE, Vigneron DB (2017) Development of high resolution 3D hyperpolarized carbon-13 MR molecular imaging techniques. Magn Reson Imaging 38:152-162

308. Kettunen MI, Kennedy BW, Hu DE, Brindle KM (2013) Spin echo measurements of the extravasation and tumor cell uptake of hyperpolarized [1-(13)C]lactate and [1-(13)C]pyruvate. Magn Reson Med 70(5):1200-1209

309. Yen YF, Le Roux P, Mayer D, King R, Spielman D, Tropp J, Butts Pauly K, Pfefferbaum A, Vasanawala S, Hurd R (2010) $T_{2}$ relaxation times of ${ }^{13} \mathrm{C}$ metabolites in a rat hepatocellular carcinoma model measured in vivo using ${ }^{13} \mathrm{C}$-MRS of hyperpolarized $\left[1{ }^{13}\right.$ C]pyruvate. NMR Biomed 23(4):414-423

310. Hürlimann MD (2001) Diffusion and relaxation effects in general stray field NMR experiments. J Magn Reson 148(2):367-378

311. Ziener CH, Kampf T, Jakob PM, Bauer WR (2010) Diffusion effects on the CPMG relaxation rate in a dipolar field. J Magn Reson 202(1):38-42 
312. Simbrunner J (1995) Analysis of Carr-Purcell sequences with nonideal pulses. J Magn Reson B 109:301-309

313. Ross A, Czisch M, King GC (1997) Systematic errors associated with the CPMG pulse sequence and their effect on motional analysis of biomolecules. J Magn Reson 124:355-365

314. Joe E, Lee J, Lee H, Yang S, Choi Y-S, Wang E, Song H-T, Kim D-H (2017) Dual component analysis for in vivo $T_{2}{ }^{*}$ decay of hyperpolarized ${ }^{13} \mathrm{C}$ metabolites. Investig Magn Reson Imaging 21(1): $1-8$

315. Yu H, McKenzie CA, Shimakawa A, Vu AT, Brau ACS, Beatty PJ, Pineda AR, Brittain JH, Reeder SB (2007) Multiecho reconstruction for simultaneous water-fat decomposition and $T_{2}{ }^{*}$ estimation. J Magn Reson Imaging 26(4):1153-1161

316. Khegai O, Schulte RF, Janich MA, Menzel MI, Farrell E, Otto AM, Ardenkjaer-Larsen JH, Glaser SJ, Haase A, Schwaiger M, Wiesinger F (2014) Apparent rate constant mapping using hyperpolarized $\left[1-{ }^{13} \mathrm{C}\right]$ pyruvate. NMR Biomed 27(10):1256-1265

317. Kern AL, Vogel-Claussen J (2018) Hyperpolarized gas MRI in pulmonology. Br J Radiol 91(1084):20170647

318. Deninger AJ, Eberle B, Ebert M, Grossmann T, Heil W, Kauczor H, Lauer L, Markstaller K, Otten E, Schmiedeskamp J, Schreiber W, Surkau R, Thelen M, Weiler N (1999) Quantification of regional intrapulmonary oxygen partial pressure evolution during apnea by (3)He MRI. J Magn Reson 141(2):207-216

319. Albert MS, Balamore D (1998) Development of hyperpolarized noble gas MRI. Nucl Instrum Methods Phys Res, Sect A 402(2):441-453

320. Möller HE, Chen XJ, Saam B, Hagspiel KD, Johnson GA, Altes TA, de Lange EE, Kauczor HU (2002) MRI of the lungs using hyperpolarized noble gases. Magn Reson Med 47(6):1029-1051

321. Kauczor H, Surkau R, Roberts T (1998) MRI using hyperpolarized noble gases. Eur Radiol 8(5):820-827

322. Roos JE, McAdams HP, Kaushik SS, Driehuys B (2015) Hyperpolarized gas MR imaging: technique and applications. Magn Reson Imaging Clin N Am 23(2):217-229

323. Fain SB, Korosec FR, Holmes JH, O'Halloran R, Sorkness RL, Grist TM (2007) Functional lung imaging using hyperpolarized gas MRI. J Magn Reson Imaging 25(5):910-923

324. Chawla MS, Chen XJ, Möller HE, Cofer GP, Wheeler CT, Hedlund LW, Johnson GA (1998) In vivo magnetic resonance vascular imaging using laser-polarized ${ }^{3} \mathrm{He}$ microbubbles. Proc Natl Acad Sci USA 95(18):10832-10835

325. Lilburn DM, Lesbats C, Six JS, Dubuis E, Yew-Booth L, Shaw DE, Belvisi MG, Birrell MA, Pavlovskaya GE, Meersmann T (2015) Hyperpolarized ${ }^{83} \mathrm{Kr}$ magnetic resonance imaging of alveolar degradation in a rat model of emphysema. J R Soc Interface 12(107):20150192

326. Swanson SD, Rosen MS, Agranoff BW, Coulter KP, Welsh RC, Chupp TE (1997) Brain MRI with laser-polarized ${ }^{129} \mathrm{Xe}$. Magn Reson Med 38(5):695-698

327. Swanson SD, Rosen MS, Coulter KP, Welsh RC, Chupp TE (1999) Distribution and dynamics of laser-polarized (129)Xe magnetization in vivo. Magn Reson Med 42(6):1137-1145

328. Johansson E, Olsson LE, Månsson S, Petersson JS, Golman K, Ståhlberg F, Wirestam R (2004) Perfusion assessment with bolus differentiation: a technique applicable to hyperpolarized tracers. Magn Reson Med 52(5):1043-1051

329. Bhattacharya P, Harris K, Lin AP, Mansson M, Norton VA, Perman WH, Weitekamp DP, Ross BD (2005) Ultra-fast three dimensional imaging of hyperpolarized ${ }^{13} \mathrm{C}$ in vivo. Magn Reson Mater Phy 18(5):245-256

330. Schmidt AB, Berner S, Braig M, Zimmermann M, Hennig J, von Elverfeldt D, Hövener J-B (2018) In vivo ${ }^{13} \mathrm{C}-\mathrm{MRI}$ using SAMBADENA. PLoS One 13(7):e0200141
331. Bhattacharya P, Chekmenev EY, Perman WH, Harris KC, Lin AP, Norton VA, Tan CT, Ross BD, Weitekamp DP (2007) Towards hyperpolarized (13)C-succinate imaging of brain cancer. J Magn Reson 186(1):150-155

332. Zacharias NM, Chan HR, Sailasuta N, Ross BD, Bhattacharya P (2012) Real-time molecular imaging of tricarboxylic acid cycle metabolism in vivo by hyperpolarized $1-{ }^{13} \mathrm{C}$ diethyl succinate. $\mathrm{J}$ Am Chem Soc 134(2):934-943

333. Cavallari E, Carrera C, Sorge M, Bonne G, Muchir A, Aime $S$, Reineri $F(2018)$ The ${ }^{13} \mathrm{C}$ hyperpolarized pyruvate generated by ParaHydrogen detects the response of the heart to altered metabolism in real time. Sci Rep 8(1):8366

334. Cassidy MC, Chan HR, Ross BD, Bhattacharya PK, Marcus CM (2013) In vivo magnetic resonance imaging of hyperpolarized silicon particles. Nat Nanotechnol 8:363

335. Ardenkjaer-Larsen JH, Laustsen C, Bowen S, Rizi R (2014) Hyperpolarized $\mathrm{H}_{2} \mathrm{O}$ MR angiography. Magn Reson Med 71(1):50-56

336. Wigh Lips $\varnothing$ K, Hansen ESS, Tougaard RS, Laustsen C, Ardenkjær-Larsen JH (2017) Renal MR angiography and perfusion in the pig using hyperpolarized water. Magn Reson Med 78(3):1131-1135

337. Lips $\varnothing \mathrm{KW}$, Hansen ESS, Tougaard RS, Laustsen C, Ardenkjær-Larsen JH (2018) Dynamic coronary MR angiography in a pig model with hyperpolarized water. Magn Reson Med 80(3):1165-1169

338. Durst M, Chiavazza E, Haase A, Aime S, Schwaiger M, Schulte $\mathrm{RF}(2016) \alpha$-trideuteromethyl $\left[{ }^{15} \mathrm{~N}\right]$ glutamine: a long-lived hyperpolarized perfusion marker. Magn Reson Med 76(6):1900-1904

339. Ardenkjaer-Larsen JH, Leach AM, Clarke N, Urbahn J, Anderson D, Skloss TW (2011) Dynamic nuclear polarization polarizer for sterile use intent. NMR Biomed 24(8):927-932

340. Warburg O (1956) On the origin of cancer cells. Science 123(3191):309-314

341. Cairns RA, Harris IS, Mak TW (2011) Regulation of cancer cell metabolism. Nat Rev Cancer 11(2):85-95

342. Jóhannesson H, Macholl S, Ardenkjaer-Larsen JH (2009) Dynamic nuclear polarization of $\left[1-{ }^{13} \mathrm{C}\right]$ pyruvic acid at 4.6 tesla. J Magn Reson 197(2):167-175

343. Golman K, Zandt RI, Lerche M, Pehrson R, Ardenkjaer-Larsen $\mathrm{JH}$ (2006) Metabolic imaging by hyperpolarized ${ }^{13} \mathrm{C}$ magnetic resonance imaging for in vivo tumor diagnosis. Cancer Res 66(22):10855-10860

344. Mayer D, Yen YF, Tropp J, Pfefferbaum A, Hurd RE, Spielman DM (2009) Application of subsecond spiral chemical shift imaging to real-time multislice metabolic imaging of the rat in vivo after injection of hyperpolarized ${ }^{13} \mathrm{C} 1$-pyruvate. Magn Reson Med 62(3):557-564

345. Grant AK, Vinogradov E, Wang X, Lenkinski RE, Alsop DC (2011) Perfusion imaging with a freely diffusible hyperpolarized contrast agent. Magn Reson Med 66(3):746-755

346. von Morze C, Larson PEZ, Hu S, Yoshihara HAI, Bok RA, Goga A, Ardenkjaer-Larsen JH, Vigneron DB (2012) Investigating tumor perfusion and metabolism using multiple hyperpolarized (13)C compounds: HP001, pyruvate and urea. Magn Reson Imaging 30(3):305-311

347. Lau JYC, Chen AP, Gu Y-P, Cunningham CH (2016) Voxelby-voxel correlations of perfusion, substrate, and metabolite signals in dynamic hyperpolarized ${ }^{13} \mathrm{C}$ imaging. NMR Biomed 29(8):1038-1047

348. Johansson E, Månsson S, Wirestam R, Svensson J, Petersson JS, Golman K, Ståhlberg F (2004) Cerebral perfusion assessment by bolus tracking using hyperpolarized ${ }^{13} \mathrm{C}$. Magn Reson Med 51(3):464-472 
349. Nielsen PM, Szocska Hansen ES, Nørlinger TS, Nørregaard R, Bonde Bertelsen L, Stødkilde Jørgensen H, Laustsen C (2016) Renal ischemia and reperfusion assessment with threedimensional hyperpolarized ${ }^{13} \mathrm{C},{ }^{15} \mathrm{~N} 2$-urea. Magn Reson Med 76(5):1524-1530

350. Lau AZ, Miller JJ, Robson MD, Tyler DJ (2017) Simultaneous assessment of cardiac metabolism and perfusion using copolarized $\left[1-{ }^{13} \mathrm{C}\right]$ pyruvate and ${ }^{13} \mathrm{C}$-urea. Magn Reson Med 77(1):151-158

351. Hundshammer C, Duwel S, Kocher SS, Gersch M, Feuerecker B, Scheurer C, Haase A, Glaser SJ, Schwaiger M, Schilling F (2017) Deuteration of hyperpolarized ${ }^{13} \mathrm{C}$-labeled zymonic acid enables sensitivity-enhanced dynamic MRI of $\mathrm{pH}$. ChemPhysChem 18(18):2422-2425

352. Hundshammer C, Duwel S, Schilling F (2017) Imaging of extracellular $\mathrm{pH}$ using hyperpolarized molecules. Isr J Chem 57:788-799

353. Rodrigues TB, Serrao EM, Kennedy BWC, Hu D-E, Kettunen MI, Brindle KM (2014) Magnetic resonance imaging of tumor glycolysis using hyperpolarized ${ }^{13} \mathrm{C}$-labeled glucose. Nat Med 20(1):93-97

354. Jensen PR, Serra SC, Miragoli L, Karlsson M, Cabella C, Poggi L, Venturi L, Tedoldi F, Lerche MH (2015) Hyperpolarized [1,3${ }^{13} \mathrm{C} 2$ ] ethyl acetoacetate is a novel diagnostic metabolic marker of liver cancer. Int J Cancer 136(4):E117-E126

355. Keshari KR, Wilson DM, Chen AP, Bok R, Larson PEZ, Hu $S$, Van Criekinge M, Macdonald JM, Vigneron DB, Kurhanewicz J (2009) Hyperpolarized $\left[2-{ }^{13} \mathrm{C}\right]$-fructose: a hemiketal DNP substrate for in vivo metabolic imaging. J Am Chem Soc 131(48):17591-17596

356. Chaumeil MM, Larson PEZ, Yoshihara HAI, Danforth OM, Vigneron DB, Nelson SJ, Pieper RO, Phillips JJ, Ronen SM (2013) Non-invasive in vivo assessment of IDH1 mutational status in glioma. Nat Commun 4:2429

357. Karlsson M, Jensen PR, Zandt R, Gisselsson A, Hansson G, Duus JØ, Meier S, Lerche MH (2010) Imaging of branched chain amino acid metabolism in tumors with hyperpolarized ${ }^{13} \mathrm{C}$ ketoisocaproate. Int J Cancer 127(3):729-736

358. Eldirdiri A, Clemmensen A, Bowen S, Kjaer A, ArdenkjaerLarsen JH (2017) Simultaneous imaging of hyperpolarized $\left[1,4-{ }^{13} \mathrm{C} 2\right]$ fumarate, $\left[1-{ }^{13} \mathrm{C}\right]$ pyruvate and ${ }^{18} \mathrm{~F}-\mathrm{FDG}$ in a rat model of necrosis in a clinical PET/MR scanner. NMR Biomed 30(12): 3803

359. Düwel S, Durst M, Gringeri CV, Kosanke Y, Gross C, Janich MA, Haase A, Glaser SJ, Schwaiger M, Schulte RF, Braren R, Menzel MI (2016) Multiparametric human hepatocellular carcinoma characterization and therapy response evaluation by hyperpolarized ${ }^{13} \mathrm{C}$ MRSI. NMR Biomed 29(7):952-960

360. Nielsen PM, Eldirdiri A, Bertelsen LB, Jørgensen HS, Ardenkjaer-Larsen JH, Laustsen C (2017) Fumarase activity: an in vivo and in vitro biomarker for acute kidney injury. Sci Rep 7:40812

361. Mayer D, Yen Y-F, Josan S, Park JM, Pfefferbaum A, Hurd RE, Spielman DM (2012) Application of hyperpolarized $\left[1-{ }^{13} \mathrm{C}\right] \mathrm{lac}-$ tate for the in vivo investigation of cardiac metabolism. NMR Biomed 25(10):1119-1124

362. Koellisch U, Gringeri CV, Rancan G, Farell EV, Menzel MI, Haase A, Schwaiger M, Schulte RF (2015) Metabolic imaging of hyperpolarized $\left[1-{ }^{13} \mathrm{C}\right]$ acetate and $\left[1-{ }^{13} \mathrm{C}\right]$ acetylcarnitine-investigation of the influence of dobutamine induced stress. Magn Reson Med 74(4):1011-1018

363. von Morze C, Bok RA, Ohliger MA, Zhu Z, Vigneron DB, Kurhanewicz J (2016) Hyperpolarized $\left[{ }^{13} \mathrm{C}\right]$ ketobutyrate, a molecular analog of pyruvate with modified specificity for LDH isoforms. Magn Reson Med 75(5):1894-1900
364. Qi H, Mariager CØ, Nielsen PM, Schroeder M, Lindhardt J, Nørregaard R, Klein JD, Sands JM, Laustsen C (2019) Glucagon infusion alters the hyperpolarized ${ }^{13} \mathrm{C}$-urea renal hemodynamic signature. NMR Biomed 32(1):e4028

365. Hansen ESS, Stewart NJ, Wild JM, Stødkilde-Jørgensen H, Laustsen C (2016) Hyperpolarized ${ }^{13} \mathrm{C},{ }^{15} \mathrm{~N} 2$-urea MRI for assessment of the urea gradient in the porcine kidney. Magn Reson Med 76(6):1895-1899

366. Mikkelsen EFR, Mariager CØ, Nørlinger T, Qi H, Schulte RF, Jakobsen S, Frøkiær J, Pedersen M, Stødkilde-Jørgensen H, Laustsen C (2017) Hyperpolarized $\left[1-{ }^{13} \mathrm{C}\right]$-acetate renal metabolic clearance rate mapping. Sci Rep 7(1):16002

367. Park JM, Josan S, Grafendorfer T, Yen YF, Hurd RE, Spielman DM, Mayer D (2013) Measuring mitochondrial metabolism in rat brain in vivo using MR spectroscopy of hyperpolarized [2-(1) (3)C]pyruvate. NMR Biomed 26(10):1197-1203

368. Hurd RE, Yen YF, Mayer D, Chen A, Wilson D, Kohler S, Bok R, Vigneron D, Kurhanewicz J, Tropp J, Spielman D, Pfefferbaum A (2010) Metabolic imaging in the anesthetized rat brain using hyperpolarized $\left[1-{ }^{13} \mathrm{C}\right]$ pyruvate and $\left[1-{ }^{13} \mathrm{C}\right]$ ethyl pyruvate. Magn Reson Med 63(5):1137-1143

369. Josan S, Hurd R, Billingsley K, Senadheera L, Park JM, Yen Y-F, Pfefferbaum A, Spielman D, Mayer D (2013) Effects of isoflurane anesthesia on hyperpolarized (13)C metabolic measurements in rat brain. Magn Reson Med 70(4):1117-1124

370. Dzien P, Kettunen MI, Marco-Rius I, Serrao EM, Rodrigues TB, Larkin TJ, Timm KN, Brindle KM (2015) 13C magnetic resonance spectroscopic imaging of hyperpolarized $\left[1-{ }^{13} \mathrm{C}, \mathrm{U}_{-}^{2} \mathrm{H}_{5}\right]$ ethanol oxidation can be used to assess aldehyde dehydrogenase activity in vivo. Magn Reson Med 73(5):1733-1740

371. von Morze C, Chang G-Y, Larson PEZ, Shang H, Allu PKR, Bok RA, Crane JC, Olson MP, Tan CT, Marco-Rius I, Nelson SJ, Kurhanewicz J, Pearce D, Vigneron DB (2017) Detection of localized changes in the metabolism of hyperpolarized gluconeogenic precursors ${ }^{13} \mathrm{C}$-lactate and ${ }^{13} \mathrm{C}$-pyruvate in kidney and liver. Magn Reson Med 77(4):1429-1437

372. Wang JX, Merritt ME, Sherry D, Malloy CR (2016) A general chemical shift decomposition method for hyperpolarized ${ }^{13} \mathrm{C}$ metabolite magnetic resonance imaging. Magn Reson Chem 54(8):665-673

373. Keshari KR, Kurhanewicz J, Bok R, Larson PE, Vigneron DB, Wilson DM (2011) Hyperpolarized ${ }^{13} \mathrm{C}$ dehydroascorbate as an endogenous redox sensor for in vivo metabolic imaging. Proc Natl Acad Sci USA 108(46):18606-18611

374. Wang J-X, Merritt ME, Sherry AD, Malloy CR (2016) Accelerated chemical shift imaging of hyperpolarized ${ }^{13} \mathrm{C}$ metabolites. Magn Reson Med 76(4):1033-1038

375. MacKenzie JD, Yen Y-F, Mayer D, Tropp JS, Hurd RE, Spielman DM (2011) Detection of inflammatory arthritis by using hyperpolarized ${ }^{13} \mathrm{C}$-pyruvate with MR imaging and spectroscopy. Radiology 259(2):414-420

376. Gutte H, Hansen AE, Henriksen ST, Johannesen HH, Ardenkjaer-Larsen J, Vignaud A, Hansen AE, Børresen B, Klausen TL, Wittekind A-MN, Gillings N, Kristensen AT, Clemmensen A, Højgaard L, Kjær A (2014) Simultaneous hyperpolarized ${ }^{13} \mathrm{C}$-pyruvate MRI and ${ }^{18} \mathrm{~F}$-FDG-PET in cancer (hyperPET): feasibility of a new imaging concept using a clinical PET/MRI scanner. Am J Nucl Med Mol Imaging 5(1):38-45

377. Chen Y, Kim H, Bok R, Sukumar S, Mu X, Sheldon RA, Barkovich AJ, Ferriero DM, Xu D (2016) Pyruvate to lactate metabolic changes during neurodevelopment measured dynamically using hyperpolarized 13C imaging in juvenile murine brain. Dev Neurosci 38(1):34-40

378. Lauritzen MH, Laustsen C, Butt SA, Magnusson P, Søgaard LV, Ardenkjær-Larsen JH, Åkeson P (2013) Enhancing the $\left[{ }^{13} \mathrm{C}\right]$ bicarbonate signal in cardiac hyperpolarized $\left[1-{ }^{13} \mathrm{C}\right]$ pyruvate 
MRS studies by infusion of glucose, insulin and potassium. NMR Biomed 26(11):1496-1500

379. Laustsen C, Østergaard JA, Lauritzen MH, Nørregaard R, Bowen S, Søgaard LV, Flyvbjerg A, Pedersen M, Ardenkjær-Larsen JH (2013) Assessment of early diabetic renal changes with hyperpolarized $\left[1-{ }^{13}\right.$ C]pyruvate. Diabetes/metab Res Rev 29(2):125-129

380. Laustsen C, Hansen ESS, Kjaergaard U, Bertelsen LB, Ringgaard S, Stødkilde-Jørgensen H (2015) Acute porcine renal metabolic effect of endogastric soft drink administration assessed with hyperpolarized $\left[1-{ }^{13} \mathrm{C}\right]$ pyruvate. Magn Reson Med 74(2):558-563

381. Thind K, Chen A, Friesen-Waldner L, Ouriadov A, Scholl TJ, Fox M, Wong E, VanDyk J, Hope A, Santyr G (2013) Detection of radiation-induced lung injury using hyperpolarized ${ }^{13} \mathrm{C}$ magnetic resonance spectroscopy and imaging. Magn Reson Med 70(3):601-609

382. Riis-Vestergaard MJ, Breining P, Pedersen SB, Laustsen C, Stodkilde-Jorgensen H, Borghammer P, Jessen N, Richelsen B (2018) Evaluation of active brown adipose tissue by the use of hyperpolarized $\left[1-{ }^{13}\right.$ C]pyruvate MRI in mice. Int J Mol Sci 19(9):2597

383. Joe E, Lee H, Lee J, Seungwook Y, Choi YS, Wang E, Song HT, Kim DH (2017) An indirect method for in vivo $T_{2}$ mapping of $\left[1-{ }^{13} \mathrm{C}\right]$ pyruvate using hyperpolarized ${ }^{13} \mathrm{C}$ CSI. NMR Biomed 30(5):e3690

384. Gordon JW, Niles DJ, Adamson EB, Johnson KM, Fain SB (2016) Application of flow sensitive gradients for improved measures of metabolism using hyperpolarized ${ }^{13} \mathrm{C}$ MRI. Magn Reson Med 75(3): 1242-1248

385. Lau AZ, Chen AP, Barry J, Graham JJ, Dominguez-Viqueira W, Ghugre NR, Wright GA, Cunningham CH (2013) Reproducibility study for free-breathing measurements of pyruvate metabolism using hyperpolarized ${ }^{13} \mathrm{C}$ in the heart. Magn Reson Med 69(4):1063-1071

386. Flori A, Frijia F, Lionetti V, Ardenkjaer-Larsen JH, Positano V, Giovannetti G, Schulte RF, Wiesinger F, Recchia FA, Landini L, Santarelli MF, Lombardi M, Menichetti LJAMR (2012) DNP methods for cardiac metabolic imaging with hyperpolarized $\left[1-{ }^{13} \mathrm{C}\right]$ pyruvate large dose injection in pigs. Appl Magn Reson 43(1):299-310

387. Miller JJ, Grist JT, Serres S, Larkin JR, Lau AZ, Ray K, Fisher KR, Hansen E, Tougaard RS, Nielsen PM, Lindhardt J, Laustsen C, Gallagher FA, Tyler DJ, Sibson N $(2018){ }^{13}$ C pyruvate transport across the blood-brain barrier in preclinical hyperpolarised MRI. Sci Rep 8(1): 15082

388. Josan S, Spielman D, Yen Y-F, Hurd R, Pfefferbaum A, Mayer D (2012) Fast volumetric imaging of ethanol metabolism in rat liver with hyperpolarized [1-(13)C]pyruvate. NMR Biomed 25(8):993-999

389. Markovic S, Fages A, Roussel T, Hadas R, Brandis A, Neeman M, Frydman L (2018) Placental physiology monitored by hyperpolarized dynamic ${ }^{13} \mathrm{C}$ magnetic resonance. Proc Natl Acad Sci USA 115(10):E2429-E2436

390. Albers MJ, Bok R, Chen AP, Cunningham CH, Zierhut ML, Zhang VY, Kohler SJ, Tropp J, Hurd RE, Yen Y-F, Nelson SJ, Vigneron DB, Kurhanewicz J (2008) Hyperpolarized ${ }^{13} \mathrm{C}$ lactate, pyruvate, and alanine: noninvasive biomarkers for prostate cancer detection and grading. Cancer Res 68(20):8607-8615

391. Chen H-Y, Gordon JW, Bok RA, Cao P, von Morze C, van Criekinge M, Milshteyn E, Carvajal L, Hurd RE, Kurhanewicz J, Vigneron DB, Larson PEZ (2019) Pulse sequence considerations for quantification of pyruvate-to-lactate conversion $\mathrm{kPL}$ in hyperpolarized ${ }^{13} \mathrm{C}$ imaging. NMR Biomed 32(3):e4052

392. Baligand C, Qin H, True-Yasaki A, Gordon JW, von Morze C, Santos JD, Wilson DM, Raffai R, Cowley PM, Baker AJ, Kurhanewicz J, Lovett DH, Wang ZJ (2017) Hyperpolarized ${ }^{13} \mathrm{C}$ magnetic resonance evaluation of renal ischemia reperfusion injury in a murine model. NMR Biomed. https://doi.org/10.1002/ nbm. 3765

393. Park I, Bok R, Ozawa T, Phillips JJ, James CD, Vigneron DB, Ronen SM, Nelson SJ (2011) Detection of early response to temozolomide treatment in brain tumors using hyperpolarized ${ }^{13} \mathrm{C}$ MR metabolic imaging. J Magn Reson Imaging 33(6):1284-1290

394. Wilson DM, Keshari KR, Larson PE, Chen AP, Hu S, Van Criekinge M, Bok R, Nelson SJ, Macdonald JM, Vigneron DB, Kurhanewicz J (2010) Multi-compound polarization by DNP allows simultaneous assessment of multiple enzymatic activities in vivo. J Magn Reson 205(1):141-147

395. von Morze C, Larson PE, Hu S, Keshari K, Wilson DM, Ardenkjaer-Larsen JH, Goga A, Bok R, Kurhanewicz J, Vigneron DB (2011) Imaging of blood flow using hyperpolarized $\left[{ }^{13} \mathrm{C}\right]$ urea in preclinical cancer models. J Magn Reson Imaging 33(3):692-697

396. von Morze C, Bok RA, Sands JM, Kurhanewicz J, Vigneron DB (2012) Monitoring urea transport in rat kidney in vivo using hyperpolarized ${ }^{13} \mathrm{C}$ magnetic resonance imaging. Am J Physiol Renal Physiol 302(12):F1658-F1662

397. Durst M, Koellisch U, Gringeri C, Janich MA, Rancan G, Frank A, Wiesinger F, Menzel MI, Haase A, Schulte RF (2014) Bolus tracking for improved metabolic imaging of hyperpolarised compounds. J Magn Reson 243:40-46

398. Korenchan DE, Flavell RR, Baligand C, Sriram R, Neumann K, Sukumar S, VanBrocklin H, Vigneron DB, Wilson DM, Kurhanewicz J (2016) Dynamic nuclear polarization of biocompatible ${ }^{13} \mathrm{C}$-enriched carbonates for in vivo $\mathrm{pH}$ imaging. Chem Commun (Camb) 52(14):3030-3033

399. von Morze C, Reed G, Shin P, Larson PE, Hu S, Bok R, Vigneron DB (2011) Multi-band frequency encoding method for metabolic imaging with hyperpolarized [1-(13)C]pyruvate. J Magn Reson 211(2):109-113

400. Chen WC, Teo XQ, Lee MY, Radda GK, Lee P (2015) Robust hyperpolarized ${ }^{13} \mathrm{C}$ metabolic imaging with selective non-excitation of pyruvate (SNEP). NMR Biomed 28(8):1021-1030

401. Park I, Larson PEZ, Tropp JL, Carvajal L, Reed G, Bok R, Robb F, Bringas J, Kells A, Pivirotto P, Bankiewicz K, Vigneron DB, Nelson SJ (2014) Dynamic hyperpolarized carbon-13 MR metabolic imaging of nonhuman primate brain. Magn Reson Med 71(1):19-25

402. h-Ici DO, Wespi P, Busch J, Wissmann L, Krajewski M, Weiss K, Sigfridsson A, Messroghli D, Kozerke S (2016) Hyperpolarized metabolic MR imaging of acute myocardial changes and recovery after ischemia-reperfusion in a small-animal model. Radiology 278(3):742-751

403. Lau AZ, Chen AP, Gu Y, Ladouceur-Wodzak M, Nayak KS, Cunningham CH (2013) Noninvasive identification and assessment of functional brown adipose tissue in rodents using hyperpolarized ${ }^{13} \mathrm{C}$ imaging. Int $\mathrm{J}$ Obes 38:126

404. Scholz DJ, Otto AM, Hintermair J, Schilling F, Frank A, Kollisch U, Janich MA, Schulte RF, Schwaiger M, Haase A, Menzel MI (2015) Parameterization of hyperpolarized ${ }^{13} \mathrm{C}$-bicarbonate-dissolution dynamic nuclear polarization. MAGMA 28(6):591-598

405. Josan S, Hurd R, Park JM, Yen YF, Watkins R, Pfefferbaum A, Spielman D, Mayer D (2014) Dynamic metabolic imaging of hyperpolarized $\left[2{ }^{13} \mathrm{C}\right]$ pyruvate using spiral chemical shift imaging with alternating spectral band excitation. Magn Reson Med 71(6):2051-2058

Publisher's Note Springer Nature remains neutral with regard to jurisdictional claims in published maps and institutional affiliations. 